\title{
Host Receptors of Influenza Viruses and Coronaviruses-Molecular Mechanisms of Recognition
}

\author{
Nongluk Sriwilaijaroen ${ }^{1,2, *}$ and Yasuo Suzuki ${ }^{2,3, *}$ \\ 1 Department of Preclinical Sciences, Faculty of Medicine, Thammasat University, Pathumthani 12120, Thailand \\ 2 School of Pharmaceutical Sciences, University of Shizuoka, Shizuoka, Shizuoka 422-8526, Japan \\ 3 College of Life and Health Sciences, Chubu University, Kasugai, Aichi 487-8501, Japan \\ * Correspondence: snongluk@hotmail.com (N.S.); suzukiy@isc.chubu.ac.jp (Y.S.); Tel.: +66-2926-9766 (N.S.); \\ +81-568-51-6391 (Y.S.)
}

Received: 9 September 2020; Accepted: 30 September 2020; Published: 6 October 2020

check for updates

\begin{abstract}
Among the four genera of influenza viruses (IVs) and the four genera of coronaviruses (CoVs), zoonotic $\alpha \mathrm{IV}$ and $\beta \mathrm{CoV}$ have occasionally caused airborne epidemic outbreaks in humans, who are immunologically naïve, and the outbreaks have resulted in high fatality rates as well as social and economic disruption and losses. The most devasting influenza A virus (IAV) in $\alpha \mathrm{IV}$, pandemic H1N1 in 1918, which caused at least 40 million deaths from about 500 million cases of infection, was the first recorded emergence of IAVs in humans. Usually, a novel human-adapted virus replaces the preexisting human-adapted virus. Interestingly, two IAV subtypes, A/H3N2/1968 and $\mathrm{A} / \mathrm{H} 1 \mathrm{~N} 1 / 2009$ variants, and two lineages of influenza B viruses (IBV) in $\beta I V, B / Y a m a g a t a$ and B/Victoria lineage-like viruses, remain seasonally detectable in humans. Both influenza $C$ viruses (ICVs) in $\gamma \mathrm{IV}$ and four human CoVs, HCoV-229E and HCoV-NL63 in $\alpha \mathrm{CoV}$ and HCoV-OC43 and HCoV-HKU1 in $\beta \mathrm{CoV}$, usually cause mild respiratory infections. Much attention has been given to CoVs since the global epidemic outbreaks of $\beta S A R S-C o V$ in 2002-2004 and $\beta$ MERS-CoV from 2012 to present. $\beta S A R S-C o V-2$, which is causing the ongoing COVID-19 pandemic that has resulted in 890,392 deaths from about 27 million cases of infection as of 8 September 2020, has provoked worldwide investigations of CoVs. With the aim of developing efficient strategies for controlling virus outbreaks and recurrences of seasonal virus variants, here we overview the structures, diversities, host ranges and host receptors of all IVs and CoVs and critically review current knowledge of receptor binding specificity of spike glycoproteins, which mediates infection, of IVs and of zoonotic, pandemic and seasonal CoVs.
\end{abstract}

Keywords: influenza viruses; coronaviruses; host range; spikes; receptors; sialyl glycans; protein receptors

\section{Introduction}

A pandemic respiratory disease is one of the scariest diseases due to its rapid spread among immunologically naïve humans and due to the fact that there is no vaccine against a new virus strain with a zoonotic origin. In the past two decades, there have been several outbreaks of zoonotic origin in human populations including the chikungunya outbreak in Caribbean countries and South America in 2013-2014 [1], Zika outbreak in the Americas in 2015-2016 [2], Ebola outbreak in 2014-2016 in West Africa [3], HPAI and LPAI outbreaks several times in many countries including Egypt, China, Indonesia, Canada and Australia [4,5], SARS-CoV outbreak in 2002-2004 in 26 countries [6,7], and MERS-CoV outbreak since 2012 in 27 countries [8]. However, a pandemic had not occurred until airborne viruses, including a quadruplex influenza A (H1N1) virus of swine origin and SARS-CoV-2 [9], emerged. The new H1N1 virus caused the 2009 influenza pandemic in June 2009 [10]. SARS-CoV-2, which causes COrona VIrus Disease 2019 (COVID-19), became the first recorded coronavirus pandemic 
on 11 March 2020 [11]. There are various influenza viruses (IVs) and various coronaviruses (CoVs), which are grouped into 4 genera, alpha, beta, gamma and delta IVs/CoVs (Tables 1 and 2).

Of the three genera of IVs, alpha IVs (IAVs), beta IVs (IBVs) and gamma IVs (ICVs), that infect humans, eight segmented (-)ssRNA-containing IAVs (A/H3N2/68 and A/H1N1/09 variants) and IBVs (B/Yamagata and B/Victoria lineage-like viruses) with hemagglutinin (HA) spikes cause seasonal influenza epidemics that spread rapidly and cause mild to severe or fatal illnesses. Seasonal influenza vaccines and anti-influenza drugs against IAVs and IBVs are available, but seasonal influenza still causes up to 5 million severe illnesses and up to 650,000 deaths each year [12]. Thus, epidemics of IAVs and IBVs are important public health issues [12]. Seven segmented (-)ssRNA-containing ICVs with hemagglutinin-esterase-fusion (HEF) spikes usually cause mild upper respiratory disease but can cause lower respiratory disease in children and severe illness in infants [13]. Other seven segmented (-)ssRNA-containing IDVs with HEF spikes mainly infect cattle and cause respiratory illness [14]. These IDVs seem to have a zoonotic potential to infect humans, but whether they can cause illness in humans remains unknown [15]. Among all known influenza viruses, only IAVs are subtyped according to their HAs $(\mathrm{H})$ and neuraminidase (NA or N) spikes into H1-H18 and N1-N11. Several subtypes of IAVs, including H1N1, H3N2 and H5N1, have crossed the species barrier to infect a variety of birds and mammals including humans, indicating that they have zoonotic potential. IAVs not only mutate quickly but also prefer to reassort with other IAVs to form a new strain. Due to these properties, IAVs have caused four pandemics in the past 102 years $[10,16]$. These viruses continued to threat human health seasonally. However, the first recorded pandemic virus, A/H1N1/1918-derived virus, disappeared from human circulation after the appearance of the A/H2N2/1957 pandemic virus containing five gene segments (PB2, PA, NP, M and NS) from human A/H1N1/1918-derived virus. Similarly, A/H2N2/1957-derived virus disappeared after the appearance of A/H3N2/1968 pandemic virus containing six gene segments (PB2, PA, NP, NA, M and NS) from human A/H2N2/1957-derived virus. In 1977, A/H1N1/1918-derived virus reemerged, probably due to accidental release from a laboratory, as a low-grade A/H1N1/1977 pandemic virus that primarily affected young immunologically naïve people $[17,18]$ who were born after the end of the H1 period (1957 and later). This resulted in two subtypes of IAVs circulating in humans, A/H1N1/1977-derived and A/H3N2/1968-derived viruses. After the appearance of the $\mathrm{A} / \mathrm{H} 1 \mathrm{~N} 1 / 2009$ pandemic virus containing one human gene segment (PB1) from A/H3N2/1968-derived virus and three gene segments (H1, NP and NS) from classical swine A/H1N1 virus believed to have been transmitted from A/H1N1/1918-derived virus between 1918 and 1920, A/H1N1/1977-derived virus disappeared from human circulation $[4,19]$. The disappearance of that virus resulted in only A/H1N1/2009-derived and A/H3N2/1968-derived viruses remaining in circulation in humans. Thus, IAVs are important not only because human IAVs cause seasonal influenza but also because nonhuman IAVs cause farm animal diseases, sporadic zoonotic outbreaks and periodic unpredictable pandemics.

Of the four genera of single linear (+)ssRNA-containing CoVs, only $\alpha \mathrm{CoV}$ members (HCoV-229E and HCoV-NL63) and $\beta \mathrm{CoV}$ members (HCoV-OC43, HCoV-HKU1, SARS-CoV, MERS-CoV and SARS-CoV-2) have so far been reported to infect humans. HCoV-229E, HCoV-NL63, HCoV-OC43 and HCoV-HKU1 circulating in humans usually cause mild upper respiratory diseases [20], and there is still no vaccine or antiviral drug against these HCoVs [21]. Zoonotic SARS-CoV, a highly lethal $\mathrm{CoV}$ causing SARS disease, emerged in 2002. However, no SARS cases were reported after 29 April 2004 and the World Health Organization (WHO) officially announced on 18 May 2004 that the SARS outbreak had been contained [22]. Zoonotic MERS-CoV, another highly lethal $\mathrm{CoV}$ causing MERS disease, emerged in 2012. MERS cases are still being reported to WHO [8]. An anti-MERS drug and MERS vaccine are still not available. Zoonotic SARS-CoV-2 emerged in December 2019 and is causing the ongoing COVID-19 pandemic [11]. Many efforts are being made to develop COVID vaccines and anti-COVID drugs. As in the case of IAVs, CoVs have been isolated from a wide range of host species, and some of the isolated $\mathrm{CoVs}$ are zoonotic with the potential to cause an unpredictable pandemic. CoVs must therefore be controlled (Table 2). 
Table 1. Host range, viral receptor-binding glycoproteins and host receptors of influenza viruses.

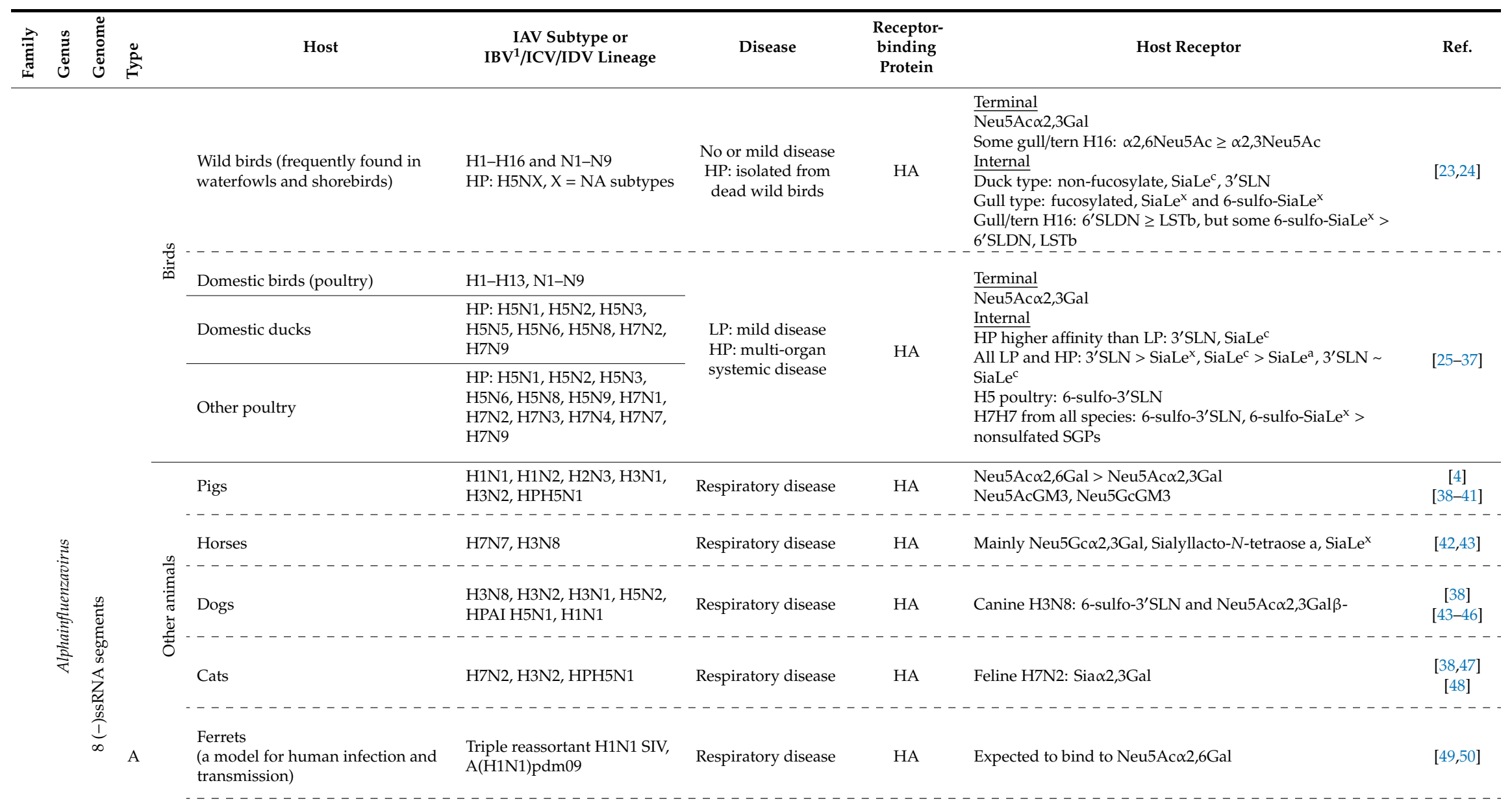




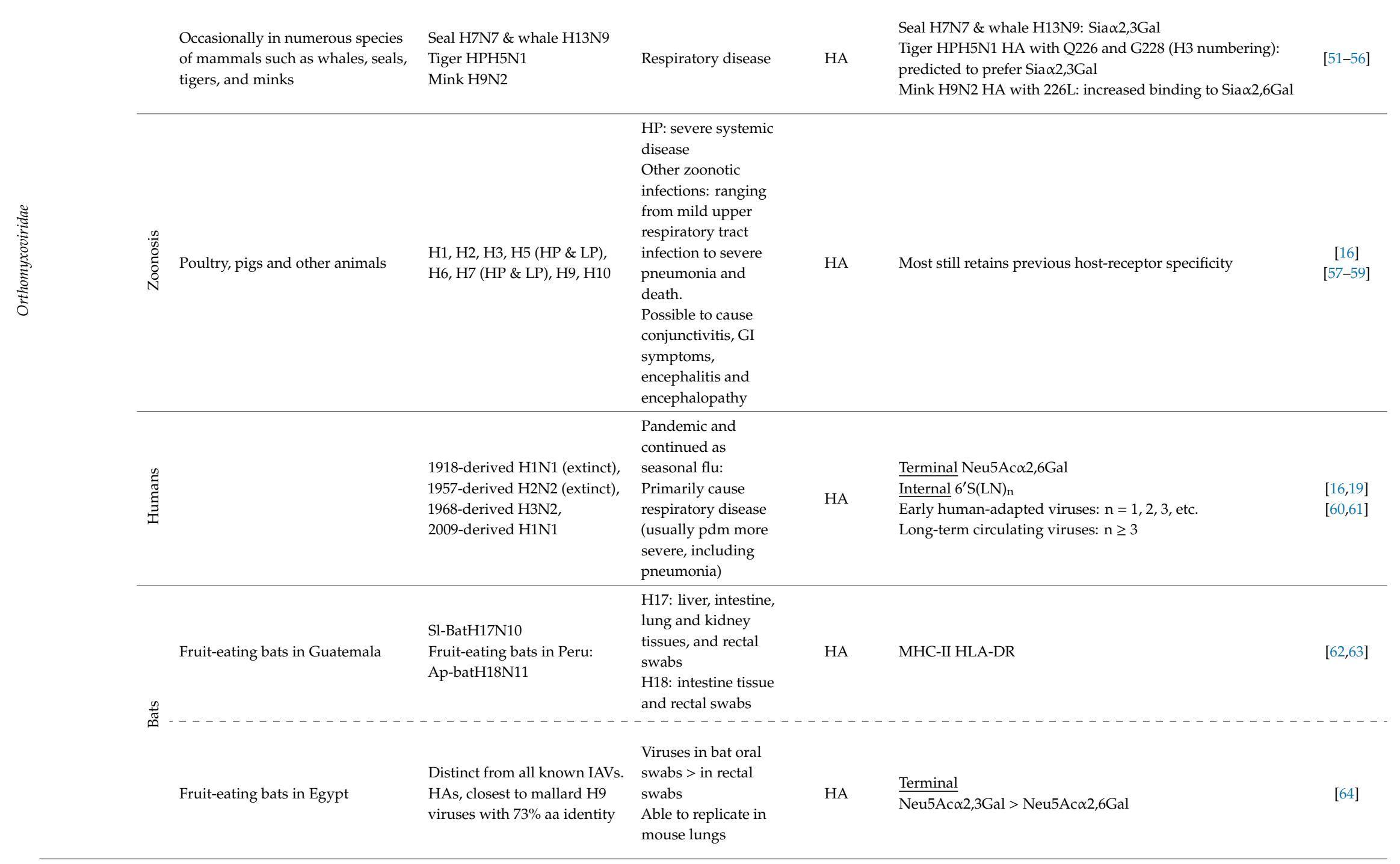




\begin{tabular}{|c|c|c|c|c|c|c|c|c|}
\hline 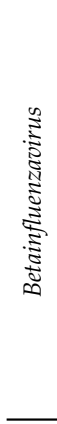 & 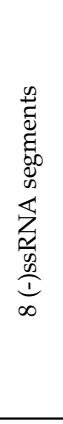 & B & $\begin{array}{l}\text { Humans, } \\
\text { sporadically in seals, pigs, horses, } \\
\text { pheasants and dogs. }\end{array}$ & $\begin{array}{l}\text { Influenza B viruses (IBVs) } \\
2 \text { lineages } \\
\text { - Victoria lineage } \\
\text { B/Victoria/2/87-like viruses } \\
\text { - Yamagata lineage: } \\
\text { B/Yamagata/16/88-like } \\
\text { viruses }\end{array}$ & Seasonal flu & HA & $\begin{array}{l}\text { Wild types of both Yamagata (HA with F95 and N194) and } \\
\text { Victoria (HA with G141, R162 and D196) lineages: } \\
\text { Neu5Ac } \alpha 2,6 \mathrm{Gal}>\text { Neu5Ac } \alpha 2,3 \mathrm{Gal} \\
2001-2007 \text { clinical isolates in Taiwan: } \\
83 \% \text { of Yamagata-like strains prefer } \alpha 2,6 \mathrm{Sia} ; 17 \% \text { prefer both } \\
\alpha 2,3 \mathrm{Sia} \text { and } \alpha 2,6 \mathrm{Sia} \text {. } \\
54 \% \text { of Victoria-like strains prefer both } \alpha 2,3 \mathrm{Sia} \text { and } \alpha 2,6 \mathrm{Sia} ; \\
25 \% \text { prefer sulfated glycan, either } \beta \text {-Gal-3-sulfate or } \\
6 \text {-HSO } \mathrm{H}_{3} \text {-Gal } \beta 1,4 \mathrm{GlcNAc} ; 21 \% \text { prefer } \alpha 2,6 \mathrm{Sia} \text {. } \\
\text { Dual } \alpha 2,3 \mathrm{Sia} \text { and } \alpha 2,6 \mathrm{Sia}-\mathrm{binding} \text { viruses seem to be } \\
\text { associated with bronchopneumonia and gastrointestinal } \\
\text { symptoms. }\end{array}$ & [65-68] \\
\hline 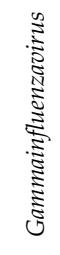 & 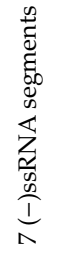 & C & $\begin{array}{l}\text { Humans (particularly in infants and } \\
\text { children), pigs, cattle }\end{array}$ & $\begin{array}{l}\text { Influenza C viruses (ICVs) } \\
6 \text { lineages: C/Taylor, } \\
\text { C/Mississippi, C/Aichi, } \\
\text { C/Yamagata, C/Kanagawa } \\
\text { and C/Sao Paulo }\end{array}$ & Usually mild flu & HEF & $\begin{array}{l}\text { Terminal } \\
\text { C/Johannesburg/1/66 (C/Aichi lineage): Neu5,9Ac } 2 \alpha 2,6 \mathrm{Gal}\end{array}$ & [69-72] \\
\hline 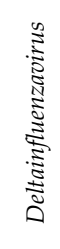 & 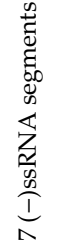 & D & $\begin{array}{l}\text { Pigs, cattle, } \\
91 \% \text { seropositivity found among } \\
\text { persons working with cattle }\end{array}$ & $\begin{array}{l}\text { Influenza D viruses (IDVs) } \\
3 \text { lineages: D/OK, D/660 and } \\
\text { D/Japanese } \\
\text { D/Japanese lineage contains } 2 \\
\text { sublineages: } \mathrm{D} / \text { Yama2016 } \\
\text { and D/Yama2019 }\end{array}$ & Usually mild flu & HEF & $\begin{array}{l}\text { Terminal } \\
\text { D/OK: Neu5,9Ac and Neu5Gc9Ac either linked to } \alpha 2,6 \mathrm{Gal} \\
\text { or } \alpha 2,3 \mathrm{Gal} \\
\text { D/660: Neu5,9Ac2 } \alpha 2,6 \mathrm{Gal} \text {, Neu5Gc9Ac } \alpha 2,6 \mathrm{Gal} \text { and } \\
\text { Neu5Gc9Ac } \alpha 2,3 \mathrm{Gal}\end{array}$ & $\begin{array}{c}{[15,72]} \\
{[73]}\end{array}$ \\
\hline
\end{tabular}

3'SLN: 3' sialyllactosamine (Neu5Ac $\alpha 2,3 \mathrm{Gal} \beta 1$,4GlcNAc $\beta 1$ ); 6'SLDN: Neu5Ac $\alpha 2,6 \mathrm{GalNAc} \beta 1,4 \mathrm{GlcNAc} \beta 1$; GI: gastrointestinal; HA: hemagglutinin; HEF: hemagglutinin-esterase-fusion; HLA-DR: human leukocyte antigen DR isotype; HP: highly pathogenic virus; IAV: influenza A virus; IBV ${ }^{1}$ : influenza B virus; ICV: influenza C virus; IDV: influenza D virus; LP: low pathogenic virus; LSTb: lactoseries tetrasaccharide $b$ (Gal $\beta 1,3($ Neu5Ac $\alpha 2,6)$ GlcNAc $\beta 1,3 G a l \beta 1,4 G l c \beta 1)$; MHC-II: major histocompatibility complex II; NA: neuraminidase; Neu5,9Ac2: 5- $N$-acetyl-9-O-acetylneuraminic acid; Neu5Ac: 5- $N$-acetylneuraminic acid; Neu5AcGM3: Neu5Ac $\alpha 2,3 G a l \beta 1,4 G l c \beta 1-1$ 'Ceramide; Neu5Gc: 5- $N$-glycolylneuraminic acid; Neu5GcGM3:

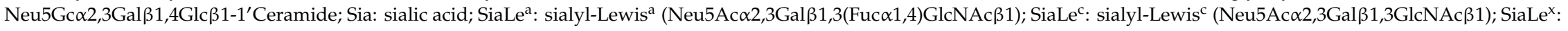
sialyl-Lewis ${ }^{\times}$(Neu5Ac $\alpha 2,3 \mathrm{Gal} \beta 1,4($ Fuc $\alpha 1,3)$ GlcNAc $\beta 1$ ); Sialyllacto- $N$-tetraose a: Neu5Ac $\alpha 2,3 \mathrm{Gal} \beta 1,3 \mathrm{GlcNAc} \beta 1,3 \mathrm{Gal} \beta 1-4 \mathrm{Glc} \beta 1$; SIV: swine influenza virus. 
Table 2. Host range, viral receptor-binding glycoproteins and host receptors of coronaviruses.

\begin{tabular}{|c|c|c|c|c|c|c|c|}
\hline \multirow{2}{*}{\multicolumn{2}{|c|}{ 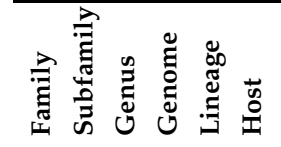 }} & \multirow{2}{*}{$\mathrm{CoV}$} & \multirow{2}{*}{ Disease } & \multirow{2}{*}{$\begin{array}{l}\text { Receptor- } \\
\text { binding } \\
\text { Protein }\end{array}$} & \multicolumn{2}{|c|}{ Host Receptor } & \multirow{2}{*}{ Ref. } \\
\hline & & & & & Primary Receptor & Attachment Factor & \\
\hline \multirow{11}{*}{ 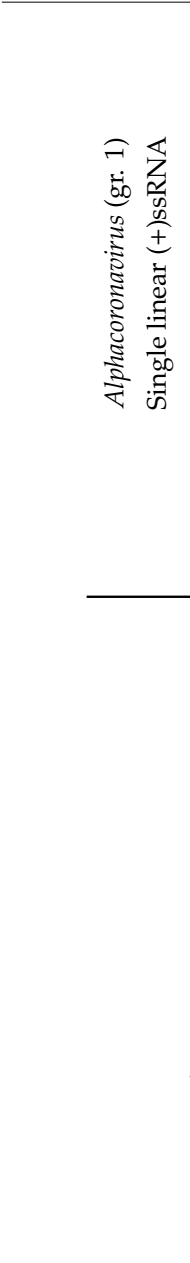 } & 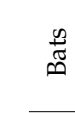 & $\begin{array}{l}\text { Ro(HKU10)-, Hi(HKU10)-, } \\
\text { Rh(HKU2)-, Sc(512)-, Mi(1A, 1B, } \\
\text { HKU8)- BatCoV }\end{array}$ & Unknown & & & & [74] \\
\hline & $\frac{\sqrt[n]{\Xi}}{\widetilde{\Xi}}$ & $\begin{array}{l}\text { FeCoV I \& II (nonvirulent form of } \\
\text { FCoV), CCoV, TGEV, PEDV }\end{array}$ & Gastroenteritis & S1 & $\begin{array}{l}\mathrm{S} 1^{\mathrm{B}}(\mathrm{S} 1-\mathrm{CTD}) \\
\text { Aminopeptidase N (APN; CD13), } \\
\text { not for PEDV and FeCoV I }\end{array}$ & $\begin{array}{l}\frac{\mathrm{S} 1^{\mathrm{A}}(\mathrm{S} 1-\mathrm{NTD})}{\alpha 2,3 \mathrm{Neu} 5 \mathrm{Gc}>\mathrm{Neu} 5 \mathrm{Ac} \text { (TGEV traveling to a }} \\
\text { target site), Neu5Ac }>\text { Neu5Gc (PEDV) }\end{array}$ & {$[75-80]$} \\
\hline & $\begin{array}{l}\text { है } \\
\stackrel{\Xi}{\Xi}\end{array}$ & FIPV (virulent form of FCoV) & $\begin{array}{l}\text { Peritonitis, } \\
\text { severe wasting }\end{array}$ & S1 & fAPN for type II, not type I FIPV & Coreceptor for both types I and II: DC-SIGN & {$[81,82]$} \\
\hline & & -------------- & -------- & ------- & --------------- & --------------- & --- \\
\hline & & PRCoV & $\begin{array}{l}\text { Respiratory } \\
\text { disease }\end{array}$ & S1-CTD & pAPN (res. 366-369, 727-790) & & [83] \\
\hline & $\begin{array}{l}\text { 节 } \\
\text { 章 } \\
\text { 至 }\end{array}$ & HCoV-229E, HCoV-NL63 & Generally URTI & S1-CTD & $\begin{array}{l}\text { NL63: hACE2 } \\
\text { 229E: hAPN (res. 208, 241-319) }\end{array}$ & & [84] \\
\hline & & ChRCoV (HKU24) & Unknown & & 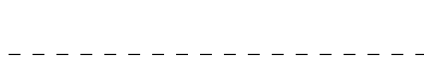 & & [85] \\
\hline & $\begin{array}{l}\frac{n}{\tilde{\Xi}} \\
\frac{0}{0} \\
\approx\end{array}$ & $\mathrm{RCoV}$ & $\begin{array}{l}\text { Respiratory } \\
\text { disease, } \\
\text { sialodacryoadenitis }\end{array}$ & $\mathrm{HE}$ & Unknown & $\begin{array}{l}\text { HE (type II) } \\
\text { 4-O-Ac-Sias, } 4,5-\text { di- } N \text {-acetylneuraminic acid } \\
\alpha \text {-methylglycoside }(\alpha-4-N-\text {-Ac-Sia })\end{array}$ & {$[86,87]$} \\
\hline & & MHV & $\begin{array}{l}\text { Gastroenteritis, } \\
\text { hepatitis, } \\
\text { encephalomyelitis }\end{array}$ & S1-NTD, HE & $\frac{\text { S1-NTD }}{\text { Murine CEACAM1 }}$ & $\begin{array}{l}\frac{\mathrm{HE}}{\text { Strain DVIM: 9-O-Ac-Sias }} \\
\text { Strains S, JHM: 4-O-Ac-Sias }\end{array}$ & {$[88,89]$} \\
\hline & \multirow{2}{*}{ 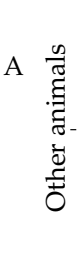 } & BCoV, EqCoV(ECoV) & $\begin{array}{l}\text { Enteritis, } \\
\text { respiratory } \\
\text { disease }\end{array}$ & S1-NTD, HE & $\begin{array}{l}\text { S1-NTD } \\
\text { 9-O-acetylated sialoglycans } \\
\text { (unknown for EqCoV) }\end{array}$ & $\begin{array}{l}\text { HE (type I) } \\
\text { 9-O-acetylated sialoglycans, } \\
\text { 7,9-di-O-acetyl Sia }\end{array}$ & {$[86,90]$} \\
\hline & & PHEV & $\begin{array}{l}\text { Vomiting, } \\
\text { wasting, } \\
\text { encephalomyelitis }\end{array}$ & $\mathrm{S} 1, \mathrm{HE}$ & $\begin{array}{l}\text { S1 (res. 291-548) Porcine NCAM } \\
\text { S1-NTD 9-O-Ac-Sia }\end{array}$ & $\frac{\mathrm{HE}}{9-\mathrm{O}-\mathrm{Ac}-\mathrm{Sias}}$ & [91-93] \\
\hline
\end{tabular}




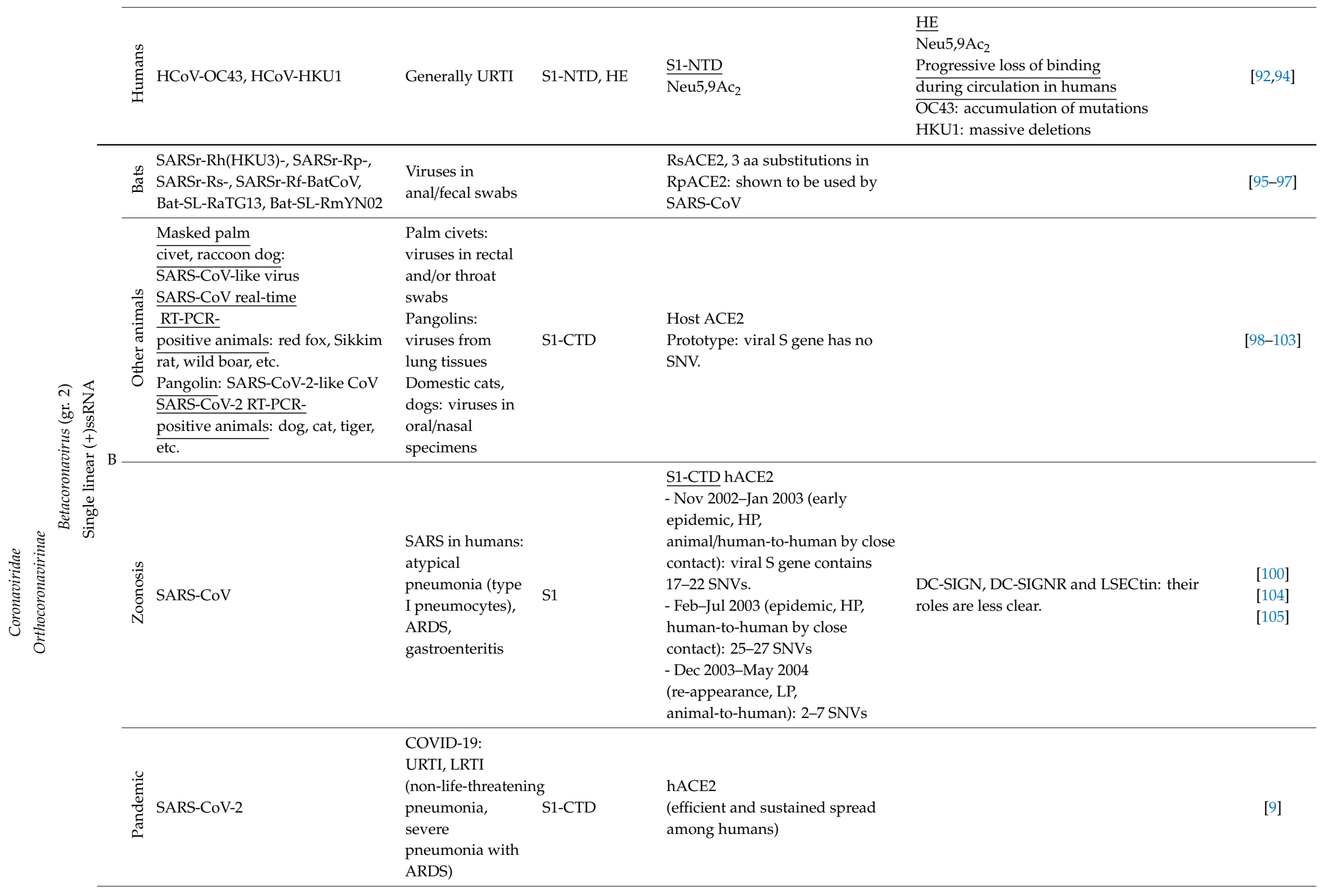




\begin{tabular}{|c|c|c|c|c|c|c|}
\hline$\frac{\infty}{\pi}$ & $\begin{array}{l}\text { Ty(HKU4)-, Hp(HKU25)-, } \\
\text { Pi(HKU5)-BatCoV, NeoCoV }\end{array}$ & Virus in feces & S1 & $\begin{array}{l}\frac{\text { S1-CTD }}{\text { Ty- and Hp-BatCoVs, but not }} \\
\text { Pi-BatCoV, can bind to hDPP4. }\end{array}$ & $\begin{array}{l}\frac{\text { S1-NTD }}{\text { Binds to the intestinal epithelium in common }} \\
\text { pipistrelle bats but not in serotine bats and } \\
\text { frugivorous bats. }\end{array}$ & [106-108] \\
\hline 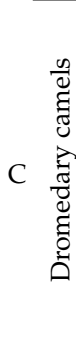 & dromedary MERS-CoV & $\begin{array}{l}\text { Virus/RNA in } \\
\text { nasal swabs and } \\
\text { lung tissue } \\
\text { samples. } \\
\text { An experimental } \\
\text { study: } \\
\text { mild upper } \\
\text { respiratory tract } \\
\text { disease }\end{array}$ & S1 & $\begin{array}{l}\frac{\text { S1-CTD }}{\text { dromedary DDP4 }} \\
\text { found in various organs, } \\
\text { particularly in nasal turbinate, } \\
\text { trachea and lungs }\end{array}$ & $\begin{array}{l}\frac{\mathrm{S} 1-\mathrm{NTD}}{\alpha 2,3-\text { sialic acid }} \\
\text { The } \mathrm{S} 1^{\mathrm{A}} \text { domain binds to the dromedary } \\
\text { nasal epithelium but not to the } \\
\text { porcine/rabbit nasal epithelium. }\end{array}$ & [108-111] \\
\hline $\begin{array}{l}\frac{n}{W} \\
0 \\
0 \\
0 \\
\text { N }\end{array}$ & MERS-CoV & $\begin{array}{l}\text { Atypical } \\
\text { pneumonia }\end{array}$ & S1 & $\begin{array}{l}\text { S1-CTD } \\
\text { hDDP4 (CD26) } \\
\text { Note: Intercellular spread of the } \\
\text { virus through cell-cell fusion does } \\
\text { not require DDP4 receptors but } \\
\text { requires TMPRSS2 activity. }\end{array}$ & $\begin{array}{l}\text { S1-NTD } \\
\text { Short and long } \alpha 2,3 \mathrm{Neu} 5 \mathrm{Ac}>\alpha 2,6 \mathrm{Neu} 5 \mathrm{Ac} \\
\text { glycans } \\
\text { The } \mathrm{S} 1^{\mathrm{A}} \text { domain binds to the human alveolar } \\
\text { epithelium (type II pneumocytes). }\end{array}$ & $\begin{array}{l}{[104]} \\
{[108]} \\
{[112]} \\
{[113]}\end{array}$ \\
\hline $\mathrm{D} \underset{\oplus}{\stackrel{0}{\pi}}$ & Ro-BatCoV (HKU9) & Unknown & & & & [74] \\
\hline : & Infectious bronchitis virus $\left(\mathrm{IBV}^{2}\right)$ & $\begin{array}{l}\text { Bronchitis, } \\
\text { nephritis, } \\
\text { reproductive } \\
\text { problems }\end{array}$ & S1-NTD & $\begin{array}{l}\text { IBV: } \alpha 2,3 \text {-linked sialic acids type } \\
1 \text { lactosamines } \\
\text { IBV strain Beaudette: heparan } \\
\text { sulfate }\end{array}$ & & $\begin{array}{l}{[114]} \\
{[115]}\end{array}$ \\
\hline & $\mathrm{TuCoV}(\mathrm{TCoV}), \mathrm{GfCoV}$ & Enteritis & S1 & $\begin{array}{l}\text { Nonsialylated type } 2 \\
\text { poly- } N \text {-acetyl-lactosamines }\end{array}$ & & [114] \\
\hline
\end{tabular}




\begin{tabular}{|c|c|c|c|c|c|}
\hline 官 & 串 FalCoV, HouCoV, $\mathrm{PiCoV}$ & Unknown & & & [116] \\
\hline 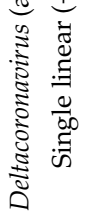 & 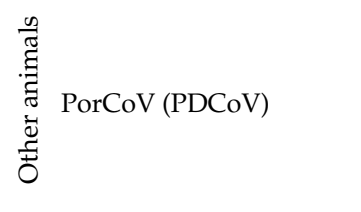 & $\begin{array}{l}\text { Diarrhea in } \\
\text { newborn piglets }\end{array}$ & S1 & $\begin{array}{l}\text { pAPN in porcine alveolar } \\
\text { macrophages but not necessary } \\
\text { for infection of lung-derived } \\
\text { fibroblast cells }\end{array}$ & [77] \\
\hline
\end{tabular}

9-O-acetyl-sialic acid; aa: amino acid; ACE2: angiotensin-converting enzyme 2; Ap-: Artibeus planirostris; APN: aminopeptidase N; ARDS: acute respiratory distress syndrome Bat-SL-RaTG13: SARS-like CoV isolated from Rhinolophus affinis (Ra); Bat-SL-RmYN02: SARS-like CoV number 02 isolated from Rhinolophus malayanus (Rm) in China's Yunnan (YN) province; BCoV: bovine coronavirus; CCoV: canine coronavirus; CEACAM1: carcinoembryonic antigen-related cell adhesion molecule 1; ChRCoV: China Rattus coronavirus; CoV: coronavirus; CTD: C-terminal domain; DC-SIGN: dendritic cell-specific ICAM-3 grabbing non-integrin; DC-SIGNR: DC-SIGN-related protein; EqCoV (ECoV): equine coronavirus; FalCoV: falcon coronavirus; FCoV: feline coronavirus; FeCoV I \& II: feline coronavirus type I \& II; FIPV: feline infectious peritonitis; GfCoV: guineafowl coronavirus; HCoV: human coronavirus; HE: hemagglutinin-esterase; Hi-: Hipposideros bat; HouCoV: houbara bustard coronavirus; Hp-: Chinese pipistrelle bat (Hypsugo pulveratus); IBV²: infectious bronchitis virus; LRTI: lower respiratory tract infection; LSECtin: liver and lymph node sinusoidal endothelial cell C-type lectin; MERS-CoV: Middle East respiratory syndrome-coronavirus; MHV: mouse hepatitis virus; Mi-: Miniopterus bat; NCAM: neural cell adhesion molecule; Neo-: Neoromicia capensis; NTD: N-terminal domain; PEDV: porcine epidemic diarrhea virus; PHEV: porcine hemagglutinating encephalomyelitis virus; Pi-: Pipistrellus bat; PiCoV: pigeon coronavirus; PorCoV (PDCoV): Porcine deltacoronavirus; PRCoV: porcine respiratory coronavirus; RCoV: rat coronavirus; Rf-: Rhinolophus ferrumequinum; Rh-: Rhinolophus bat; Ro-: Rousettus bat; Rp-: Rhinolophus pusillus; Rs-: Rhinolophus sinicus; S1: receptor-binding subunit of spike (S) protein; SARS-CoV: severe acute respiratory syndrome coronavirus; SARS-CoV-2: severe acute respiratory syndrome coronavirus-2; SARSr-CoV: SARS-related coronavirus; Sc-: Scotophilus bat; Sl-: Sturnira lilium; SNVs: single nucleotide variants; TGEV: transmissible gastroenteritis virus; TuCoV(TCoV): turkey coronavirus; Ty-: Tylonycteris bat; URTI: upper respiratory tract infection. 
The structures, diversities, host ranges and receptors of IVs and CoVs are summarized in this review. The host range of an infection depends on specific interactions between the virus strain and the host species. We will critically review current knowledge of receptor binding specificity, a crucial determinant of the host range, of IVs and human-infecting CoVs with appropriate viral historical perspective.

\section{Overview of Structures, Host Ranges and Receptors of Influenza Viruses and Coronaviruses}

Tables 1 and 2 show the host ranges, diseases, receptor-binding viral spikes and receptors of influenza viruses (IVs) and coronaviruses (CoVs), respectively. According to the International Committee on Taxonomy of Viruses [117], IVs in the family Orthomyxoviridae are divided into four genera: Alphainfluenzavirus, Betainfluenzavirus, Gammainfluenzavirus and Deltainfluenzavirus (previously, Influenzavirus $A, B, C$ and $D$, respectively). CoVs in the subfamily Orthocoronavirinae of the family Coronaviridae are divided into four genera: Alphacoronavirus ( $\alpha \mathrm{CoV}$, previously group 1$)$, Betacoronavirus $(\beta \mathrm{CoV}$, previously group 2$)$, Gammacoronavirus $(\gamma \mathrm{CoV}$, previously group 3$)$ and Deltacoronavirus $(\delta \mathrm{CoV}$, a new group). The genus $\beta \mathrm{CoV}$ is subdivided into four lineages: $\mathrm{A}, \mathrm{B}, \mathrm{C}$ and $\mathrm{D}$. Both IVs and CoVs are enveloped single-stranded RNA viruses. However, IV genomes are negative-sense, linear RNA segments (eight segments for influenza A and B viruses and seven segments for influenza C and D viruses [86]), whereas the CoV genome is a positive-sense, linear RNA molecule [118]. Various CoVs cause a variety of diseases in mammals and birds [118]. In contrast, IVs in mammals (except for bat H17 and H18 viruses that were found in rectal swabs $[119,120])$ mainly cause respiratory infection $[4,42]$, whereas infection of IVs in birds occurs in the intestinal and respiratory tracts [121,122]. The virus host range is chiefly determined by the viral spike glycoproteins carrying receptor binding sites for attachment of host receptors initiating virus infection. To bind to host receptors, influenza A viruses (IAVs) and influenza B viruses (IBVs) use hemagglutinin (HA), while influenza C viruses (ICVs) and influenza D viruses (IDVs) use hemagglutinin-esterase-fusion (HEF) to bind to host receptors as indicated in Table 1. Only IAVs have a broad range of host species. An IAV structure with HA spikes and the position of a receptor binding site (RBS) on an HA1 subunit are shown in Figure 1. Avian IAVs from wild birds are thought to be the origin of all mammalian IAVs (not known for bat H17 and H18 viruses) including all human IAVs [123]. CoVs use their spike (S) glycoproteins in N- and/or C-terminal domains of the S1 subunit, S1-NTD and/or S1-CTD, respectively, as indicated in Table 2. Specially, $\mathrm{CoVs}$ in lineage $\mathrm{A}$ of the genus $\beta \mathrm{CoV}$ have additional spike glycoproteins, hemagglutinin-esterases (HEs), possibly acquired from influenza C virus (ICV) during mixed infection [124]. A CoV structure with S and HE spikes and positions of S1-NTD and S1-CTD on the S spike are shown in Figure 2. Bat CoVs are likely to be the ancestral origins of two seasonal $\alpha$ CoVs, HCoV-229E $[125,126]$ and HCoV-NL63 [127], two zoonotic lineage B and lineage C $\beta$ CoVs, SARS-CoV (which has disappeared in humans) [128-130] and MERS-CoV [108,131], respectively, and an ongoing pandemic lineage B $\beta C \mathrm{CoV}$, SARS-CoV-2 [132,133]. Rodent CoVs are likely to be the ancestral origins of two seasonal lineage A $\beta \mathrm{CoVs}, \mathrm{HCoV}-\mathrm{OC} 43$ and HCoV-HKU1 [85]. So far, $\gamma \mathrm{CoVs}$ and $\delta \mathrm{CoVs}$ have been mainly found in birds [85]. This review will focus on human viruses and potential zoonotic viruses and the main spike glycoproteins determining host-specific virus infection. 


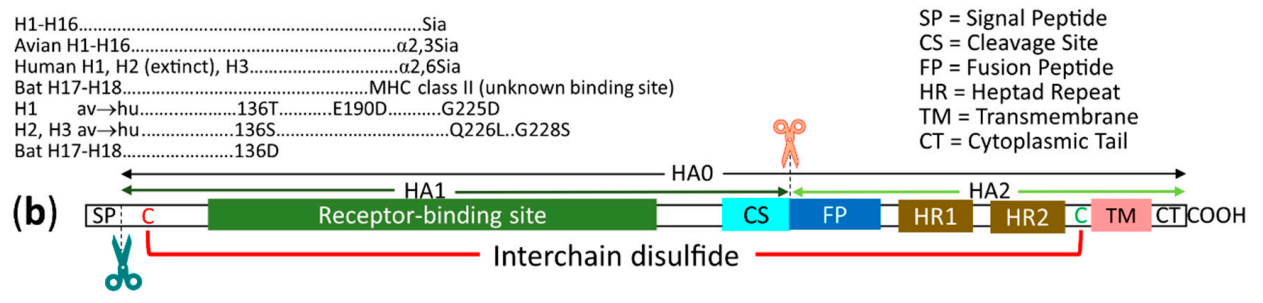

(a) NEP (NS2)

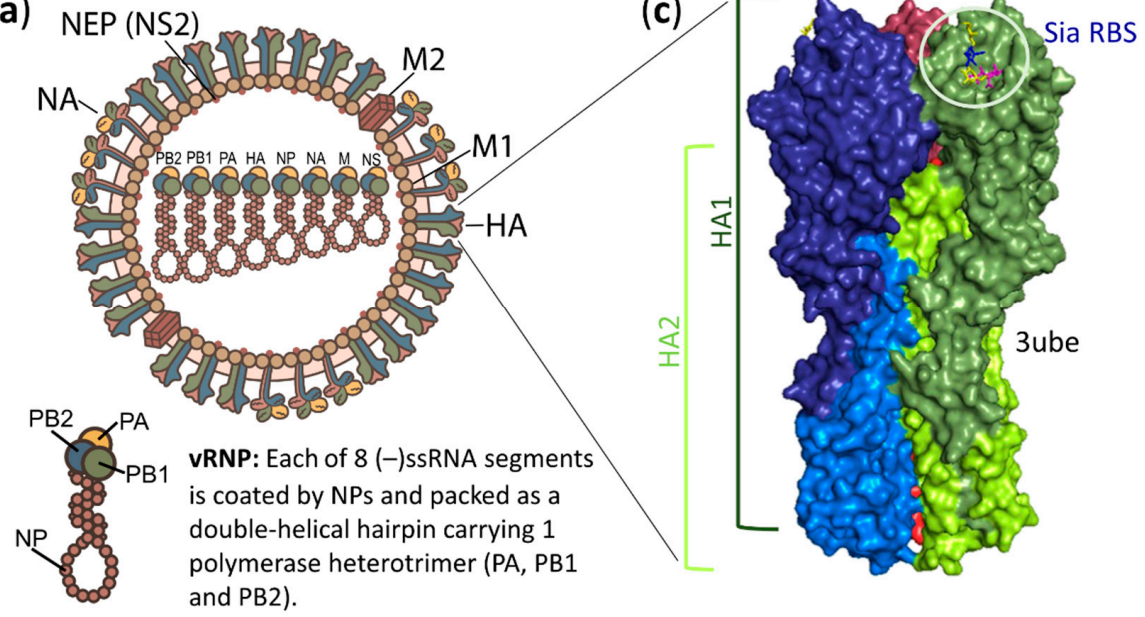

Figure 1. Schematic structures of an IAV and its HA. (a) The virion is pleomorphic from spherical to filamentous. It contains eight negative sense, single-stranded RNA genomic segments, each coated with nucleoproteins (NPs) and bound to a heterotrimeric RNA polymerase complex of PA, PB1 and PB2 that forms as a viral ribonucleoprotein (vRNP). All 8 vRNPs are surrounded by a lipid bilayer (envelope). Whereas the inner layer of the envelope is attached to matrix 1 (M1) proteins bound to vRNPs and to nuclear export proteins (NEPs, formerly named NS2 proteins), the outer layer is spiked with HAs and NAs and channeled with matrix 2 (M2) proteins. (b) Diagram of an unfolded HA polypeptide. The signal peptide (SP) at the N-terminus is removed during the cotranslational translocation of a nascent HA into the ER [134]. The synthesized single polypeptide HA is designed to be HA0 (inactive form) that carries HA1 and HA2 subunits. The HA1 subunit, in addition to being a major antigen, contains a receptor binding site, which binds specifically to a sialyl glycan as indicated, except for H17 and H18 viruses. A cleavage site (CS) is located at the end of the HA1 subunit. The HA1 CS usually contains a single basic aa (X-R/K) that can be cleaved extracellularly by tissue-specific expressed trypsin-like serine endoproteases. In contrast, the HA1 CS with additional basic amino acids (R/K-R) may be cleaved intracellularly by ubiquitous proteases (furin and PC5/6) in the trans-Golgi compartment recognizing the R-X-R/K-R motif or cleaved extracellularly by ubiquitous proteases (MSPL and TMPRSS13) in the plasma membrane recognizing the R/K-X-R/K-R motif, and the virus can thus cause systemic infection and is classified as a highly pathogenic (HP) virus $[135,136]$. After the cleavage, the HA1 and HA2 subunits remain disulfide-linked between Cys (C, red) and Cys (C, green) of the two subunits, giving the fusion-active form of the HA. The HA2 subunit carries a hydrophobic fusion peptide (FP) at the N-terminus followed by heptad repeats 1 and 2 (HR1 and HR2). Upon activation at low $\mathrm{pH}$, these 3 regions work cooperatively to fuse viral and cellular membranes together, releasing vRNPs into the host cell. The HA2 subunit also contains a transmembrane domain (TM) anchoring the viral membrane (envelope) and promoting full fusion [137]. A hydrophilic cytoplasmic tail (CT) at the C-terminus of the HA2 subunit can also affect the fusion process [138]. (c) Side view of a surface diagram of a trimeric HA. This representative viral HA is from pdb ID of 3ube, which showed a 2009 pandemic HA in complex with lactoseries tetrasaccharide c (LSTc, Neu5Ac $\alpha 2,6 \mathrm{Gal} \beta 1,4 \mathrm{GlcNAc} \beta 1,3 \mathrm{Gal} \beta 1,4 \mathrm{Glc}$ ) [139]. Each monomer of the HA trimer is colored as follows: deep blue, HA1 and marine blue, HA2; green smudge, HA1 and lemon, HA2; raspberry, HA1 and red, HA2. The receptor binding site, which carries a part of the LSTc ligand (magenta stick, Neu5Ac; yellow stick, Gal; blue stick, GlcNAc; yellow stick, Gal), is located on each globular head, which is a part of HA1 on a stalk composed of the remaining part of HA1 and all HA2. 


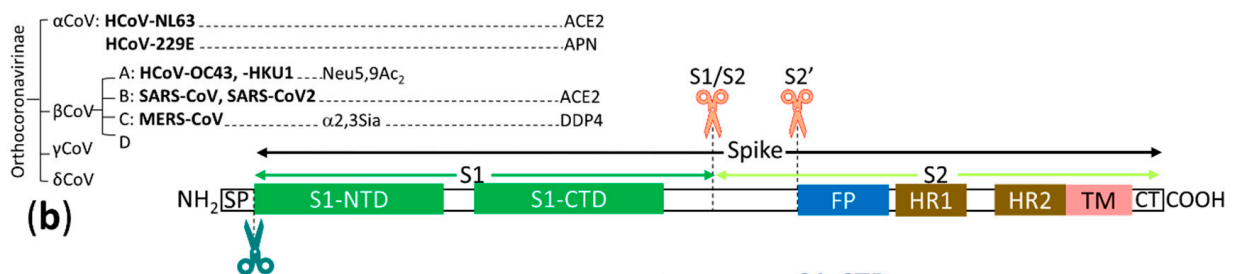

(a)
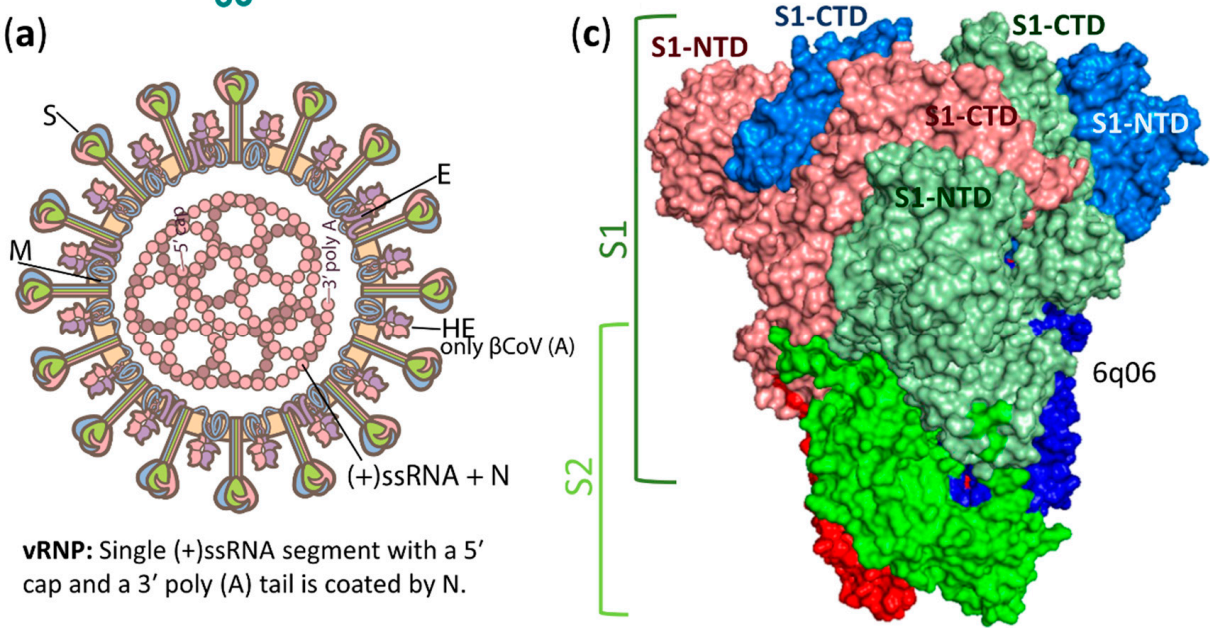
VRNP: Single (+)ssRNA segment with a $5^{\prime}$
cap and a $3^{\prime}$ poly (A) tail is coated by $N$.

Figure 2. Schematic structures of a $\mathrm{CoV}$ and its spike protein. (a) The $\mathrm{CoV}$ is a pleomorphic spherical enveloped particle. It contains a linear positive-sense, single-stranded RNA with a $5^{\prime}$ cap and a $3^{\prime}$ poly(A) tail that are enclosed by nucleocapsid $(\mathrm{N})$ proteins. The lipid bilayer envelope carries 3-4 structural proteins. (i) Membrane (M) proteins are the most abundant small triple-spanning transmembrane proteins that define the virion morphology and are major coordinators of virion assembly [140]. (ii) Envelope (E) proteins are minor channel-spanning transmembrane proteins that work together with the M proteins for virion assembly, budding and release [141]. (iii) Spike (S) proteins are homotrimeric type I transmembrane glycoproteins [142] protruding from the virion envelope (20 nm in length) that resemble a crown (Latin: corona) under an electron microscope. S proteins are major antigenic surface proteins and are critical for virion entry into a specific host cell by binding to a specific receptor(s) on the host cell surface and mediating membrane fusion [143]. (iv) The members of $\beta \mathrm{CoV}$ lineage A have additional short hemagglutinin esterase (HE) spikes (5 nm in length), which are homodimeric type I transmembrane glycoproteins. CoV HE has the potential to evolve its $\mathrm{O}$-Ac-Sia receptor-binding specificity and activity, along with its companion $\mathrm{S}$ proteins, in balance with its receptor-destroying sialate $O$-acetylesterase activity for efficient virus infection and spread [86,94,144]. (b) Diagram of the unfolded S polypeptide composed of an N-terminal signal peptide (SP), an S1 subunit and an S2 subunit. The N-terminal signal peptide is a short type 1 signal hydrophobic peptide probably cleaved during cotranslational transport across the endoplasmic reticulum [145]. The S1 subunit carries 2 important domains, an S1 N-terminal domain (S1-NTD or S1 ${ }^{\mathrm{A}}$ ) and an S1 C-terminal domain (S1-CTD or $\mathrm{S1}^{\mathrm{B}}$ ), one of which or both of which function as a host receptor-binding domain depending on the virus. Host receptors of CoVs affecting humans are shown above the bound S1 domain. The S1/S2 boundary with multiple basic aa residues may be potentially cleaved by furin during virus exit, while the monobasic cleavage site may be cleaved by a target cell protease, such as TMPRSS2 (trypsin-like protease) and cathepsin L [146], generating the S1 and S2 subunits with a noncovalently link [147]. The S2 subunit carries 5 regions. (i) The S2' cleavage site may contain monobasic or two basic residues that must be cleaved by a host protease [146]. Both S1/S2 and S2' cleavage sites must be cleaved to enable its $S$ protein to mediate membrane fusion. (ii) A fusion peptide (FP) that mediates fusion of the virion envelope with the cellular plasma membrane or with the cellular endosomal membrane, followed by (iii) 2 heptad repeats (HR1 and HR2) promoting fusion [147], (iv) a transmembrane (TM) domain anchoring to the envelope and (v) a cytoplasmic tail (CT). (c) Side view of a surface diagram of a trimeric CoV S protein (pdb: 6q06 [148]). Each monomer of the S trimer is colored as follows: salmon, S1 and red, S2; marine blue, S1 and blue, S2; pale green, S1 and green, S2. S1-NTD and S1-CTD are on each $\mathrm{S} 1$ head above each S2 stalk. 


\section{Sialyl Glycan Receptor-Dependent Recognition of Influenza A (H1-H16) Viruses, Egyptian Fruit Bat-Isolated Influenza A Virus, Influenza B, C and D Viruses and Lineage A $\beta$ CoVs ( $\beta 1 \mathrm{CoVs})$}

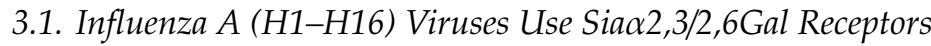

HAs of H1-H16 viruses recognize specific sialyl glycans on the host epithelial cell surface, as a crucial step mediating virus infection (Figure 3a). IAVs from avians, either wild birds or domestic birds, typically prefer the $\alpha 2,3$ Sia terminal. Surprisingly, a recent study showed that some gull/tern H16 viruses prefer $\alpha 2,6 \mathrm{Neu} 5 \mathrm{Ac}$ over or equal to the $\alpha 2,3 \mathrm{Neu} 5 \mathrm{Ac}$ terminal of synthetic sialylglycopolymers [23]. It was suggested that the particularly distinctive receptor-binding specificity of H16 viruses may be related to their HAs containing A138S (found in human 1977-derived H1N1 viruses, reducing binding to $\alpha 2,3 \mathrm{Neu} 5 \mathrm{Ac}$ receptors) and E190T (the amino acid (aa) at position 190 determining binding specificity of H1N1 viruses to the sialyl linkage type) [23]. Usually, viruses adapt to bind to sialyl glycans dominant in the host target tissues. Information on virus collection from oral, nasal, nasopharyngeal, cloacal or feces swabs and sialyl glycan analysis of tissues of specific wild birds shedding the virus in the sample collection may lead to a better understanding of why some H16 viruses display binding distinct from that of other avian viruses. Binding preference for the internal part of sialyl glycans appears to differ among different viruses based on birds of isolation as indicated in Table 1.

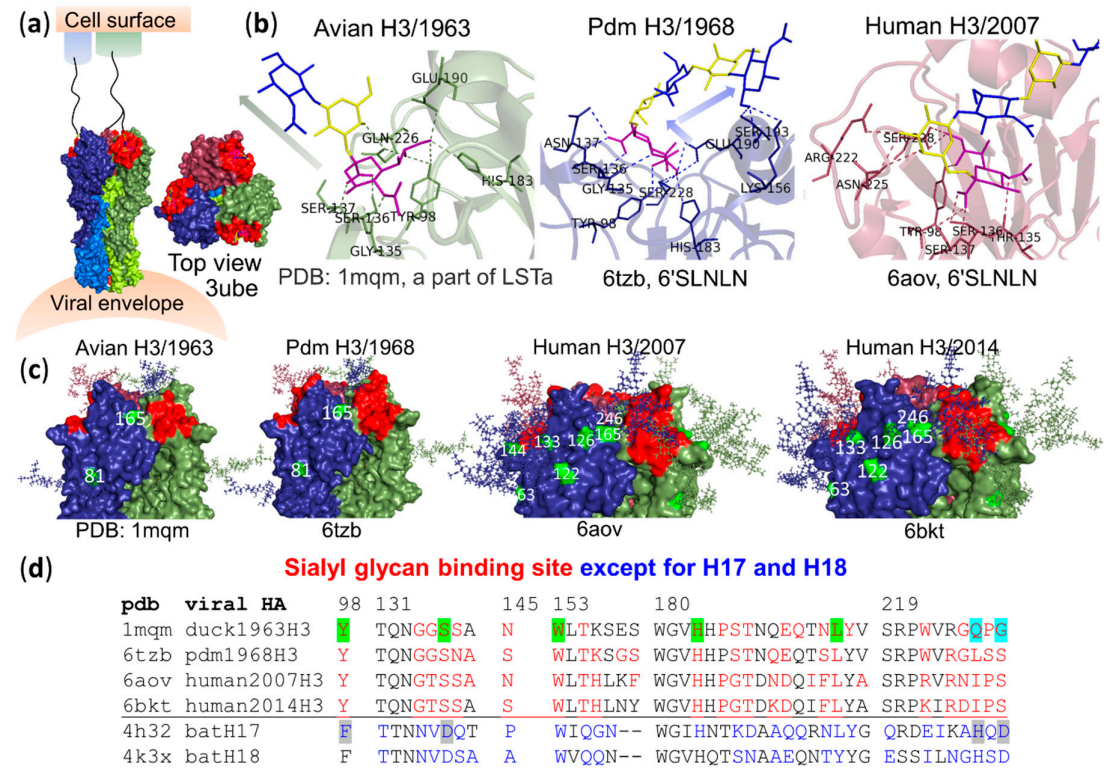

Figure 3. Binding of avian, pandemic (pdm) and seasonal HAs to specific sialyl glycans. (a) HA trimer binding to sialyl glycan receptors on the host cell surface. (b) Direct interactions in stick models between aa residues in avian/1963 (green smudge color), pdm/1968 (deep blue color) and seasonal/2007 (raspberry color) H3 HA receptor binding sites and sugar residues, a part of lactoseries tetrasaccharide a (LSTa; Neu5Ac $\alpha 2,3 \mathrm{Gal} \beta 1,3 \mathrm{GlcNAc} \beta 1,3 \mathrm{Gal} \beta 1,4 \mathrm{Glc}), 6$ ' sialyl di- $N$-acetyllactosamine (6'SLNLN; Neu5Ac $\left.\alpha 2,6(\mathrm{Gal} \beta 1,4 \mathrm{GlcNAc})_{2}\right)$ and 6'SLNLN, respectively. Neu5Ac, magenta; Gal, yellow; GlcNAc, blue. (c) Comparison of the number of glycosylation sites (green residues) on the HA1 globular head trimer (surface diagram) between avian, pdm and seasonal H3 HAs. Glycans were in silico added into $\mathrm{N}$-glycosylation sites (NXS/T, X = any residue except for Pro) on the H3 HA heads by GlyProt and are shown as sticks with organic spheres. (d) Alignment showing aa changes in RBS (H3 numbering). Amino acids in avian, pdm and seasonal H3 HAs and in H17-H18 HAs generating a shallow pocket are labeled red and blue, respectively. Highly conserved amino acids giving direct interactions with Sia are highlighted in green. Well-known amino acids in HA sequences that are critical for determination of the sialyl linkage-type of avian and human host cells are highlighted in cyan. 1mqm, 6tzb, 6aov and 6bkt are from [149-152], respectively. The amino acid alignments shown in this figure and in the other figures were performed by using Clustal Omega [153]. 
Several zoonotic influenza virus subtypes (Table 1) including avian subtypes H5N1, H7N9 and H9N2 and swine subtypes H1N1, H1N2 and H3N2 have been occasionally reported to cross the species barrier to infect humans [57]. However, human-to-human transmission of nonhuman viruses has been limited and non-sustained [154]. Viruses in four historical pandemics acquired strong binding to human-type $\alpha 2,6 \mathrm{Neu} 5 \mathrm{Ac}$ receptors for efficient human-to-human transmission [19,155-157]. (i) The H1N1 Spanish pandemic in 1918-1919 was found to include at least two strains with distinct receptor-binding properties during the pandemic period [155]. First, viral HAs have a single aa substitution, E190D, in the receptor-binding site (RBS) and bind to both avian-type and human-type receptors. Second, there are two aa substitutions in the HA RBS, E190D and G225D, that enable HA adaptation to bind only to $\alpha 2,6$ Neu5Ac receptors. (ii) The H2N2 Asian pandemic in 1957-1958 had virus isolates from two stages of the pandemic. In the early pandemic stage, virus isolates can be divided into three subpopulations based on receptor binding specificities: avian-like viruses with 226Q and 228G in the HA RBS, atypical viruses with Q226L and 228G, and classic human viruses with Q226L and G228S that have preferential binding to avian-type receptors, both avian-type and human-type receptors, and human-type receptors, respectively. In the subsequent stage, all virus isolates have Q226L and G228S substitutions with preferential binding to human-type receptors [156]. (iii) The virus in the H3N2 Hong Kong pandemic in 1968-1969 had the same acquisition of Q226L and G228S substitutions in the HA RBS as that in the H2 pandemic for switching from avian-type to human-type receptor binding preference [157]. (iv) The virus in the H1N1 swine pandemic in 2009-2010 had 190D and 225D in the HA RBS as in the swine H1 HA RBS recognizing human-type $\alpha 2,6 \mathrm{Neu} 5 \mathrm{Ac}$ receptors that are abundant in the porcine lung, which is the main site of swine IAV replication $[19,39]$. Protein engineering by chimeragenesis and site-directed mutagenesis of $\mathrm{H} 1$ proteins suggested that A200T and A227E substitutions in the H1 swine pandemic were responsible for efficient and sustained human-to-human transmission. Molecular modeling revealed hydrogen bond formation between T200 and Q191 in the 190-helix that is important for receptor binding preference of H1 HAs and between E227 and Gal next to Sia [158].

Based on historical data, after a pandemic virus continued to circulate as a seasonal strain, the preexisting seasonal virus, which donated at least three gene segments to the pandemic virus, disappeared from human circulation. The disappearance of 1918-derived H1N1, 1957-derived H2N2 and 1977-derived H1N1 (being the 1918-derived H1N1, recurrent from a research laboratory in 1977, same as the classical swine H1N1 viruses) [159] has resulted in only 1968-derived H3N2 and 2009-derived H1N1 viruses remaining in human circulation. Despite binding to human-type receptors being essential for influenza virus transmission among humans, the binding of 1968-derived H3N2 viruses to the human-type receptor analog $\alpha 2,6$ sialyl $N$-acetyllactosamine (6'SLN)-polyacrylamide started to decrease significantly in 2001 and seemed to be completely lost in 2010 [160]. However, after the discovery [161] and the widespread use of long $\alpha 2,6$ sialylated $\mathrm{N}$-glycans with multiple LN repeats for studies on influenza virus binding specificity, it appeared that 1968-derived H3N2 viruses have evolved binding preference for human-type receptors with LacNAc (LN) repeats $[60,162]$. Based on the binding preferences to short 3'SLN and 6'SLN and long 3'SLNLNLN and 6'SLNLNLN linked to a polyglutamic acid, IAVs can be divided into two groups [19]. Group 1 are avian viruses, including $\mathrm{H} 5 \mathrm{~N} 1$ and $\mathrm{H} 5 \mathrm{~N} 3$ viruses, that preferentially bind to terminal $\alpha 2,3 \mathrm{Neu} 5 \mathrm{Ac}$ with either short or long LN chains. Group 2 consists of viruses that preferentially bind to terminal $\alpha 2,6 \mathrm{Neu} 5 \mathrm{Ac}$, and the viruses can be further divided into two subgroups. Subgroup 2-1 includes swine H1N2/2008 and pdm H1N1/2009 viruses, which can bind to both short and long $\alpha 2,6$ sialylated glycans. These results support the hypothesis that pigs are vessels to generate viral HAs with pandemic potential [41]. However, the pdm H1N1/2009 viruses acquired at least two amino acids that are different from the swine H1 HA, A200T and A227E, and they are responsible for the binding differences in fetuin, chicken erythrocytes and human erythrocytes and are believed to be determinants of the shift in binding specificity from swine-type to human-type [158]. Further investigation to find the $\alpha 2,6$ sialyl glycan structure that is able to clearly distinguish binding specificity between swine and 
pandemic viruses is needed since such sialyl glycans could be useful for surveillance and prevention of a pandemic. Subgroup 2-2 consists of long-term circulating human viruses including human $\mathrm{H} 3 \mathrm{~N} 2 / 2008$ viruses and human H1N1/2004 and H1N1/2006 viruses, which have binding preference to the long $\alpha 2,6$ sialyl glycan.

Structural comparison of avian-type and human-type receptors interacting with the receptor binding sites of avian H3/1963, pandemic (pdm) H3/1968 and human H3/2007 (Figure 3b) revealed that trisaccharide Neu5Ac $\alpha 2,3 \mathrm{Gal} \beta 1,3 \mathrm{GlcNAc}$ of lactoseries tetrasaccharide a (LSTa) interacts with the avian H3/1963 binding site in a cone-like topology (1mqm [149]), whereas 6'SLNLN interacts with pandemic H3/1968 (6tzb [150]) and human H3/2007 binding sites in an umbrella-like topology (6aov [151]). Residues 226 and 228 are important in determining sialyl linkage binding specificity. As shown in Figure 3b, Q226 in the avian H3/1963 binding site directly forms hydrogen bonds with Sia-1 and Gal-2 of LSTa, whereas S228 in the pdm H3/1968 binding site directly forms a hydrogen bond with Sia-1 of 6'SLNLN and S228 in the human H3/2007 binding site directly forms two hydrogen bonds with Sia-1 of 6'SLNLN. Although no direct interaction of residue 226 in pdm and human H3 HAs was found, a previous study suggested that L226Q mutation in the HA decreases $\alpha 2,6 \mathrm{Neu} 5 \mathrm{Ac}$ binding preference. Both G228 and S228 can be found in H3 avian HAs, whereas only S228 is found in human H3 HAs [149]. L226 is not conserved during circulation in humans; L226V and V226I substitutions were observed before 2001 and in 2004, respectively [160].

Similar to the H1 HA receptor binding site [10], two sets of human receptor binding residues provide networks to make contact with the long human-type receptor that results in an umbrella-like topology of the receptor. (i) A base region Neu5Ac $\alpha 2,6 \mathrm{Gal} \beta 1$ - motif is governed by residues 131-138 in a 130-loop, residues $140-145$ in a 140-loop and residues 219-228 in a 220-loop [163]. Figure 3b shows direct H-bond formation between Y98, G135, S136, N137, H183, E190 and S228 in the pdm H3/1968 binding site and Sia-1 of 6'SLNLN. In the human H3/2007 binding site, Y98, T135, S136, S137, S228, R222, and N225 make direct H-bonds with Sia-1 and Gal-2, respectively, of 6'SLNLN. (ii) The extension region -4GlcNAc $\beta 1,4 \mathrm{Gal} \beta 1,4 \mathrm{GlcNAc}$ motif is governed by residues 190-196 in a 190-helix and residues 156-160 in a 150-loop [163], and S193 and K156 in the pdm H3/1968 binding site were observed to generate direct H-bonds with GlcNAc-5 of 6'SLNLN. Amino acid change in HA during co-evolution with humans occurs to evade human immunity. Not only is there a change in antigenicity but the number of glycosylation sites masking antigenicity also increases over time as shown in Figure 3c; the numbers of glycosylation sites/monomer are two for avian H3/1968 HA, two for pdm H3/1968 HA, seven for human H3/2007 HA and six for human H3/2014. The limitation of increase in the number of glycosylation sites might be because the change of the virus must have a balance between mutation and selection for optimal immune evasion and infection. Taken together, the change in receptor binding specificity of long-term circulating human IAVs from short and long to long $\alpha 2,6$ sialylated glycans may have resulted from aa change in the RBS (Figure $3 b, d$ ) and an increase in glycosylation sites surrounding the RBS, possibly making the shallow RBS deeper (Figure 3c). The differences in receptor binding preferences of avian, pandemic and long-term circulating human IAVs are associated with viral pathology along the human respiratory tract containing different sialylated glycan structures. The preferential binding of avian and pandemic viruses to both short and extended receptors can typically cause diffuse alveolar damage, resulting in greater severity than that caused by long-term circulating human viruses with preference for long receptors that rarely infect human alveoli $[164,165]$. This correlates well with our finding that human alveolar $N$-glycans consist of mainly short receptors, 22.32: 0.17: 16.10: $0.15 \mathrm{~mol} \%$ (Neu5Ac $\alpha 2,3 \mathrm{LN}$ : Neu5Ac $\alpha 2,3$ ( $\alpha 1$,3fucosylated LN): Neu5Ac $\alpha 2,6 \mathrm{LN}$ : Neu5Ac-LN-LN), of total human alveolar $N$-glycans [19]. Sialyl $N$-glycans with various numbers of LN units (up to 10 units) have been reported in human lungs (principally terminated in $\alpha 2,3 \mathrm{Neu} 5 \mathrm{Ac}$ [166]) and the human bronchus, whereas fewer extended LN profiles can be detected in the human nasopharynx [167]. Although structures of glycans in the human trachea have not be determined, the pdm H1N1/2009 virus was found at higher levels in tracheal aspirate 
specimens than in throat or nasopharyngeal swabs [168]. Uncomplicated long-term circulating human viruses are related to tracheobronchitis [169].

\subsection{Egyptian Fruit Bat-Isolated Influenza A Virus Uses Siad2,3Gal Receptors}

In 2019, Kandeil et al. [64] reported a new IAV isolated in 2017 from Egyptian fruit bats (Rousettus aegyptiacus, family Pteropodidae) in an abandoned mudbrick house in a densely inhabited agricultural village in the Nile Delta, Egypt. The new IAV was found more frequently in oral swabs than in rectal swabs. Each of eight genomic segments of this newly characterized bat influenza $\mathrm{A} / \mathrm{bat} / \mathrm{Egypt} / 381 \mathrm{OP} / 2017$ virus was shown to have nucleotide (nt) and aa sequences similar to those in genes of other avian IAVs isolated from wild birds, except for those in the PA gene, which are similar to those in the PA gene of an equine IAV (H7N7). The HA protein of the Egyptian bat IAVs is closely related to the group 1 cluster of HA subtypes with highest similarity (73\% identity) to the H9 HA of influenza A/mallard/Ohio/13OS3856/2013 virus (H9N2). A receptor binding assay indicated that the Egyptian bat virus possessing Q226 (H3 numbering) in the RBS showed a clear binding preference for $\alpha 2,3$ sialyllactose receptors over $\alpha 2,6$ sialyllactose receptors, suggesting that Sia $\alpha 2,3 \mathrm{Gal}$ receptors might be abundant in the infection sites in Egyptian fruit bats. Further investigation of that possibility is required. The virus was speculated to originate from an avian host, and that speculation was supported by the finding that the virus can grow well in allantoic fluid cavities of embryonated chicken eggs. The virus can also propagate in MDCK cells and in the lungs of C57BL/6 mice and BALB/c mice, indicating the possibility of the virus causing infection in other mammalian species. Thus, surveillance of IAVs among bats and distribution in other animals should be performed.

\subsection{Influenza B Viruses Use Siaa2,3/2,6Gal Receptors}

In 1940, a new serotype of influenza viruses was isolated and designated type B. The first strain was named B/Lee/1940. Influenza B viruses have continued to cause respiratory disease in humans with antigenic change. Although HA and NA antigenic differences within influenza B viruses (IBVs) are not sufficient to separate antigenic subtypes, there were sufficient antigenic differences to classify IBVs into two lineages: (i) Victoria lineage B/Victoria/2/1987-like and (ii) Yamagata lineage B/Yamagata/16/1988-like viruses [170]. Consequently, morbidity and mortality-associated seasonal influenza is currently caused by the two lineages of IBVs and two subtypes of IAVs, 1968-derived H3N2 and 2009-derived H1N1 viruses. In contrast to IAVs, IBVs infect mainly humans, although there are sporadic reports of IBV infection in seals, pigs, horses, pheasants and dogs [65]. Similar to IAVs, IBVs have eight (-)ssRNA genome segments and possess receptor-binding and -destroying activities on different molecules, homo-trimeric HA and homo-tetrameric NA glycoproteins. Clinically approved NA inhibitors (NAIs), including zanamivir, oseltamivir, laninamivir and peramivir, are now used for treatment of infection with not only IAVs but also IBVs [171]. Several chemical compounds that have been developed as anti-influenza A NAs, including Neu5Ac2en mimetics for minimizing side effects on human Neu1-Neu4 enzymes [172,173] and NA covalent inhibitors for irreversible NA inhibition [174] and Psidium guajava Linn. (guava) tea [175] and povidone-iodine that possess anti-influenza A sialidase activities [176] might be able to inhibit influenza B viruses.

Receptor binding specificity determines the site of virus infection. It appears that wild-type influenza B/Victoria HAs possessing G141, R162 and D196 [67] and B/Yamagata HAs with F95 and N194 [68] clearly exhibit binding preference to human-type $\alpha 2,6 \mathrm{Neu} 5 \mathrm{Ac}$ receptors. Investigation of receptor binding preference of IBV clinical isolates in Taiwan during the period from 2001 to 2007 (Table 1) revealed that (i) $83 \%$ of Yamagata-like strains prefer $\alpha 2,6$ Sia receptors, whereas $17 \%$ of them prefer both $\alpha 2,3 \mathrm{Sia}$ and $\alpha 2,6 \mathrm{Sia}$ and (ii) $54 \%$ of Victoria-like strains prefer both $\alpha 2,3 \mathrm{Sia}$ and $\alpha 2,6 \mathrm{Sia}$, whereas $25 \%$ of them prefer sulfated glycan, either $\beta$-Gal-3-sulfate or $6-\mathrm{HSO}_{3}$-Gal $\beta 1,4 \mathrm{GlcNAc}$, and $21 \%$ of them prefer $\alpha 2,6 \mathrm{Sia}$. The viruses with dual $\alpha 2,3 \mathrm{Sia}$ and $\alpha 2,6 \mathrm{Sia}$-binding preferences were shown to be associated with bronchopneumonia and gastrointestinal symptoms [66]. These findings indicate 
that the evolution of receptor binding specificity in IBVs in circulation is different from that in IAVs and indicate tissue tropism and pathogenicity of IBVs, possibly affecting virus transmission.

\subsection{Influenza C Viruses Use Neu5,9Ac2}

In 1947, a new influenza virus without cross-reactive antisera against IAV (PR8) and IBV (Lee) was first isolated by R.M. Taylor from throat washings of a New York man during an influenza outbreak [177]. It was later designated type $C$ and the first strain was named C/Taylor/1233/1947. ICV usually causes mild upper respiratory infection but can cause lower respiratory infection in children less than 2 years of age [178]. Most humans acquire antibodies to ICV at a young age $[178,179]$ and antigenicity of ICV is stable, with no antigenic change being detected for at least 30 years [71]. These facts may be related to the limited outbreaks of ICV in humans, mainly in children. Although ICV antigenicity is stable, comparison of HE gene sequences in viruses isolated from 1947 to 2014 demonstrated that there are six lineages comprised of C/Taylor/1233/1947, C/Kanagawa/1/1976, C/Mississippi/1980, C/Aichi/1/1981, C/Yamagata/26/1981 and C/Sao Paulo/378/1982 [71]. ICVs have also been isolated from pigs [69] and cattle [70] (Table 1).

Different from IAVs and IBVs, ICV possesses hemagglutinin and receptor-destroying enzyme (RDE) on the same homotrimeric glycoprotein having multifunctional hemagglutinin (receptor-binding and membrane fusion activities) and esterase (receptor-destroying activity) and so-called hemagglutinin-esterase-fusion (HEF) protein [180]. The glycoprotein HEF spikes are encoded by the fourth gene segment, and only the ICV (-)ssRNA genome is comprised of only seven gene segments [181].

Thin-layer chromatography (TLC), gas-liquid chromatography (GLC) and high-performance liquid chromatography (HPLC) analyses of rat alpha 1-macroglobulin (RMG) and bovine submaxillary mucin (BSM) incubated with ICV in comparison with those incubated with neuraminidase from A. ureafaciens revealed that RMG and BSM incubated with ICV have a reduced amount of Neu5,9Ac 2 but an increased amount of Neu5Ac. After confirmation by using purified Neu5,9Ac 2 instead of RMG and BSM, it was concluded that RDE of ICV is neuraminate $O$-acetylesterase (9-O-acetyl $\mathrm{N}$-acetylneuraminate $\mathrm{O}$-acetylhydrolase (EC 3.1.1.53) catalyzing removal of the 9-O-acetyl group from Neu5,9 $\mathrm{Ac}_{2}$, not cleaving the terminal Neu5Ac from glycoconjugate [182]. RMG and BSM can potentially inhibit hemagglutination by ICV at $4^{\circ} \mathrm{C}$, and their inhibitory effects were abolished by pre-incubation of RMG and BSM with ICV at $37^{\circ} \mathrm{C}$ [182]. This evidence suggested that $\mathrm{Neu} 5,9 \mathrm{Ac}_{2}$ is a receptor of ICV on the cell surface.

Receptor binding analysis of C/Johannesburg/1/66 classified in C/Aichi lineage [71] on a sialoglycan microarray showed that the virus predominantly binds to Neu5,9Ac $2 \alpha 2,6 \mathrm{Gal} \beta 1,4 \mathrm{GlcNAc}$ $\beta 1,2 \mathrm{Man} \alpha 3$ (Neu5,9Ac $2 \alpha 2,6 \mathrm{Gal} \beta 1,4 \mathrm{GlcNAc} \beta 1,2 \mathrm{Man} \alpha 6$ )Man $\beta 1,4 \mathrm{GlcNAc} \beta 1,4 \mathrm{GlcNAcitol}-\mathrm{AEAB}$ [72]. Further studies by using ICVs from other lineages may help to clarify whether receptor binding specificity of all ICVs to Neu5,9Ac 2 depends on the $\alpha 2,6$ linkage or not.

\subsection{Influenza D Viruses Use Neu5,9Ac2 and Neu5Gc9Ac Receptors}

In 2011, a novel virus isolated from a nasal swab of a 15-week-old pig with influenza-like symptoms in Oklahoma in the USA was found to possess seven (-)ssRNA genomic segments and HEF spike glycoproteins and to share approximately $50 \%$ overall aa sequence identity with human ICVs, and it was named C/swine/Oklahoma/1334/2011 (C/OK) [183]. At first, it was suggested to be a new subtype of ICVs due to (i) no cross-reaction of C/OK with human ICVs determined by hemagglutination inhibition assays and (ii) a wider cellular tropism of C/OK than that of a human ICV determined by cell culture studies [183]. In 2016, however, it was determined by the International Committee on Taxonomy of Viruses that this novel influenza virus is distinct from other types, and it was officially classified in a new genus, Deltainfluenzavirus, and so-called influenza D virus (IDV, type (species) D). As shown in Table 1, in addition to pigs, IDVs have been isolated from cattle and have so far been classified into three lineages: D/OK (D/swine/Oklahoma/1334/2011-like viruses), D/660 (D/bovine/Oklahoma/660/2013-like viruses) and D/Japanese, with D/Japanese lineage being further classified into 2 sublineages, D/Yama2016 
(D/bovine/Yamagata/10710/2016-like viruses) and D/Yama2019 (D/bovine/Yamagata/1/2019-like viruses), based on phylogenetic and antigenic analyses [73]. Although there has been only serological evidence suggesting that IDV can infect humans [15], the virus may acquire mutations to potentially infect humans and to cause influenza illness in humans.

The host range of IVs is primarily determined by receptor binding specificity of the viruses. Recently, Liu et al. compared receptor binding specificities of IDVs and their related ICVs by a sialoglycan microarray approach [72]. Strain D/swine/Oklahoma/1334/2011 (D/OK) showed preferential binding to Neu5,9Ac 2 and Neu5Gc9Ac either linked to $\alpha 2,6 \mathrm{Gal}$ or $\alpha 2,3 \mathrm{Gal}$ and strain D/bovine/Oklahoma/660/2013 /660) preferred to bind to Neu5,9Ac $2 \alpha 2,6 \mathrm{Gal}$, Neu5Gc9Ac $\alpha 2,6 \mathrm{Gal}$ and Neu5Gc9Ac $\alpha 2,3 \mathrm{Gal}$, whereas strain C/Johannesburg/1/1966 dominantly recognized Neu5,9Ac $2 \alpha 2,6 \mathrm{Gal}_{\text {. }}$ The broader receptor recognition by IDVs than by human ICV could explain why cellular tropism of IDVs is wider than that of human ICVs. Binding of IDVs to both Neu5,9Ac 2 and Neu5Gc9Ac, different from human ICV binding to $\mathrm{Neu} 5,9 \mathrm{Ac}_{2}$, could be determined by their different HEF-binding pockets. It was shown that different from human ICV HEF of C/Johannesburg/1/1966, swine IDV HEF of D/OK has an open cavity between the 230-helix and 270-loop in the receptor-binding site, which is thought to allow for accommodation of diverse glycan receptors, including Neu5Gc9Ac harboring an extra hydroxyl group on the $\mathrm{N}$-acetyl group of C5 Neu5Gc and different sialyl linkages [184]. Further investigation of the structure of the bovine IDV HEF-binding pocket might lead to an understanding of different receptor binding preferences of swine and bovine IDVs. Receptor binding specificity of viruses is believed to be associated with receptors present on the target tissue. Glycoconjugate structures terminated with $\mathrm{Neu} 5,9 \mathrm{Ac}_{2}$ and Neu5Gc9Ac along the bovine, porcine and human respiratory tracts have not been determined and further investigation is therefore needed. Previous findings that there is no Neu5Gc production in healthy humans due to mutation of a gene encoding CMP-Neu5Ac hydroxylase, which converts CMP-Neu5Ac to CMP-Neu5Gc [42,185], could explain why human ICVs prefer binding to Neu5,9Ac 2 , whereas swine and bovine IDVs can bind preferentially to both $\mathrm{Neu} 5,9 \mathrm{Ac}_{2}$ and 9-O-acetylated Neu5Gc.

\section{6. $\beta 1 \mathrm{HCoV}$-OC43 and $\beta 1 \mathrm{HCoV}-\mathrm{HKU1}$ Use Neu5,9Ac, Receptors}

HCoV-OC43 strain was first detected in 1967 by an organ culture technique from throat washings of patients with common colds [186], but its complete genomic sequence was not reported until 2004 [187]. HCoV-HKU1 was first characterized in 2005 by Woo et al. at the University of Hong Kong (HKU) from a nasopharyngeal aspirate of a patient with pneumonia [188]. Based on genomic sequences reported so far, there is no bat $\mathrm{CoV}$ classified as a $\beta \mathrm{CoV}$ lineage A. Based on phylogenetic analysis, both HCoV-OC43 and HCoV-HKU1 $\beta \mathrm{CoV}$ lineage A probably originated in rodents [85]. While an intermediate host of HCoV-HKU1 remains unknown, HCoV-OC43 is believed to have cattle serving as intermediate hosts from rodents to humans [189].

$\mathrm{HCoV}-\mathrm{OC} 43$ does not bind to and agglutinate erythrocytes pretreated with 9-O-acetyl esterase from either influenza C virus or bovine CoV [190]. HCoV-HKU1 does not infect primary human ciliated airway epithelial cells pretreated with an expressed HKU1 hemagglutinin-esterase (HE) protein possessing 9-O-acetylesterase activity [191]. These findings suggest that both $\mathrm{HCoV}-\mathrm{OC} 43$ and HCoV-HKU1 bind to 9-O-acetylated sialyl glycans (Figure 4a) on the host cell surface for mediating virus infection. As shown in Table 2, the 9-O-Ac-Sia receptor-binding function of homodimeric HE proteins, comprised of a receptor-binding (lectin) domain and receptor-destroying domain, of HCoV-OC43 and $\mathrm{HCoV}-\mathrm{HKU} 1$ was reported to be lost, and its loss was reported to be associated with an accumulation of mutations in the OC43-HE lectin domain or massive deletions found in the HKU1-HE lectin domain during evolution in humans [94]. Binding of the S1 subunit of another type of spike, a homotrimeric spike (S) protein (Figure 2), of HCoV-OC43 and HCoV-HKU1 on human rhabdomyosarcoma cells was shown and was reported to be reduced by pretreating the cells with HKU1-HE, OC43-HE or BCoV-HE, but not by pretreating the cells with MHV-S-HE, possessing 4-O-acetylesterase activity [191]. 
These findings suggested that 9-O-Ac-Sia is an essential receptor for infection of $\mathrm{HCoV}-\mathrm{OC} 43$ and HCoV-HKU1 mediated by the S1 subunit of their S proteins.

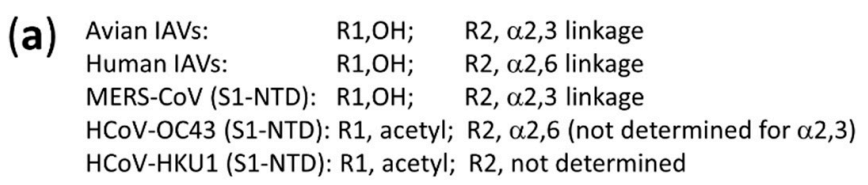

\section{(b) Binding site on APN for 229E S1-CTD}

\begin{tabular}{|c|c|c|c|c|}
\hline$\frac{\text { APN }}{\text { BatHa }}$ & $\frac{\mathrm{Ac} \cdot \text { No. } / \mathrm{pdb}}{\mathrm{XP} \_019495554}$ & 212 & $\begin{array}{l}245 \\
\text { SNLT }\end{array}$ & $\begin{array}{l}289 \\
\text { SEFTAVEET }\end{array}$ \\
\hline CamelCd & KAB1257137 & $\begin{array}{l}\text { A } \\
208\end{array}$ & $\begin{array}{l}\text { KDLT } \\
\mathbf{2 4 1}\end{array}$ & $\begin{array}{l}\text { SEFTCVEGK } \\
\mathbf{2 8 5}\end{array}$ \\
\hline Human & 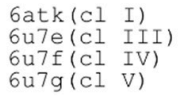 & $\begin{array}{l}\text { A } \\
\text { A } \\
\text { A } \\
\text { A }\end{array}$ & $\begin{array}{l}\text { KDLT } \\
\text { KDLT } \\
\text { KDLT } \\
\text { KDLT }\end{array}$ & $\begin{array}{l}\text { SEFDYVEKQ } \\
\text { SEFDYVEKQ } \\
\text { SEFDYVEKQ } \\
\text { SEFDYVEKQ }\end{array}$ \\
\hline
\end{tabular}

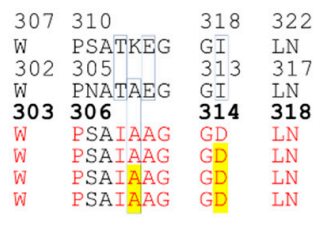

Binding site on ACE2 for NL63, SARS-COV, SARS-COV-2 S1-CTD

\begin{tabular}{|c|c|c|c|c|c|c|c|}
\hline $\mathrm{ACE} 2$ & 19 & 38 & & 76 & 321 & 350353 & 382 \\
\hline$\overline{\text { BatHa }}$ & SNSEDLAKEFLDKFNTE & & LSSL & QCKRAKDY & PNMTKGFWEN & DLGKGDFR & DMAYAIQ \\
\hline BatRs & STTEDEAKMFLDKFNTK & KAEDLSE & QSSL & QSKLAKNY & PNMTEGFWNN & DLGKGDFR & D \\
\hline BatRf & STTEDLAKKFLDDFNSE & AENLSE & QSSL & QSKLAKNF & PNMTEGFWNN & DLGKGDFR & DMAYAS \\
\hline Civet & STTEELAKTFLETFNYE & AQELSY & QSSV & QSKLAQTY & PNMTQGFWEN & DLGKGDFR & DMAYA \\
\hline Pango & STSDEEAKTFLEKFNSE & AEELSY & QSSL & QSKIAKNY & PKMTQTFWEN & DLGKHDER & DI \\
\hline umanNL & STIEEQAKTFLDKFNHE & AEDLEY & QSSL & QSTLAQMY & PNMTQGEWEN & DLGKGDFR & DMAY \\
\hline Humans1 & STIEEQAKTFLDKFNHE & AEDLFY & QSSL & QSTLAQMY & PNMTQGFWEN & DLGKGDFR & \\
\hline Humans2 & STIEEQAKTFLDKFNHE & AED & QSSL & QSTLAQMY & PNMTQGFWEN & DLGKGDFR & DIMAY \\
\hline \multicolumn{8}{|c|}{ Binding site on DDP4 for MERS-CoV S1-CTD } \\
\hline DDP4 & Ac. No. & 265 & 280 & & 311322 & & \\
\hline BatTp & AzO92860.1 & $\begin{array}{l}\text { VKLY } \\
266\end{array}$ & $\begin{array}{l}\mathrm{PKQ} \\
284\end{array}$ & ITAPASVLK & $\begin{array}{ll}\text { W } & \text { DICDY } \\
315 & 326\end{array}$ & & \\
\hline Cam & XP_01 & VKFF & $S R Q 1$ & IVPPASVLI & DVCDY & & ST \\
\hline Huma & $\mathrm{AA} \overline{\mathrm{H}} 65265.1$ & VKFF & SIQ] & ITAPASMLI & DICDY & $S-G$ & NCLVAR \\
\hline
\end{tabular}

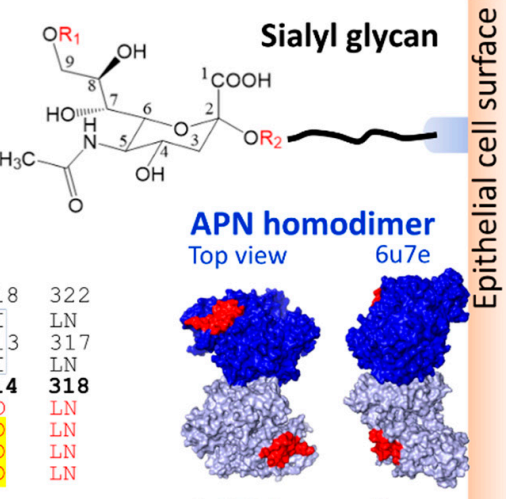

ACE2 homodimer
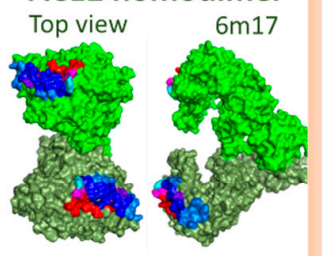

DDP4 homodimer

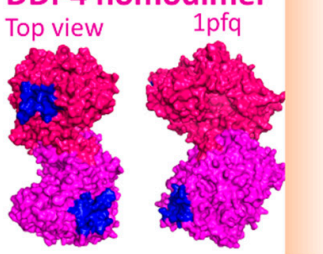

Figure 4. Sialyl glycans and proteins on the epithelial cell surface that are important determinants for IAV and CoV infections. (a) Sialyl glycan receptors of IAVs and CoVs. Whereas most IAV HAs prefer the most common Sia, Neu5Ac, over Neu5Gc as a receptor [192], HCoV-OC43 and -HKU1 S1-NTDs recognize Neu5Ac modified with an O-acetyl group at the C9-position (R1), Neu5,9Ac2 [92,193]. It is well known that sialyl linkage at the C2-position (R2) is a key host determinant of IAVs and that change of their binding preference from $\alpha 2,3$ to $\alpha 2,6$ is a critical factor of avian-to-human host switch [10]. In contrast, there has not been sufficient study on the linkage specificity of HCoV-OC43 and -HKU1 binding, although it is known that HCoV-43 can bind to Neu5,9Ac $2 \alpha 2,6 \mathrm{Gal} \beta 1,4 \mathrm{GlcNAc}$ (9-O-Ac-6SLN) [193]. Distinct from $\beta 1 \mathrm{CoVs}$, additional O-acetylation at the C7 or C9-position to Neu5Ac impedes the binding of MERS-CoV ( $\beta 3 \mathrm{CoVs}$ ) [112]. Like avian IAV HAs, MERS-CoV S1-NTD prefers Neu5Ac linked to $\alpha 2,3$ over $\alpha 2,6$ [148]. (b) Protein receptors of CoVs. Only virus binding site (VBS), receptor amino acids covering the area of the interface between the protein receptor and the indicated viral S1-CTD, are colored. Ac. No., accession number; BatHa, Hipposideros armiger; camelCd, Camelus dromedaries, batHa, Hipposideros armiger (Ac.No., XP_019522954.1); batRs, Rhinolophus sinicus (Ac.No., AGZ48803.1); batRf, Rhinolophus ferrumequinum (Ac.No., XP_032963186.1); civet, Paguma larvata (Ac.No., AAX63775.1); pangolin, Manis javanica (Ac.No., XP_017505752.1); human ACE2 (Ac.No., ACT66268); NL, NL63; S1, SARS-CoV; S2, SARS-CoV-2; batTp, Tylonycteris pachypus; camelCb, Camelus bactrianus. Right: Sialyl glycan structure and top view and side view of surface diagrams of protein receptors. VBSs are colored according to the aa sequences on the left-hand side. 6u7e, 6m17, 1pfq are from [194-196], respectively.

The S1 subunit of the S protein is composed of four domains, A through $\mathrm{D}\left(\mathrm{S} 1^{\mathrm{A}}\right.$ through $\left.\mathrm{S} 1^{\mathrm{D}}\right)$ domains from the N-terminus [112]. By using OC43 or HKU1 S1 ${ }^{\mathrm{A}}-\mathrm{Fc}$ proteins in a direct binding assay, HCoV-OC43 and HCoV-HKU1 were shown to bind to the receptors via domain A (S1-NTD (Figure 5a), residues 15-302 based on the S protein of OC43 strain ATCC VR-759) [92]. However, binding of 
HKU1 S1 ${ }^{\mathrm{A}}$ to its receptors on rat erythrocytes can be detected when HKU1 S1 ${ }^{\mathrm{A}}-\mathrm{Fc}$ proteins have been conjugated to nanoparticles but cannot be detected by using free HKU1 S1 ${ }^{\mathrm{A}}$-Fc proteins (the standard method), indicating the requirement of multivalency of HKU1 S1 ${ }^{\mathrm{A}}-\mathrm{Fc}$ proteins for binding to rat erythrocytes. Based on structural analysis, residues 28-34 (element 1) and/or residues 243-252 (element 2) in HKU1 S1 ${ }^{\mathrm{A}}$ (Figure 5b) were thought to hamper the binding of HKU1 S1 ${ }^{\mathrm{A}}$. The mutant HKU1 S1 ${ }^{\mathrm{A}}$ was generated by replacement of one or both of their elements with the corresponding element(s) from bovine coronavirus (BCoV), which is believed to be the ancestor of OC43. The free mutant HKU1 S1 ${ }^{\mathrm{A}}-\mathrm{Fc}$ proteins with only one replacement at element 2 were found to bind to rat erythrocytes. The free mutant HKU1 S1 ${ }^{\mathrm{A}}-\mathrm{Fc}$ proteins with replacement of both elements showed greater binding to rat erythrocytes. In comparison with binding of the wild-type HKU1 S1 ${ }^{\mathrm{A}}$ conjugated with nanoparticles to rat erythrocytes, the mutant HKU1 S1 ${ }^{\mathrm{A}}$ with removal of a glycosylation site at element 2 (N251Q) showed increased binding, and the mutant HKU1 S1 ${ }^{\mathrm{A}}$ with removal of the glycosylation sites in both elements (N29Q in element $1+$ N251Q in element 2) showed greater binding. These findings indicated that binding of HKU1 S1 ${ }^{\mathrm{A}}$ to its receptors on rat erythrocytes is impeded by both the RBS architecture and N-glycans on the RBS [92]. Binding of free HKU1 S1 or free HKU1 $S 1^{\mathrm{A}}$ not only to rat erythrocytes but also to mouse erythrocytes and to BSM cannot be detected by the standard method unlike other 9-O-Ac-Sia-binding $\beta 1 \mathrm{CoVs}$, including HCoV-OC43 for which their free $S 1$ and $S 1^{A}$ detectably bind to those erythrocytes and BSM [92,191]. The difference of HKU1 from other 9-O-Ac-Sia-binding $\beta 1 \mathrm{CoVs}$ was suggested to be due to receptor fine-specificity determined by elements 1 and 2. The effects of the internal part of the glycan structure, such as Sia $\alpha 2,3 / 2,6 \mathrm{Gal}$ and $\mathrm{LN}$ repeats, on binding of HKU1 in comparison with other 9-O-Ac-Sia-binding $\beta 1 \mathrm{CoVs}$ should be further determined.

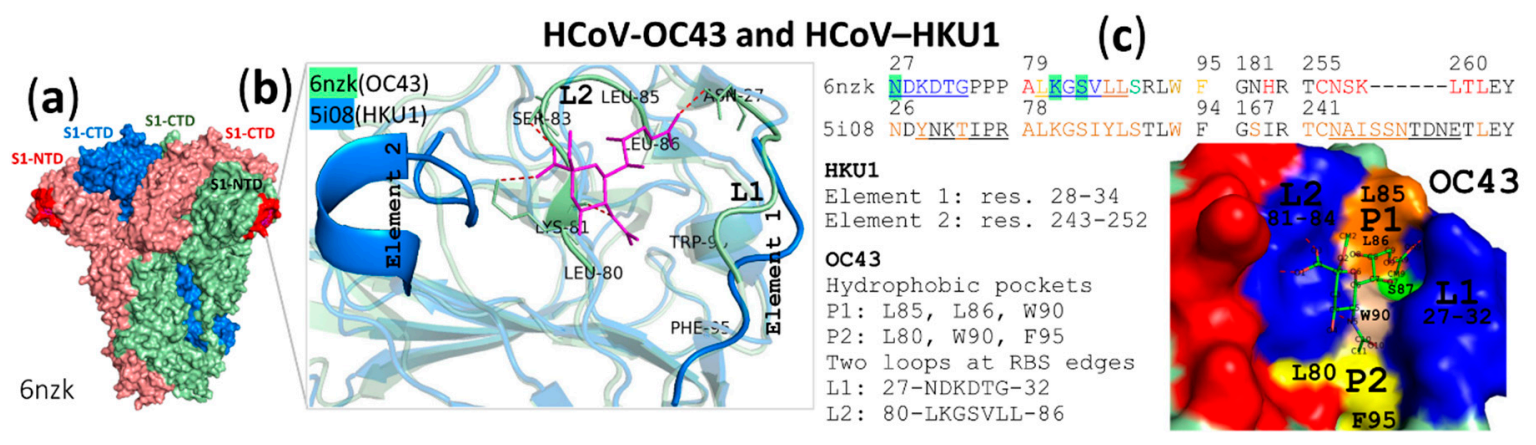

Figure 5. Comparison of Sia binding sites in S1-NTDs of HCoV-OC43 and HCoV-HKU1. (a) Side view of the position of RBSs (red) in S1-NTDs of the trimeric HCoV-OC43 spike bound with Neu5,9Ac 2 in magenta stick (pdb: 6nzk [193]). (b) Superimposition between the RBS of HCoV-OC43 pale green spike in complex with Neu5,9 $\mathrm{Ac}_{2}$ in magenta stick (pdb: 6nzk) and the RBS of HCoV-HKU1 marine spike (pdb: $5 \mathrm{i08}$ [197]). Three aa residues (S83, N27 and K81) that directly interact with Neu5,9Ac 2 are shown in red sticks. (c) Alignment of aa sequences of HCoV-OC43 and HCoV-HKU1 S1-NTDs. Residues directly interacting with the receptor are highlighted green. Right: Residues covering the S1-NTD surface area facing the $\mathrm{Neu} 5,9 \mathrm{Ac}_{2}$ receptor, being the RBS, are at the canyon bottom with ridges of HKU1 elements 1 and 2 according to Hulswit et al. [92]. Two loops, L1 and L2, at RBS edges are shown in dark blue and two hydrophobic pockets are shown in orange (P1) and yellow (P2) separated by lightorange (W90) according to Tortorici et al. [193]. Red is the ridge in OC43 S1-NTD corresponding to HKU1 element 1.

The cryo-electron microscopy structure of an HCoV-OC43 S trimer in complex with a 9-O-Ac-Me-Sia revealed that a sialoside-binding site was located at the surface-exposed groove of each $S 1^{\mathrm{A}}$ monomer (Figure 5a) [193]. The sialoside-binding groove (Figure 5b,c) is formed by two loops, L1 consisting of 27-NDKDTG-32 and L2 consisting of 80-LKGSVLL-86 at the RBS edges, two hydrophobic pockets separated by the indole side chain of W90, P1 consisting of L85, L86 and W90 and P2 consisting of L80, W90 and F95 [193], and a residue, S87, interacting with L1 [92]. Substitutions of N27 having 
an H-bond with OA9 of the 9-O-acetyl carbonyl group, K81 forming H-bonds with O1 and N5 of Sia, or S83 containing an H-bond with O3 of Sia C1, with alanine and mutations of L80, L86 or W90 in hydrophobic pockets accommodating the 5- $\mathrm{N}$-acyl moiety and the 9-O-acetyl-methyl moiety provided a mutant $\mathrm{HCOV}-\mathrm{OC} 43 \mathrm{~S}^{\mathrm{A}}$ that had lost the ability to bind to 9-O-Ac-6SLN. Substitutions at N27, T31, L80, K81, S83, L86 and W90 completely blocked the entry of pseudotyped VSV $\Delta \mathrm{G}$ particles harboring HCoV-OC43 S proteins into HEK293T cells. These results confirmed that residues in the surface-exposed groove are critical for interaction with the 9-O-Ac-Sia receptor and that their interactions are essential for mediating viral entry [193]. Interestingly, HCoV-OC43 S1 ${ }^{\mathrm{A}}$ recognized 9-O-Ac-Sia bound to Gal via $\alpha 2,6$ linkage. More research on binding specificity of both animal and human 9-O-Ac-Sia-binding $\beta 1 \mathrm{CoVs}$ to the internal part of the receptor in combination with analysis of 9-O-Ac-Sia-containing glycan structures expressed on host tissues and analysis of changes in the viral $\mathrm{S} 1^{\mathrm{A}}$ proteins could reveal which part of 9-O-Ac-Sia-containing glycans determines host/tissue tropism of $\beta 1 \mathrm{CoVs}$ and changes in the viral $\mathrm{S}^{\mathrm{A}}$ proteins associated with host/tissue tropism.

\section{Protein Receptor-Dependent Recognition of Influenza A (H17-H18) Viruses and $\alpha$ CoVs, Lineage B $\beta$ CoVs ( $\beta 2 \mathrm{CoVs})$}

\subsection{Frugivorous Bat-Identified Influenza A (H17-H18) Viruses Use MHC Class II as a Receptor}

The genomes of new IAV subtypes, H17N10, which was identified in liver, intestine, lung and kidney tissues and in rectal swabs, but not in oral swabs, of frugivorous yellow-shouldered bats (Sturnira lilium, family Phyllostomidae) in Guatemala [119], and H18N11, which was identified in intestine tissue and in rectal swabs of frugivorous flat-faced bats (Artibeus planirostris, family Phyllostomidae) in Peru [120] during the period from 2009 to 2010, were reported in 2012 and in 2013, respectively (Table 1). Based on aa sequences of $\mathrm{H} 1-\mathrm{H} 18 \mathrm{HAs}$, both bat $\mathrm{H} 17$ and $\mathrm{H} 18$ HAs are more similar to H1-H2, H5-H6, H8-H9, H11-H13 and H16 in group 1 than to H3-H4, H7, H10 and H14-H15 in group 2 [198]. Analysis of the crystal structures of bat H17 and H18 HAs revealed that their overall structures retain possession of typical IAV HA molecules including the receptor binding site (RBS). However, bat HAs showed no binding to any of 610 diverse structures of glycans including more than 100 sialylated glycans with either $\alpha 2,3, \alpha 2,6, \alpha 2,8$ or mixed linkages. Detailed structural analysis (Figure 3d) revealed that at least four residues unique to bat H17 and H18 HAs seem to substantially reject a sialylated glycan from the bat RBS. (i) Highly conserved Y98 anchoring Sia is replaced by F98 in bat HAs. (ii) Highly conserved Q226 in H1 HAs and Q/L/I226 (a determinant of sialyl linkage specificity) in H3 HAs is replaced by H226 in bat HAs. (iii) The large residue D228 in bat HAs would make a steric clash with the side chain of Sia. (iv) The other large negatively charged residue D136 in bat HAs, possibly the most important residue, would provide electrostatic repulsion to a negatively charged sialylated glycan. Both structural and functional studies on bat HAs strongly confirmed that bat H17 and H18 HAs do not bind to sialylated glycans [120].

In 2019, human leukocyte antigen DR (HLA-DR) isotype, one of the three major MHC class II isotypes, found on susceptible cell lines including MDCKII clone no. 1, human U-87MG cells, human Calu-3 cells and human haematopoietic cancer cells was shown by the following findings to be required for mediating entry of pseudotyped viruses harboring H17 HAs [63] or H18 HAs [62] into a mammalian cell: (i) knockdown of HLA-DRA or HLA-DR $\alpha$-chain or cell preincubation with an HLA-DRA-targeting antibody significantly reduced both H17- and H18-pseudotyped virus infections, (ii) ectopic expression of HLA-DR in non-susceptible cell lines rendered them susceptible to both H17and H18-pseudotyped virus infections, (iii) expression of HLA-DR from other mammals, including different bat species, pigs and mice, or from chickens makes cells susceptible to H18-pseudotyped virus infection and (iv) intranasal infection of mice with H18N11 virus led to viral replication in the upper respiratory tracts of the mice. While these findings suggested possible spread of bat H17 and H18 viruses to other vertebrates, recent studies have shown that wild-type H18N11 infection is restricted to bats and that H18N11 has poor replication in mice and ferrets [199]. The potential of these viruses 
to spread to and infect other animals and the tissue tropism within other animals remain unclear. Characterization of direct binding of H17 and H18 HAs to MHC-II is also required.

\section{2. $\alpha$ HCoV-229E Uses hAPN Receptors}

HCoV-229E was first recorded in the mid-1960s by two different groups in different countries: (i) Tyrrell and Bynoe [200] isolated the virus in a research unit in Salisbury, Wilts, England, and most of their work was done with a nasal swab of number B814 from a volunteer boy with a common cold and (ii) Hamre and Procknow isolated the virus from five medical students, including four students with mild upper respiratory illnesses (URIs) and one healthy student, using acute URI specimen number 229E as the prototype strain in the University of Chicago, United States [201]. Recently, investigation of the ancestral origins of the virus revealed that $\mathrm{HCoV}-229 \mathrm{E}$ has a high genetic identity to GhanaBt-CoVGrp1, a member of the bat $\mathrm{CoV}$ group (lineage) 1 that was isolated from fecal samples but was not found in oral swabs from insect-eating leaf-nosed bats, Hipposidero (H.) caffer (cf.) ruber $[125,126]$ and H. abae, but not $H$. jonesi and H. cf. gigas [126], in Ghana, Africa. Results of molecular clock analyses indicated that HCoV-229E and GhanaBt-CoVGrp1 shared an old ancestor in approximately 1686-1800 C.E. [125]. In generic CoV RT-PCR screening, nasal swabs, but not fecal samples, from dromedary camels in Kenya and the Kingdom of Saudi Arabia (KSA) were positive for $\mathrm{HCoV} 229 \mathrm{E}-$ related $\mathrm{CoV}$ (camelid-229E CoV), suggesting that the viruses are endemic in dromedaries. The results of genomic and phylogenetic analyses suggested that both human-derived and dromedary-derived CoVs are monophyletic [202]. The findings provide important implications for the emergence of HCoV-229E evolving from HCoV-229E-related CoVs (bat-229E CoVs) in bats of the genus Hipposideros in Africa as natural hosts $[125,126]$ via dromedary camels in Africa and KSA as intermediate hosts [202].

As in the case of $\alpha$ HCoV-NL63 virus shown in Figure 6a, $\alpha$ 229E viruses use their S1-CTDs on the top center of each $\mathrm{S} 1$ monomer of the $\mathrm{S}$ trimer to bind to host receptors. It is notable that about 396 amino acids at the N-terminus of the S protein of ancestral bat-229E CoV, which causes gastrointestinal tract infection, are deleted in $\mathrm{HCoV}-229 \mathrm{E}$ and camelid-229E CoV, which cause respiratory tract infection. Although this N-terminal spike deletion is not involved in the receptor binding site (RBS), it was presumed that the deletion is associated with the change in CoV tissue tropism from the gastrointestinal tract to the respiratory tract [203]. Further studies on its location on the spike 3D structure and on the mechanism of its function, which is thought to support virus replication in the bat gastrointestinal tract, as well as how the deletion helps the virus to replicate in the camel and human respiratory tracts may lead to an understanding of the molecular mechanisms of infection in the gastrointestinal and respiratory tracts. An understanding of the molecular mechanisms might lead to future prevention of gastrointestinal and respiratory infections.

To enter cells, 229E viruses must bind to aminopeptidase N (APN) receptors (Figure 7a), dimeric glycoproteins that protrude from the epithelial cell surface (Figure $4 \mathrm{~b}$ ). Analysis of the crystal structures of HCoV-229E from four of six different classes that replaced each other in the human population [83], classified by an RBD sequence variant (aa 302-417), in complex with human APN (hAPN) revealed locations of a viral binding site (VBS) on hAPN (Figure $4 \mathrm{~b}$ ) and a receptor binding site (RBS) on the viral RBD (Figure 7b). The RBS is composed of residues with red letter codes (Figure 7c) in loops 1, 2 and 3 (residues 308-408 based on class I numbering, Figure $7 \mathrm{~b}$ ) on a six-stranded $\beta$-sheet peptide (Figure 7a). It should be noted that these loops are immunogenic [206]. The virus diverged into different classes with highly variable residues in the exposed loop sequences in order to evade neutralization by antibodies as observed by using IgG1 monoclonal antibodies against class I, a reference strain, in a viral infection inhibition assay [83]. Results of surface plasmon resonance binding assays showed that these virus variants had differences in binding affinity for hAPN receptors [83]. These differences in binding affinity might be for optimal escape and entry due to adaptation and selection of the virus to continue circulation under the condition of host environment pressure. 
(a) Alphacoronavirus

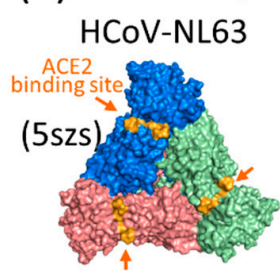

Top view

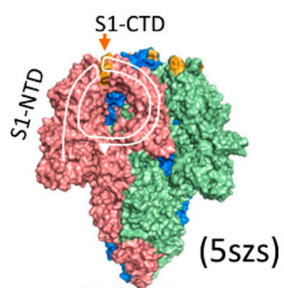

Side view Lying state (b)

Betacoronavirus

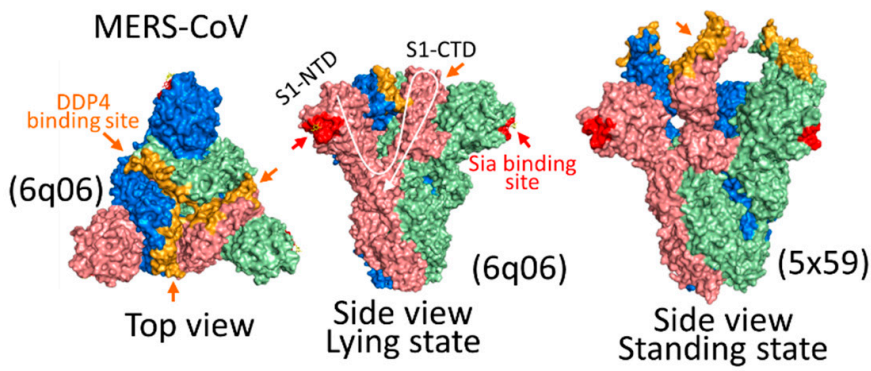

Figure 6. Structural comparison of $\alpha \mathrm{CoV}$ and $\beta \mathrm{CoV}$ spike (S) proteins. Top and side views of homotrimeric $S$ proteins, which are colored in salmon, marine and pale green, of $\alpha \mathrm{CoV}$ (HCoV-NL63, pdb: 5szs [204]) (a) and $\beta \mathrm{CoV}$ (MERS-CoV, pdb: 6q06 [148] and 5x59 [205]) (b). Notably, a difference in folding of the S1 subunit (white arrow) of each monomer of $\alpha \mathrm{CoV}$ and $\beta \mathrm{CoV}$ s proteins results in a difference in positions of the S1-CTD subdomain, next to the S1-NTD subdomain in $\alpha \mathrm{CoV}$ but substantially separated from S1-NTD in $\beta \mathrm{CoV}$. Consequently, the $\alpha \mathrm{CoV}$ S trimer has a simple intra-subdomain packing, whereas $\beta \mathrm{CoV}$ has an intricate cross-subdomain packing as shown in the top and side views. S1-NTD is located on the external surface of the S1 trimer. S1-NTD, which functions as a receptor binding site, typically recognizes a host sugar receptor, except for MHV S1-NTD, which recognizes CEACAM1. In contrast, S1-CTD is located on the internal surface of the S1 trimer in the lying state. S1-CTD can undergo dynamic conformational changes to the standing state for efficient binding to its receptor. After binding, S1-CTD will be stabilized in the standing conformation. So far, S1-CTD, which functions as a receptor binding site, has been found to bind to a host protein receptor.
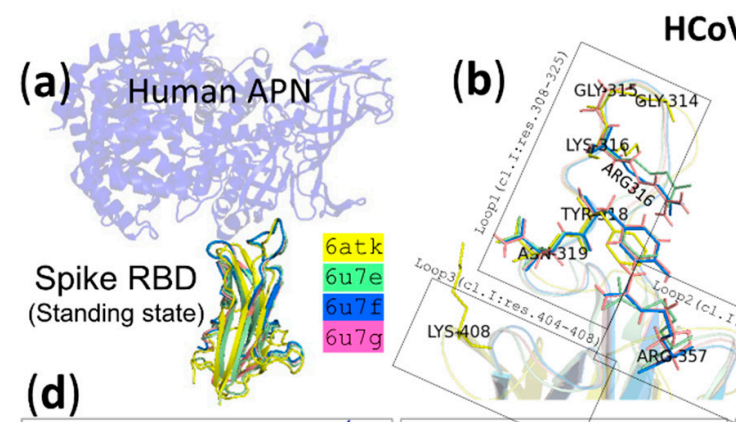

HCoV-229E
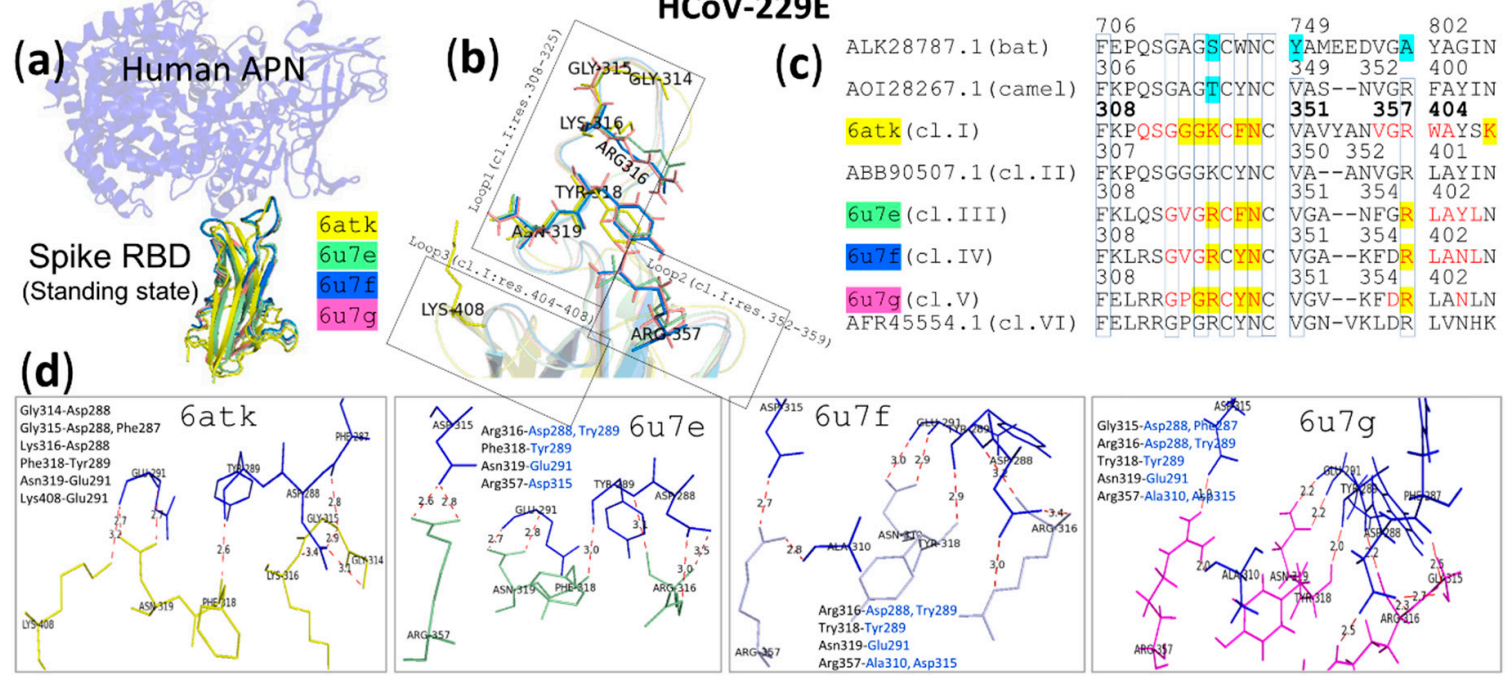

Figure 7. Comparison of receptor binding sites of six classes of S1-CTD RBDs of HCoV-229E variants. (a) Superimposition of pdb-available four classes (pdb: 6atk-class I (yellow), 6u7e-class III (pale green), 6u7f-class IV (marine) and 6u7e-class V (salmon)) of the S1-CTD RBDs of HCoV-229E variants in complex with human APN (transparent blue). (b) Positions of important aa residues in receptor binding sites (RBSs) of the four classes of the S1-CTD RBDs that have direct interactions with human APN. (c) Alignment of aa sequences of six classes of the S1-CTD RBDs. Residues in the S1-CTD RBDs facing the human APN receptor, called RBSs, are shown in red. The residues in RBSs directly interacting with residues in the APN receptor are highlighted in yellow. (d) Direct interactions between aa residues in human APN (blue sticks) and aa residues in RBSs of each S1-CTD RBD class. The bond lengths are shown on the dashed lines in angstrom units. 6atk is from [83], and 6u7e, 6u7f and 6u7g are from [194]. 
Mutagenesis of class I revealed that a C317S/C320S double mutation within loop 1 abolished binding to hAPN, suggesting that the C317-C320 disulfide bond is important for loop 1 folding and interaction with hAPN. While an F318A mutant showed a 13-fold reduction in affinity, both N319A and W404A mutations lead to a loss of hAPN binding [83]. Alignment of the RBS aa sequences of 6 classes of HCoV-229E with bat-229E CoV and camelid-229E CoV (Figure 7c) showed that 6 amino acids, F308, G313, G315, C317, C320 and N319 (based on class I numbering), are highly conserved among different classes and hosts. V351 and R359 are conserved in respiratory-transmitted viruses, HCoV-229E and camelid-229E CoV, but not in an oral-fecal-transmitted virus, bat-229E CoV. Amino acids at positions of K/R316, F/Y318 and N319 were observed in all 4 crystal structures to form hydrogen bonds with the receptor, principally stabilizing viral-receptor interactions (Figure 7d). However, the observation that bat- and camelid-229E CoVs contain S/T with a polar uncharged side chain instead of K/R316 with a longer charged side chain suggests that the amino acid at this position may be responsible for the change in receptor binding specificity from bat/camel to human APN receptors that is required for interspecies transmission.

Viral binding sites on hAPN, based on interface residues of hAPN (red letter codes in Figure $4 \mathrm{~b}$ ) to 4 classes of HCoV-229E RBD [194] were aligned with bat H. armiger APN, due to the unavailability of APN of H. cf. ruber and H. abae, which are known to be bat hosts of HCoV-229E-related CoVs, and Camelus dromedarius APN. E291N, K292E, Q293T triple mutations generating a glycosylation site at position 291 in the hAPN abolished binding to all $6 \mathrm{HCoV}-229 \mathrm{E}$ RBD classes [83], being in agreement with the finding that E291 plays a critical role in the formation of hydrogen bonds with N319 of the HCoV-229E RBD. Both E291 of hAPN and N319 of HCoV-229E RBDs are highly conserved among different hosts. In addition to E291, several amino acids on the viral binding site including A208, L243, T244, S285 E286, F287, V290, W303, P360, A308, G312, G314, L318 and N319 (based on hAPN numbering) are highly conserved among different hosts, and these amino acids on APN may therefore play a role in interspecies transmission of $\mathrm{HCoV}-229 \mathrm{E}-$ related CoVs, a possibility that should be further investigated. The specific binding of HCoV-229E-related CoVs to their host APN should be governed by other amino acids that are not conserved among different host species. These amino acids might be (i) K241, D242, and A310 in human and camel APNs, which are different from those in bat APN that carries S241, N242 and K310, (ii) D288, I309, A311, and D315, which are different from those in bat and camel APNs that carry T288, T309, E311, and I315, and (iii) Y289 and K292, which are different from those in bat APN carrying A289 and E292 and camel APN carrying C289 and G292. Mutations in hAPN, D288A, Y289A, V290G, I309A and L318A, resulted in hAPN binding affinity to HCoV-229E RBD, and the V290G mutant showed the greatest reduction (30-fold reduction) of binding affinity, indicating receptor binding specificity of the HCoV-229E RBD [83]. An understanding of the alteration in $229 \mathrm{E}$ receptor binding specificity should lead to prevention of virus infection and transmission.

\section{3. $\alpha$ HCoV-NL63, $\beta 2$ SARS-CoV and $\beta 2$ SARS-CoV-2 Use hACE2 Receptors}

\subsection{1. $\alpha \mathrm{HCoV}-\mathrm{NL} 63$}

HCoV-NL63 was first isolated from the culture supernatant of tertiary monkey kidney cells inoculated with a nasopharyngeal aspirate specimen, no. NL63, obtained from a 7-month-old baby girl with bronchiolitis and conjunctivitis in Slotervaart Hospital, Amsterdam, The Netherlands in 2003 and it was reported in 2004 [207]. In 2005, a novel strain, HCoV-New Haven (HCoV-NH), was identified by RT-PCR from RNA respiratory specimens collected from children less than 5 years of age from 2002 to 2003 in Yale-New Haven Hospital, New Haven, Connecticut, US. HCoV sequence comparisons revealed that $\mathrm{HCoV}-\mathrm{NH}$ is likely to be the same species as HCoV-NL63, suggesting worldwide distribution of respiratory tract disease caused by HCoV-NL63, particularly in children [208]. 
In 2010, metagenomic analysis of viruses from feces, oral swabs, urine and tissues of 3 North American bat species, including big brown bats (Eptesicus fuscus), tricolored bats (Perimyotis subflavus) and little brown bats (Myotis lucifugus) in the Ridge and Valley physiographic province, by Appalachian Laboratory of the University of Maryland Center revealed that HCoV-NL63-related CoV, named Appalachian Ridge CoV strain 2 (ARCoV.2), existed in feces of tricolored bats in the family Vespertilionidae [209]. The results of molecular clock analysis suggested that HCoV-NL63 shares a common ancestor with ARCoV.2 with a most recent common ancestor (MRCA) of approximately 1190-1449 C.E [210]. In 2017, BtKYNL63-9a was reported to be the most closely related to HCoV-NL63 among three HCoV-NL63-related CoVs that were identified in fecal specimens collected between 2007 and 2010 from African trident bats (Triaenops afer) in the family Hipposideridae in Kenya and to be more closely related to HCoV-NL63 than to ARCoV.2 [127]. However, the genetic distance between HCoV-NL63 and ARCoV.2 or between HCoV-NL63 and BtKYNL63-9a is too large, and both ARCoV.2 and BtKYNL63-9a are therefore classified as not conspecific with HCoV-NL63 [211]. Based on the results of phylogenetic analyses, all proteins of HCoV-NL63 were found to cluster with the Triaenops bat NL63-related group, except for the S protein, which was nested within the Hipposideros bat 229E-related group, suggesting a chimeric genome of HCoV-NL63. Genome comparison indicated that there are two recombination breakpoints in the $S$ gene: (i) near the $5^{\prime}$ end and (ii) at around 200 nucleotides upstream of the $3^{\prime}$ end. These data suggested that the conspecific ancestor of HCoV-NL63 is a recombination virus that emerged through co-infection between the Triaenops bat NL63-related CoV and the Hipposideros bat 229E-related CoV [127]. Thus, the recombinant virus should exist in bats or in an intermediate host (currently unknown for HCoV-NL63, probably a terrestrial mammal) that should be further identified. In addition, investigation of the relationship between Perimyotis ARCoV.2 and Triaenops bat NL63-related CoV may contribute to an understanding of the evolutionary origin prior to emergence of the recombinant ancestor of HCoV-NL63.

\subsection{2. $\beta 2$ SARS-CoV}

SARS-CoV caused an epidemic outbreak of severe acute respiratory syndrome (SARS), which was first reported in November 2002 in Foshan, Guangdong in South China and it spread quickly from late February 2003. A global alert was issued by the WHO in March 2003, and it was declared to be contained in July 2003 [212,213]. The cumulative number of confirmed cases of SARS in the global epidemic from 1 November 2002 to 11 July 2003 was 8437 with 813 deaths (case fatality ratio of 9.6\%) in 26 countries (29 areas) of $6 \mathrm{WHO}$ regions [6]. In the post-global epidemic of SARS, 15 additional cases with one death from reappearance four times were reported during the period from December 2003 to May 2004. One reappearance with four cases in which only mild symptoms occurred was related to a restaurant serving palm civet meat (three cases) and house rats (one case) in Guangdong, China [214], indicating reintroduction of animal viruses into humans and the importance of effective surveillance for zoonotic diseases [215]. The other three reappearances were related to laboratory accidents in Singapore, Taiwan and China. The viruses from Singapore and Taiwan laboratories were not transmitted to others, while two infected cases from a Beijing laboratory subsequently spread to seven others with close contact, resulting in one death. This evidence indicated the importance of biosafety and biosecurity in a laboratory. Since the announcement by the WHO on 18 May 2004 that the SARS outbreak in China was contained, no SARS case has been reported [216].

Since reemergence of SARS from an animal virus could happen at any time, an understanding of the molecular evolution of the virus causing the past global epidemic may help to control future SARS outbreaks. Most of the human cases at the beginning of the SARS epidemic were caused by exposure to market animals (zoonotic source) [217]. Although more than 10 mammalian species, but no avian 
species, were discovered to be susceptible to infection with either SARS-CoV or SARS-related CoVs (SARSr-CoVs), both the number of animals traded in Guangdong, China, and the detection rate were higher in Himalayan or masked palm civets (Paguma larvata) than in other animals. Moreover, there were close matches between sequences of civet viruses and sequences of human viruses from each human outbreak, including the 2002-2003 epidemic and the 2003-2004 episode. These findings suggested that palm civets are important intermediate hosts for transmission of the virus to humans [218], probably through direct/indirect contact or inhalation of contaminated materials/droplets. Screening of SARSr-CoVs in palm civets by real-time RT-PCR and nested RT-PCR for detection of the N gene and $P$ gene revealed the presence of the virus in rectal and/or throat swabs [100]. Major genetic variations in the $S$ gene were found by genomic sequence analyses of civet viruses (SARSr-CoVs) and human viruses (SARS-CoVs), indicating that changes in the $S$ gene are likely to be critical for shifting the virus from civet-to-human to human-to-human transmission that caused the 2002-2003 epidemic [214]. Kan et al. [100] analyzed all available SARS S gene sequences and found 27 signature nucleotide variations (SNVs). Based on SNVs and a phylogenetic tree of the SARS S genes from animal and human viruses, the viruses were divided into four groups. (i) Viruses without SNVs in the S gene, called a prototype group, were isolated from raccoon dogs and a palm civet but not from humans, suggesting that they can cause only animal-to-animal transmission. (ii) Viruses with two to seven SNVs generate up to six aa changes at the positions of 147, 228, 240, 479, 821 and 1080. These viruses were isolated from palm civets and from mild symptomatic patients (so-called low-pathogenic group) during the 2003-2004 episode, indicating that the virus in a palm civet can acquire the ability to infect humans. (iii) Viruses with 17 to 22 SNVs cause further eleven aa changes at the positions of 360, 462, $472,480,487,609,613,665,743,765$, and 1163. These viruses were isolated from palm civets and raccoon dogs in 2003 and from patients with severe symptoms (so-called high-pathogenic group) who had close contact with infected animals or patients in the early-phase epidemic (16 November 2002 to 30 January 2003). This evidence indicated the possibility that animal species other than civets may be intermediate hosts transferring the animal virus to humans. The SNVs of viruses in this group indicated that the virus in palm civets and raccoon dogs can evolve not only to infect humans but also to spread from one human to other humans by close contact, indicating the possibility that these animals and humans may share similar receptor structures. (iv) Viruses with 25 to 27 SNVs cause up to four aa further changes at the positions of 227, 244, 344, and 778. These viruses in this group were isolated from patients with severe symptoms in the middle phase (beginning on 31 January 2003: hospital phase) and late phase (beginning on 21 February 2003: hotel phase) of the 2003 epidemic that was responsible for the global outbreak, so-called large epidemic outbreak group [100].

While SARSr-CoVs are not widespread in farmed palm civets [100] and wild palm civets [219], SARSr-CoVs collected from bat anal/fecal swabs show high genetic diversity and are widespread in wild Chinese horseshoe bats in the genus Rhinolophus (Rhinolophus sinicus [95], R. pussilus (seropositive in blood specimens), R. pearsoni, R. macrotis and R. ferrumequinum [220]). Based on these observations, bats were believed to be the natural reservoir of SARS-CoVs. However, phylogenetic relationships suggested that none of the virus isolates from wild bats are direct ancestral viruses of SARS-CoV [130]. It is most likely that SARS-CoV evolved through recombination of bat SARSr-CoVs [128-130].

\subsection{3. $\beta 2$ SARS-CoV-2}

SARS-CoV-2, which shares about 80\% nt sequence identity with its elder cousin SARS-CoV [221], causes an acute respiratory disease that was officially named coronavirus disease 2019 (COVID-19). It is a novel coronavirus (2019-nCoV) that was first recognized in December 2019 in Wuhan, Hubei in Central China [222]. Different from SARS-CoV, with a mortality rate of $9.6 \%$ in cases of infection, 
SARS-CoV-2 generally causes mild to moderate disease, but it can also lead to severe disease and death in some cases $[223,224]$. Keeping the infected hosts alive enabled SARS-CoV-2 to adapt to humans with efficient human-to-human transmission. It spread rapidly worldwide, finally causing the COVID-19 pandemic, with outbreaks sustained in more than one WHO region [154], on 11 March 2020. As of 8 September 2020, the pandemic is ongoing and has caused 27,205,275 confirmed cases reported from 182 countries and 33 territories and reported from international conveyances throughout six WHO regions, resulting in 890,392 deaths, giving a tentative $3.3 \%$ case fatality rate [225].

Analysis of whole-genome sequences showed that SARS-CoV-2 shares about $96.1 \%$ identity to a bat SARSr-CoV isolated from Rhinolophus affinis (Ra) in Yunnan, China in 2013 (BatCoV RaTG13) [132,133], 93.3\% identity to a bat SARSr-CoV isolated from Rhinolophus malayanus (Rm) in Yunnan (YN), China in 2019 (BetaCoV/Rm/Yunnan/YN02/2019, RmYN02) [133], and 87.8\% and 87.6\% identity to two bat SARSr-CoVs, BatCoV RpZC45 and BatCoV RpZXC21, respectively, detected in Rhinolophus pusillus (Rp) bats from Zhoushan City (ZXC or ZC), Zhejiang Province, China in 2015 [226]. As was the case for SARS-CoV, SARS-CoV-2 is likely to have originated from Chinese horseshoe bats in the genus Rhinolophus. Although there is high sequence identity between the longest encoding gene region (1ab) of RmYN02 and 1ab of SARS-CoV-2 (nt 97.2\%, aa 98.8\%), there is low sequence identity between the SARS-CoV-2 S RBD and RaTG13 S RBD (nt 85.3\%, aa 89.3\%) or RmYN02 S RBD (nt 61.3\%, aa $62.4 \%$ ) [133]. The RBD is a major determinant of host range and it is therefore likely that there is an intermediate host facilitating a bat SARSr-CoV to acquire efficient ability to infect humans.

Although the first outbreak occurred in Wuhan, animal specimens from the Huanan seafood wholesale market in Wuhan, which sells both live and dead animals including bats, civets, snakes, poultry, pigs and dogs, were negative for SARSr-CoVs [226]. Snakes and canids (dogs) were presumed to be intermediate hosts of SARS-CoV-2 based on sequence analysis of the relative synonymous codon usage (RSCU) bias between SARS-CoV-2 and animal host species [227] and based on analysis of zinc finger antiviral protein (ZAP) expression in animal host species and tissues that drive CoV evolution to have a low-CpG (5'-Cytosin-phosphate-Guanine-3') viral genome [228], respectively. However, SARSr-CoV-2 has not been isolated from snakes and it is unlikely that the viruses can cross the species barrier from bats, warm-blooded mammals, to humans via snakes, cold-blooded reptiles. Although results of RT-PCR and serological tests confirmed SARS-CoV-2 infections in dogs, the infected dogs were with infected owners and thus humans are likely to have transferred the virus to their pets [101]. Cats, tigers and lions that were cared for by infected owners/zookeepers were also reported to have tested seropositive for SARS-CoV-2, suggesting human-to-animal transmission of COVID-19 [101]. Experimental studies showed that pigs, chickens and ducks were not susceptible to SARS-CoV-2, that dogs had little susceptibility and that both ferrets and cats were highly susceptible $[229,230]$. Experimental studies showed that there is little transmission of SARS-CoV-2 among ferrets but that cats have the potential for airborne transmission of the virus between them [230]. However, no cat-SARSr-CoV-2 has been isolated. Furthermore, there has so far been no evidence of transmission of SARS-CoV-2 or SARSr-CoV-2 from these SARS-CoV-2-susceptible animals, including canines, ferrets and felines, to humans [101,229]. Nonetheless, surveillance of both infection and dissemination of SARS-CoV-2 should be implemented. SARSr-CoV-2 has been isolated from smuggled Malayan pangolins (Manis javanica), but it has not been isolated from Chinese pangolins (Manis pentadactyla) seized in Guangxi (GX) and Guangdong (GD) in southern China [103,226,231]. Whole-genome comparison indicated that pangolin-SARSr-CoVs have a significant sequence difference from SARS-CoV-2 sequences, suggesting that current pangolin-SARSr-CoV isolates are unlikely to be the virus directly transmitted to cause SARS-CoV-2 outbreaks in humans. However, all of the studies [103,133,226,231] showed high aa sequence identities $(97.4 \%)$ between pangolin SARSr-CoV (pangolin/GD/2019 with a single consensus sequence merged from the GD/P1L and GD/P2S sequences) 
S RBD and SARS-CoV-2 S RBD. Thus, SARSr-CoV from Malayan pangolins may be able to infect humans or may provide an RBD gene region to a coinfected CoV. Malayan pangolins may serve as a vessel to generate a $\mathrm{CoV}$ with human receptor-binding potential due to the high aa sequence similarity between pangolin and human ACE2 receptors (84.8\%) [231], suggesting the need for pangolin surveillance for public health. The continued search for a SARS-CoV-2 intermediate host is essential for understanding the emergence of the COVID-19 pandemic and for future prevention and control of zoonotic CoV-related diseases.

\subsubsection{Receptor Binding Specificity of $\alpha$ HCoV-NL63, $\beta 2$ SARS-CoV and $\beta 2$ SARS-CoV-2}

Results obtained by direct biochemical methods and X-ray crystallographic studies showed that $\alpha$ HCoV-NL63 [84,232], $\beta 2$ SARS-CoV [233] and $\beta 2$ SARS-CoV-2 [195] use their S1-CTD RBD to bind to a host receptor, angiotensin-converting enzyme 2 (ACE2, a zinc peptidase), that is essential for virus entry into cells. As shown in Figure 4b, ACE2 is a homodimeric type I transmembrane protein having an orientation with the $\mathrm{N}$-terminus outside and the C-terminus inside the cytoplasm [195]. The virus-binding site (VBS) of these three CoVs is not the peptidase active site but the outer surface of the ACE2 N-terminal lobe. Analyses of cocrystal structures between RBDs of HCoV-NL63 (pdb: 3kbh [232]), SARS-CoV (pdb: 2ajf [234]) or SARS-CoV-2 (pdb: 6m0j [235]) and the human ACE2 (hACE2) receptor indicated aa residues covering the CoV-ACE2 interfaces, divided into a common region of hACE2 recognized by all three ACE2-recognizing CoVs (a hotspot region) and unique regions bound by HCoV-NL63, SARS-CoV or SARS-CoV-2 (Figure 4b, middle row). Evidence indicating that HCoV-NL63 and SARS-CoV bind to the same hotspot region on hACE2 and that their binding is important for infection was obtained from infection inhibition studies showing that the SARS-CoV RBD can inhibit lentivirus infections mediated by the S protein of either SARS-CoV or HCoV-NL63 into hACE2-expressing HEK293T cells [236]. Likewise, the use of the HCoV-NL63 RBD as a competitive inhibitor can inhibit infections of murine leukemia viruses (MLVs) mediated by SARS-CoV S protein into hACE2-expressing HEK293T cells [237]. In addition, aa changes in the hotspot region in hACE2, either L353A or D38A substitution, resulted in a significant reduction of binding interactions between the SARS-CoV or HCoV-NL63 RBD and hACE2 and reduction of MLV infections mediated by SARS-CoV or HCoV-NL63 S protein [237]. The results of these studies suggested that the hotspot region on the hACE2 VBS is a potential target for development of drugs against ACE2-binding CoVs. It should be noted that MLN-4760, an ACE2 inhibitor that binds to the ACE2 catalytic center and induces hACE2 conformational changes, did not affect interactions of SARS-CoV S1 with the hACE2 surface and did not affect SARS-CoV S protein-mediated infection. Likewise, binding of SARS-CoV S1 to hACE2 did not affect hACE2 catalytic activity [238].

The aa sequences of hACE2 were aligned with aa sequences of ACE2 orthologues of possible natural reservoirs and possible intermediate hosts. Only the aa sequences corresponding to the hACE2 interface are shown in Figure $4 \mathrm{~b}$. Adaptation of each zoonotic virus to interact with aa residues at the hACE2 binding interface is critical for efficient transmission among humans. The hACE2 residues K31, D38, Y41 and K353 are important host determinants of adaptation of civet SARSr-CoV to human SARS-CoV (Figure $4 \mathrm{~b}$ ), and viral S1 RBD residues at the positions of 479 and 487 are important determinants of SARS-CoV binding preference (Figure 8a-c). The K479N mutation from civet to human viral S1 RBD can accommodate K31 on hACE2 [238]. The S487T mutation from civet to human viral S1 RBD can accommodate a hydrophobic pocket between Y41 and K353, neutralized by D38, on the hACE2 receptor for efficient interactions [234]. These findings agree with results obtained by Kan et al. [100] suggesting that viruses with SNVs leading to aa changes at these two positions are able to be transmitted from animals to infect humans and from humans to humans by close contact. 
However, the roles of the additional 4 aa substitutions at position 344 in the RBD but outside the RBS (Figure 8b) and positions 227, 244 and 778 outside the RBD in viruses isolated from patients during the global epidemic [100] in human-to-human transmission remain unknown.

(a) $3 \mathrm{kbh}-\mathrm{NL} 63$ 2 ajf-SARS $6 \mathrm{mOj}$-SARS 2

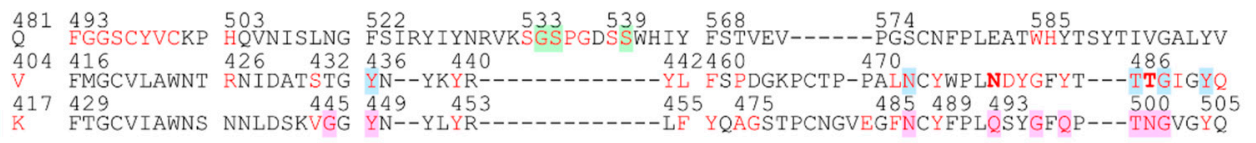

(b)

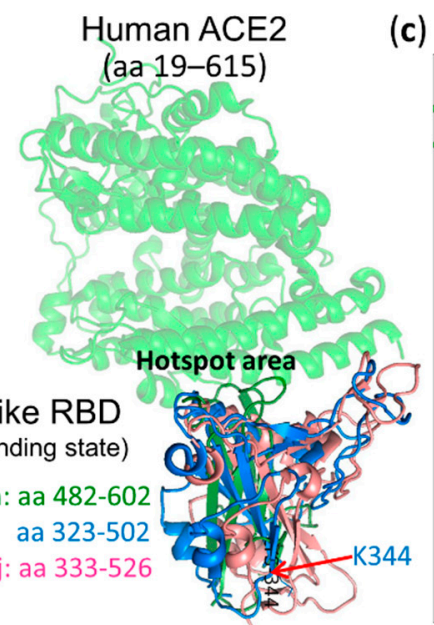

(c)

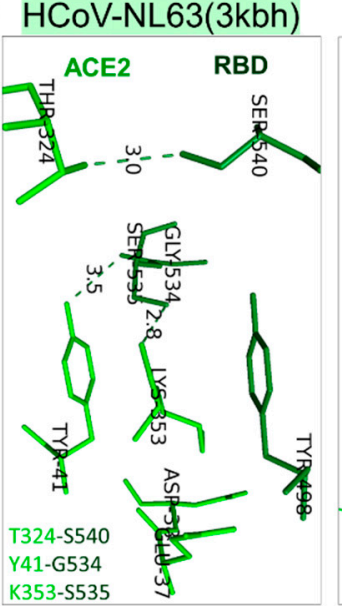

SARS-CoV(2aif)

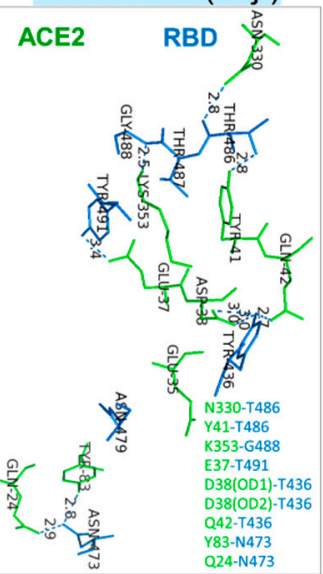

SARS-CoV2(6m0j)

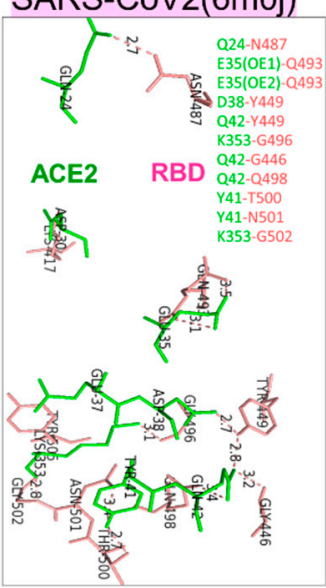

Figure 8. Comparison of receptor binding sites in S1-CTDs of HCoV-NL63, SARS-CoV and SARS-CoV2 binding to human ACE2. (a) S1-CTD receptor binding domains (RBDs) of HCoV-NL63 (pdb: 3kbh [232], forest), SARS-CoV (pdb: ajf [234], marine) and SARS-CoV-2 (pdb: 6m0j [235], salmon) in complex with human ACE2 (transparent green). (b) Direct interactions between amino acids of human ACE2 and those of the S1-CTD RBD of the indicated CoV. The bond lengths in angstroms are indicated on the dashed lines. (c) Alignment of aa sequences of the S1-CTD RBDs of the three CoVs binding to human ACE2. Amino acid residues in the S1-CTD RBDs facing the ACE2 receptor are colored in red. Residues in the S1-CTD RBDs of HCoV-NL63, SARS-CoV and SARS-CoV-2 directly interacting with residues in the ACE2 receptor are highlighted in green, blue and purple, respectively.

Crystal structure analysis indicated that the SARS-CoV-2 RBD to which hACE2 binds is almost identical to the SARS-CoV RBD [235]. Later, hACE2 amino acids at or near the RBD/ACE2 interface (Figure $4 b$ ) that could affect RBD/ACE2 binding were used for screening the capability of ACE2 of various animals used by SARS-CoV and SARS-CoV-2. ACE2 of possible SARS-CoV and SARS-CoV-2 intermediate hosts, masked palm civet and Malayan pangolin, respectively, and ACE2 of many mammals including cats, dogs, cows, buffalos, goats and sheep, but not rats (Rattus norvegicus), were predicted to be potentially recognized by SARS-CoV and SARS-CoV-2 [239,240], supporting the finding that rat ACE2 has less efficiency for binding to the SARS-CoV S1 domain and is less susceptible to SARS-CoV S protein-mediated infection [241]. However, young female Fischer 344 (F344) rats of 4 weeks of age were shown to be susceptible to infection with SARS-CoV by intranasal inoculation [242]. Western blot analysis showed that ACE2 expression in Sprague Dawley rats decreased with aging without a gender difference [243]. However, it remains unknown whether there is a difference in ACE2 sequence depending on the age of rats and whether there are differences in ACE2 expression and sequence depending on the rat strain. Based on ACE2 residues 31, 35, 38, 82 and 353, Chinese horseshoe bats, which are thought to be a natural reservoir, can be divided into two groups [240]. First, bat ACE2 of SARSr-CoV-RT-PCR-positive R. ferrumequinum (bat Rf) [220] was predicted not to have the ability to bind to either SARS-CoV-2 or SARS-CoV S protein. Second, bat ACE2 of SARSr-CoV-seropositive and 
-RT-PCR-positive R. pearsonii, R. macrotis [220], and SARSr-CoV-RT-PCR-positive R. sinicus [95] was predicted to be able to bind to both SARS-CoV-2 and SARS-CoV S proteins. Based on residues 20, 31, $41,68,83,353,355,357$ and 383, R. sinicus ACE2 was confirmed to have the potential to be used by SARS-CoV-2 [239]. These findings indicate the possibility of cross-species transmission of the virus from humans to animals carrying similar host receptor sequences, although other host factors, such as target organ temperature and cellular proteins interacting with the virus, may be involved in host range restriction of the virus. Thus, surveillance of transmission both back and forth between humans and animals is needed. The susceptible host range of HCoV-NL63, which causes mild respiratory disease [244], has not been determined. However, the host range of HCoV-NL63 might be similar to that of SARS-CoV and SARS-CoV-2, and thus a mixed infection of these different viruses to the same host cells may occur.

Although $\alpha$ HCoV-NL63, $\beta 2$ SARS-CoV and $\beta 2$ SARS-CoV-2 recognize the same ACE2 receptor and all bind to the hotspot region on ACE2 (Figure 4b, middle), they have aa differences in the RBS at the viral RBD interface (Figure 8a), suggesting that they have undergone convergent evolution for efficient ACE2 binding [232,235]. While SARS-CoV and SARS-CoV-2 have similar RBD structures with a concave surface, $\alpha$ HCoV-NL63 has no structural RBD homology to $\beta$ CoV RBDs (Figure 8b) [232,235]. Thus, we superimposed hACE2 receptors (green) in complex with HCoV-NL63 (pdb: 3kbh), SARS-CoV (pdb: 2ajf) and SARS-CoV-2 (pdb: 6m0j) as shown in Figure 8b. However, since all three viruses interact with the same hotspot region on the hACE2 receptor, RBS residues of these different viruses occupy similar positions in the hotspot area. For example, S535/T487/N501 of HCoV-NL63/SARS-CoV/SARS-CoV-2 are located near K353 and Y41 of hACE2, while Y498/Y491/Y505 of HCoV-NL63/SARS-CoV/SARS-CoV-2 are located near K353, E37 and D38 of hACE2 (Figure 8c) [235,237]. By using surface plasmon resonance with a Biacore 2000/3000 instrument, equilibrium dissociation constant ( $K d$, smaller value indicating greater binding affinity) values between HCoV-NL63 RBD and immobilized hACE2 and between SARS-CoV RBD and immobilized hACE2 were determined to be 34.9 and $20.8 \mathrm{nM}$, respectively [232,237]. It should be noted that NL63-CoV RBD-hACE2 interactions have lower koff and kon values than do SARS-CoV RBD-hACE2 interactions, suggesting that NL63-CoV $\mathrm{RBD} / \mathrm{hACE} 2$ complex has less electrostatic and more hydrophobic interactions [237]; three hydrogen bonds were observed in HCoV-NL63 RBD-hACE2 complex, but nine hydrogen bonds were observed in SARS-CoV RBD-hACE2 complex (Figure 8c). By surface plasmon resonance with a Biacore T200 instrument, the $K d$ values of SARS-CoV RBD-immobilized hACE2 and SARS-CoV-2 RBD-immobilized hACE2 were determined to be $31 \mathrm{nM}$ and $4.7 \mathrm{nM}$, respectively [235]. As mentioned earlier, S487T and K479N substitutions in the civet SARSr-CoV RBS are critical for civet-to-human transmission [238]. It appears that both T487 and N479 are substituted by N501 and Q493, respectively, in the SARS-CoV-2 RBS. N501 in the SARS-CoV RBD and T486, but not T487, in the SARS-CoV RBD (Figure 8c) form a hydrogen bond with hACE2 Y41. It is likely that subtle differences between the SARS-CoV RBD and SARS-CoV-2 RBD in interactions with hACE2 are responsible for the difference in $K d$ values of the SARS-CoV RBD and SARS-CoV-2 RBD for hACE2 [235]. For example, while N479 in the SARS-CoV RBD does not cause hydrogen bond formation, its substituted Q493 in the SARS-CoV-2 RBD makes two hydrogen bonds with E35 of hACE2. K417 in the SARS-CoV-2 RBD provides a unique interaction with huACE2 D30 and a positive charged patch on the SARS-CoV-2 RBD, which is not found on the SARS-CoV RBD (Figure 8c) [235]. A virus with a great binding affinity, which can trigger infection efficiently, could be a factor of the rapid spread of SARS-CoV-2. Other factors may be involved in driving the rapid spread of the virus. For example, the presence of a polybasic (RRAR) site at the S1/S2 cleavage site found in SARS-CoV-2, but not in other $\beta \mathrm{CoVs}$ in lineage $\mathrm{B}$, which is cleaved by furin pre-activating the viral $S$ proteins during virus exit, reduces dependence of the viral $S$ proteins on target cell proteases for virus entry and thus facilitates the virus infection [245]. 


\section{Sialyl Glycan and Protein Receptor-Dependent Recognition of Lineage C $\beta$ ( $\beta 3$ ) MERS-CoV}

A novel CoV was first isolated from the sputum of a Saudi Arabian patient who died from acute respiratory distress syndrome (ARDS) and subsequent multiorgan dysfunction syndrome (MODS) in 2012 [246], and the novel CoV was named Middle East respiratory syndrome coronavirus, MERS-CoV, in 2013 [247]. Most infected patients present with atypical pneumonia that has the potential to progress to ARDS [104,247]. Although confined to the Middle East, mainly in Saudi Arabia, human MERS-CoV infection spread to 27 other countries from people traveling. As of May 2020, 2562 cases with 881 deaths have been reported to $\mathrm{WHO}$, the case-fatality rate being approximately $34 \%$ [8]. New MERS-CoV infection cases caused by direct or indirect contact with infected dromedary camels (Camelus dromedaries) or by close contact with infected humans have continued to be reported, and MERS is thus still a disease of a global concern. By comparing 30-kb genome sequences, MERS-CoVs isolated from patients were reported to share more than $99 \%$ nt identity to dromedary MERS-CoVs [248]. Based on results of nt sequence and phylogenetic analyses, MERS-CoVs are closely related to several lineage $\mathrm{C} \beta \mathrm{CoVs} / \mathrm{RNA}$ detected in feces of different bat species but have $100 \% \mathrm{nt}$ identity to a CoV gene fragment (only 182 nucleotides) isolated from Taphozous perforatus bat feces in Bisha, Kingdom of Saudi Arabia. Based on complete genome sequences that have been so far been determined, the most closely related virus sharing about $85.6 \%$ nt identity to MERS-CoV is NeoCoV isolated from Neoromicia capensis bat feces in South Africa [106]. Dromedary camels are the only confirmed hosts of zoonotic MERS-CoV leading to human infection [111]. MERS-CoV or its RNA can be detected in dromedary nasal swabs and lung tissue samples, and an experimental study showed that MERS-CoV appears to cause mild upper respiratory tract disease in dromedary camels [109,110], suggesting that dromedary MERS-CoV is transmitted through droplets (either droplet particles or droplet nuclei) and contact routes. These findings suggested that bats are ancestral reservoir hosts and dromedary camels are intermediate reservoir hosts of MERS-CoVs.

MERS-CoV infection is initiated by attachment of its homotrimeric $S$ proteins to a host cell. By mass spectrometric analysis, dipeptidyl peptidase 4 (DPP4 or CD26) was identified to be a 110-kDa protein co-purified with MERS-CoV S1-Fc chimeric protein from the human liver (Huh-7) and African green monkey kidney (Vero) lysates. Pre-incubation of Huh-7 cells and primary human bronchial epithelial cells with anti-DPP4 immunoglobulin appeared to inhibit MERS-CoV infection. Based on these findings, MERS-CoV infection was suggested to occur via binding of MERS-CoV S1 to the cellular receptor DDP4 [249]. According to the site of virus infection in individual hosts, DDP4 was detected in the respiratory tracts of camelids and humans and was found to be rich in the intestinal tracts of pipistrelle bats, the hosts of Pipistrellus bat CoV HKU5 (Pi-BatCoV HKU5), which is closely related to MERS-CoV $[108,131]$. Like other protein-binding CoVs, except for MHV binding to the protein receptor CEACAM1 via S1-NTD [250] (Table 2), MERS-CoV binds to the outer surface of DDP4 via $\mathrm{S} 1^{\mathrm{B}}$ (S1-CTD) and it does not bind to the DDP4 catalytic pocket and does not require DDP4 catalytic activity (Figure 4b) [251]. In a cryo-EM study, each monomeric S1-CTD receptor binding surface was found to be buried in the tip of the CoV S trimer in the lying state (closed conformation, pdb: 6q06) and to be exposed in the standing state (open conformation, pdb: $5 \times 59$ ) (Figure $6 \mathrm{~b}$ ) readily bound by the receptor (Figure 9, left) [205]. Analysis of the crystal structure of MERS-CoV S1-CTD in complex with DDP4 (pdb: 4172) revealed the location of the DDP4 binding site on MERS-CoV S1-CTD (Figure 9, left) and the viral S1-CTD binding site on DDP4 (Figure 4b) and provided information on interactions between the viral S1-CTD and DDP4 [251]. Eight H-bond formations were observed between residues on the viral S1-CTD and residues on the DPP4 as follows: (i) Y499 with R336, (ii) D510 with R317, (iii) D510 with Y322, (iv) E513 with Q344, (v) E513 with A291, (vi) G538 with Q286, (vii) D539 with K267, and (viii) R542 with L294 (Figure 9, middle). 


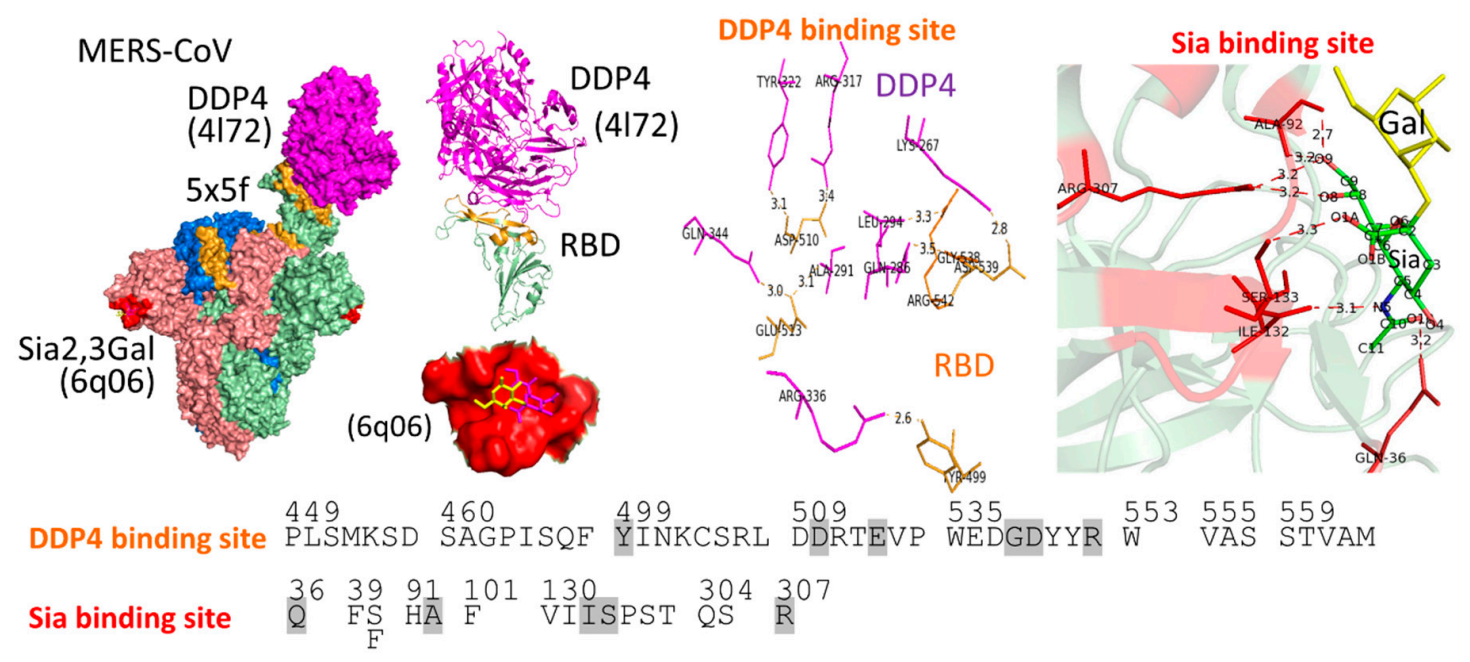

Figure 9. Binding of MERS-CoV S1-CTD to human DDP4 receptor (pdb: 4172) and S1-NTD to Sia $\alpha 2,3 \mathrm{Gal}$ receptor (pdb: 6q06). Middle: Cartoon diagram of MERS-CoV S1-CTD (pale green) in complex with human DDP4 (magenta) and surface diagram (red) of MERS-CoV S1-NTD in complex with Sia 2 2,3Gal receptor (Sia in magenta stick and Gal in yellow stick). Amino acids in the bright orange area of S1-CTD and in the red area of S1-NTD being a DDP4 binding site and a Sia binding site, respectively, are shown in the lower panel. Right: Direct interactions between amino acids of the DDP4 binding site and those of the DDP4 receptor and between amino acids of the Sia binding site and those of a Sia $\alpha 2,3 \mathrm{Gal}$ receptor. The bond distance in angstroms of each direct interaction is shown on the dash lines. Amino acids involved in indirect interactions are highlighted in gray in the lower panel. 4172, 6q06 and 5x5f are from [251], [148] and [205], respectively.

Observation of agglutination of human erythrocytes by intact MERS-CoV particles led to the finding that Sia-binding activity of MERS-CoV is mediated by multivalent S1 ${ }^{\mathrm{A}}$ (S1-NTD) [112]. One hundred thirty-five glycan structures were used for determination of receptor binding specificity of multivalent MERS-S1 ${ }^{\mathrm{A}}$-containing nanoparticles by glycan arrays. It appeared that MERS-S1 ${ }^{\mathrm{A}}$ nanoparticles bind selectively to nonmodified Neu5Ac but not to Neu5Gc or $(7) 9-O-,a c e t y l a t e d ~ N e u 5 A c$. No binding to Neu5Gc-terminated glycans was explained by steric hindrance of the extra hydroxyl group of Neu5Gc in the MERS- S1 ${ }^{A}$ hydrophobic pocket formed by F39, F101, I131 and I132 [148]. For sialyl linkage specificity, MERS-CoV S1 ${ }^{\mathrm{A}}$ prefers $\alpha 2,3$ over $\alpha 2,6$ linkages, either short, sulfated, $\alpha 2,3-$ linked mono-Sia Lewis ${ }^{X}$ or long, branched, $\alpha 2,3$-linked tri-Sia with four type 2 LN repeats. Pretreatment of Calu-3 human airway cells with neuraminidase inhibited infection of MERS-CoV, indicating that Sia is necessary for MERS-CoV infection. Accordingly, multivalent MERS-CoV S1 ${ }^{\mathrm{A}}$-containing nanoparticles were shown to specifically bind to infection sites in individual hosts: dromedary camel nasal epithelial cells, human type II pneumocytes in the alveolar wall that contains an abundance of $\alpha 2,3-$ sialyl type 2 LN and a small amount of $\alpha 2,3$-sialyl-Lewis ${ }^{X}$ [19], and pipistrelle bat intestinal epithelial cells. Removal of Sia from cell surface glycans by treatment with neuraminidase abolished binding of the nanoparticles, confirming that MERS-CoV S1 ${ }^{\mathrm{A}}$ binds to infected cells via Sia recognition [108]. The cryo-EM structure of MERS-CoV S in complex with $\alpha 2,3-S L N$ (pdb: 6q06) showed Sia binding in a surface-exposed groove (domain A) of each monomer (Figure 9, left). Analysis of the structure indicated the five residues Q36, A92, I132, S133 and R307 directly anchoring Neu5Ac as shown in Figure 9, right [148].

Recently, Qing et al. [113] demonstrated roles of $S 1^{\mathrm{A}}$ domains binding to Sia receptors and $S 1^{\mathrm{B}}$ domains binding to DDP4 receptors at different stages of virus infection. At the initial infection stage, MERS-CoV attaches to sialyl receptors on the host cell membrane and requires subsequent durable adherence to DDP4 receptors for infection. At later infection stages, MERS-CoV S proteins, which are not incorporated into progeny viruses, abundant on infected cell membranes attach to sialyl receptors on neighboring cells. This stage does not require DPP4 receptors but requires the cell surface protease TMPRSS2 for activating MERS-CoV S proteins for cell-cell fusions resulting in syncytial formation 
that rapidly spreads. These findings indicate the importance of Sia attachment playing roles in both initial and later infection stages and possibly determining the site of MERS-CoV infection since Sia attachment precedes DPP4 adherence at the initial infection stage.

\section{Conclusions and Future Perspectives}

Despite much effort in studies and preparedness from deadly viruses including HPAI, SARS and MERS outbreaks, the unexpected 2009 H1N1 strain and 2019SARS-CoV-2 quickly spread worldwide and became pandemics in 2009 and 2020, respectively. Although H5 and H7 vaccines, either monovalent or bivalent forms, are used for protection of domestic birds [252], the ever-changing and highly reassorting HPAI H5 has continued to cause outbreaks in domestic birds and to be detected in dead wild birds [24]. HPAI H7N3 in poultry has been reported until now [24]. HPAI H5N6 human cases [253] and HPAI H7N9 human cases [254] were still reported in 2019. Several avian IAVs including H7N9, HPAI H5NX (X, NA subtypes) and H9N2 sporadically cross species to infect humans. MERS-CoV is still causing an endemic in dromedary camels and human infections [8] and SARS-like CoV is still circulating in animals, notably in palm civets and raccoon dogs [100]. Thus, it is very important to understand how a new pandemic arises.

Historical data indicated that CoVs, which infect humans by using a specific host protein as a primary receptor, including HCoV-229E (APN), HCoV-NL63 (ACE2), SARS-CoV (ACE2), SARS-CoV-2 (ACE2) and MERS-CoV (DDP4), originated from bats, whereas HCoV-OC43 and HCoV-HKU1, which use $\mathrm{Neu} 5,9 \mathrm{Ac}_{2}$, originated from rodents [255]. In contrast, IAVs infecting humans using sialyl glycans are thought to have originated from wild birds. The finding that some H16 HAs isolated from wild birds contain Y98F, being different from HAs of other Sia-binding IAVs but the same as bat non-Sia-binding HAs of H17 and H18 IAVs, and the finding that there are bat $\alpha 2,3$ Sia-binding IAV isolates that are phylogenetically different from other identified IAVs with HA closest to mallard $\mathrm{H} 9$ viruses indicate the possibility of cross wild bird-to-bat and/or bat-to-wild bird transmission of IAVs [64]. Studies on evolutional changes of wild bird IAVs and bat IAVs may lead to clarification of the host origins of IAVs. An understanding of viral adaptation in the wild animals to recognize distinct receptors may lead to the establishment of strategies for efficient control of CoVs and IAVs.

Data from genome analysis of the past three IAV pandemics, except for the first identified 1918 H1N1 pandemic that remains a mystery, demonstrated that a pandemic emerged from viral reassortment with a human virus gene segment(s) and a nonhuman HA gene segment producing a major viral antigen [19]. Extensive studies on receptor binding specificities of IAVs from different hosts [19,256] have indicated that a nonhuman HA gene must acquire mutations to recognize $\alpha 2,6 \mathrm{Neu} 5 \mathrm{Ac}$ for efficient human-to-human transmission, leading to the development of several techniques for monitoring and assessing IAV pandemic potential, including a viral NA-based assay [257], a glycan microarray assay [258], an evanescent-field-activated fluorescence scanner type glycan array [259] and a glycan strip test [260]. However, occasional direct pig-to-human [261] and human-to-pig [262] transmission of swine and human IAVs, respectively, both of which preferentially bind to $\alpha 2,6$ sialyl glycans, and some avian IAVs, including HPAI H5N1 [263], H7N9 [264], H9N2 [265], H7N2 and H7N3 [266], that were reported to have increased binding to human-type $\alpha 2,6 \mathrm{Neu} 5 \mathrm{Ac}$ have not yet caused a pandemic. In addition to monitoring the $\alpha 2,3$ to $\alpha 2,6$ binding shift of HA, a simple test for monitoring shifts in other factors, such as PB2, should be developed for monitoring the situation of a virus with pandemic potential.

Different from IAVs having a segmented (-)ssRNA genome, CoVs have a nonsegmented (+)ssRNA genome. SARS-CoV and MERS-CoV originated through recombination in bats [267] and cross-species transmission to intermediate hosts, palm civets and dromedary camels, respectively, resulting in transmission to humans. Both palm civet SARSr-CoV and human SARS-CoV and dromedary camel MERS-CoV and human MERS-CoV have $99.8 \%$ nt sequence identity $[217,268]$. In contrast, a nonhuman virus that is almost identical to SARS-CoV-2 has not been identified so far, suggesting no widespread infections of a nearly identical SARS-CoV-2 in natural or intermediate hosts [269]. Based on current 
data, SARS-CoV-2 might have emerged from a quadruple recombination by which Yunnan bat RaTG13 (96.1\% nt identity with SARS-CoV-2) might be its genome backbone [226], Yunnan bat RmYN02 (93.3\% nt identity) probably gave the long replicase gene (1ab gene, sharing 97.2\% nt identity) [133], pangolin SARS-like-CoV-2/Guangdong might have provided an RBD motif-coding gene (97.4\% aa similarity) [231], and an unidentified bat virus might have donated a gene region coding a multibasic (furin, PRRAR motif) cleavage site [133]. Similarly, the $2009 \mathrm{H1N1}$ pandemic is a quadruple reassortant IAV that acquired gene segments from human IAV (PB1 gene), avian IAV (PB2 and PA genes), classical swine IAV (H1, NP and NS genes) and Eurasian avian-like swine IAV (N1 and M genes) [4].

The ability of a virus to adapt to a human environment, including human immunity and drugs, enables it to seasonally circulate in humans. Highly transmissible SARS-CoV-2, which has the same ACE2 receptor as that of HCoV-NL63, may continue to be a seasonal CoV and may undergo recombination with $\mathrm{HCoV}-\mathrm{NL} 63$ during mixed infection in the same cell. While there is no vaccine for and no specific drugs for treatment of mild common cold disease caused by HCoVs, many efforts are being made to develop both vaccines and drugs for the pandemic SARS-CoV-2. Influenza caused by seasonal IAVs can be prevented by yearly vaccination and can be treated by FDA-approved anti-flu drugs, which are divided into four groups: M2 inhibitors, a PA inhibitor, a PB1 inhibitor and NA inhibitors [270]. Nonetheless, highly mutable IAVs that possess RNA genome segments and RNA polymerase without proofreading, different from the CoV RNA genome and RNA polymerase with proofreading, have continued to circulate in humans for more than one hundred years. Structural analysis, studies on receptor binding specificity and studies on inhibition of infection by synthetic sialylglycopolymers [19,271] have suggested that there is an invariant receptor binding site (RBS) on viral HA spikes that is critical for virus binding to a human-type receptor for infection. This easily reachable drug target that is abundant on the viral envelope is a promising target for the development of a universal and permanent anti-influenza drug against human-adapted viruses of H1-H16 HA subtypes. Recently, 6SLN-lipo PGA [270,271] was shown to be effective when administered alone and to have a synergistic effect when combined with an NAI drug against both pandemic and seasonal influenza viruses. In the case of CoVs, the RBS could be a potential drug target. However, CoVs recognize different receptors including protein receptors, CEACAM1a, NCAM, DDP4, APN and ACE2, and saccharide receptors, sialylated or non-sialylated saccharides. Some CoVs also recognize a co-receptor/attachment factor by a different binding pocket of the $S$ protein and some $\beta$ CoVs also carry an HE spike protein binding to an $\mathrm{O}$-acetylated Sia receptor (Table 2). Thus, for the design of an anti-CoV against the RBS, consideration must be given to the role and importance of each receptor and to the use of two inhibitors in combination or the possibility of generating a single compound with two different inhibitory sites.

Finally, studies to understand how human viruses emerge, to understand the pathogenesis of diseases, and to produce effective, safe and permanent (if possible) vaccines/drugs are essential for virus control and eradication. However, the most important thing is creating awareness about the results of human intrusion and disturbance of wildlife in order to minimize or eliminate direct contact of domestic animals/humans with wild animals for prevention of the next emerging disease.

Author Contributions: Conceptualization, N.S. and Y.S.; writing-original draft preparation, N.S.; writing-review and editing, N.S. and Y.S. All authors have read and agreed to the published version of the manuscript.

Funding: This review was supported by TANAKA Precious Metals Foundation 2020.

Conflicts of Interest: The authors declare no conflict of interest.

\section{References}

1. Fischer, M.; Staples, J.E.; Arboviral Diseases Branch; National Center for Emerging and Zoonotic Infectious Diseases; CDC. Notes from the field: Chikungunya virus spreads in the Americas-Caribbean and South America, 2013-2014. Morb. Mortal. Wkly. Rep. 2014, 63, 500-501. [PubMed] 
2. Hennessey, M.; Fischer, M.; Staples, J.E. Zika virus spreads to new areas-Region of the Americas, May 2015-January 2016. Morb. Mortal. Wkly. Rep. 2016, 65, 55-58. [CrossRef] [PubMed]

3. Kamorudeen, R.T.; Adedokun, K.A.; Olarinmoye, A.O. Ebola outbreak in West Africa, 2014-2016: Epidemic timeline, differential diagnoses, determining factors, and lessons for future response. J. Infect. Public Health 2020, 13, 956-962. [CrossRef] [PubMed]

4. Sriwilaijaroen, N.; Suzuki, Y. Molecular basis of a pandemic of avian-type influenza virus. Methods Mol. Biol. 2014, 1200, 447-480. [PubMed]

5. WHO. Cumulative Number of Confirmed Human Cases for Avian Influenza A(H5N1) Reported to WHO, 2003-2020. Available online: https://www.who.int/influenza/human_animal_interface/2020_10_ 07_tableH5N1.pdf?ua=1 (accessed on 1 September 2020).

6. WHO. Cumulative Number of Reported Probable Cases of SARS. Available online: https://www.who.int/csr/ sars/country/2003_07_11/en/ (accessed on 1 September 2020).

7. WHO. China Reports Additional SARS Cases-update. Available online: https://www.who.int/csr/don/2004_ 04_23/en/ (accessed on 1 September 2020).

8. WHO. Middle East Respiratory Syndrome Coronavirus (MERS-CoV)-Saudi Arabia. Available online: https://www.who.int/csr/don/02-jul-2020-mers-saudi-arabia/en/ (accessed on 1 September 2020).

9. Heymann, D.L.; Shindo, N. COVID-19: What is next for public health? Lancet 2020, 395, 542-545. [CrossRef]

10. Sriwilaijaroen, N.; Suzuki, Y. Molecular basis of the structure and function of $\mathrm{H} 1$ hemagglutinin of influenza virus. Proc. Jpn. Acad. Ser. B Phys. Biol. Sci. 2012, 88, 226-249. [CrossRef] [PubMed]

11. WHO. Timeline of WHO's Response to COVID-19. Available online: https://www.who.int/news-room/detail/ 29-06-2020-covidtimeline (accessed on 1 September 2020).

12. WHO. Influenza (Seasonal). Available online: https://www.who.int/news-room/fact-sheets/detail/influenza(seasonal) (accessed on 1 September 2020).

13. Calvo, C.; Garcia-Garcia, M.L.; Centeno, M.; Perez-Brena, P.; Casas, I. Influenza C virus infection in children, Spain. Emerg. Infect. Dis. 2006, 12, 1621-1622. [CrossRef]

14. Flynn, O.; Gallagher, C.; Mooney, J.; Irvine, C.; Ducatez, M.; Hause, B.; McGrath, G.; Ryan, E. Influenza D virus in cattle, Ireland. Emerg. Infect. Dis. 2018, 24, 389-391. [CrossRef]

15. White, S.K.; Ma, W.; McDaniel, C.J.; Gray, G.C.; Lednicky, J.A. Serologic evidence of exposure to influenza D virus among persons with occupational contact with cattle. J. Clin. Virol. 2016, 81, 31-33. [CrossRef]

16. Horimoto, T.; Kawaoka, Y. Influenza: Lessons from past pandemics, warnings from current incidents. Nat. Rev. Microbiol. 2005, 3, 591-600. [CrossRef]

17. Wertheim, J.O. The re-emergence of H1N1 influenza virus in 1977: A cautionary tale for estimating divergence times using biologically unrealistic sampling dates. PLoS ONE 2010, 5, e11184. [CrossRef] [PubMed]

18. Ahmed, R.; Oldstone, M.B.; Palese, P. Protective immunity and susceptibility to infectious diseases: Lessons from the 1918 influenza pandemic. Nat. Commun. 2007, 8, 1188-1193. [CrossRef] [PubMed]

19. Sriwilaijaroen, N.; Nakakita, S.I.; Kondo, S.; Yagi, H.; Kato, K.; Murata, T.; Hiramatsu, H.; Kawahara, T.; Watanabe, Y.; Kanai, Y.; et al. N-glycan structures of human alveoli provide insight into influenza A virus infection and pathogenesis. FEBS J. 2018, 285, 1611-1634. [CrossRef] [PubMed]

20. Su, S.; Wong, G.; Shi, W.; Liu, J.; Lai, A.C.K.; Zhou, J.; Liu, W.; Bi, Y.; Gao, G.F. Epidemiology, genetic recombination, and pathogenesis of coronaviruses. Trends Microbiol. 2016, 24, 490-502. [CrossRef]

21. Liu, D.X.; Liang, J.Q.; Fung, T.S. Human Coronavirus-229E,-OC43,-NL63, and-HKU1. Ref. Modul. Life Sci. 2020. [CrossRef]

22. CDC. SARS Update-19 May 2004. Available online: https://www.cdc.gov/sars/media/2004-05-19.html (accessed on 1 September 2020).

23. Gambaryan, A.S.; Matrosovich, T.Y.; Boravleva, E.Y.; Lomakina, N.F.; Yamnikova, S.S.; Tuzikov, A.B.; Pazynina, G.V.; Bovin, N.V.; Fouchier, R.A.M.; Klenk, H.D.; et al. Receptor-binding properties of influenza viruses isolated from gulls. Virology 2018, 522, 37-45. [CrossRef]

24. OIE. Update on Avian Influenza in Animals (types H5 and H7). Available online: https://www.oie.int/animalhealth-in-the-world/update-on-avian-influenza\%20/ (accessed on 1 September 2020).

25. Deng, G.; Tan, D.; Shi, J.; Cui, P.; Jiang, Y.; Liu, L.; Tian, G.; Kawaoka, Y.; Li, C.; Chen, H. Complex reassortment of multiple subtypes of avian influenza viruses in domestic ducks at the Dongting Lake Region of China. J. Virol. 2013, 87, 9452-9462. [CrossRef] 
26. Laudert, E.; Sivanandan, V.; Halvorson, D.; Shaw, D.; Webster, R.G. Biological and molecular characterization of H13N2 influenza type A viruses isolated from turkeys and surface water. Avian Dis. 1993, 37, 793-799. [CrossRef]

27. Zhao, G.; Gu, X.; Lu, X.; Pan, J.; Duan, Z.; Zhao, K.; Gu, M.; Liu, Q.; He, L.; Chen, J.; et al. Novel reassortant highly pathogenic H5N2 avian influenza viruses in poultry in China. PLoS ONE 2012, 7, e46183. [CrossRef]

28. Gu, M.; Liu, W.; Cao, Y.; Peng, D.; Wang, X.; Wan, H.; Zhao, G.; Xu, Q.; Zhang, W.; Song, Q.; et al. Novel reassortant highly pathogenic avian influenza (H5N5) viruses in domestic ducks, China. Emerg. Infect. Dis. 2011, 17, 1060. [CrossRef]

29. Wong, F.Y.; Phommachanh, P.; Kalpravidh, W.; Chanthavisouk, C.; Gilbert, J.; Bingham, J.; Davies, K.R.; Cooke, J.; Eagles, D.; Phiphakhavong, S.; et al. Reassortant highly pathogenic influenza A(H5N6) virus in Laos. Emerg. Infect. Dis. 2015, 21, 511-516. [CrossRef] [PubMed]

30. Monne, I.; Fusaro, A.; Nelson, M.I.; Bonfanti, L.; Mulatti, P.; Hughes, J.; Murcia, P.R.; Schivo, A.; Valastro, V.; Moreno, A.; et al. Emergence of a highly pathogenic avian influenza virus from a low-pathogenic progenitor. J. Virol. 2014, 88, 4375-4388. [CrossRef] [PubMed]

31. Shi, J.; Deng, G.; Ma, S.; Zeng, X.; Yin, X.; Li, M.; Zhang, B.; Cui, P.; Chen, Y.; Yang, H.; et al. Rapid evolution of H7N9 highly pathogenic viruses that emerged in China in 2017. Cell Host Microbe 2018, 24, 558-568. [CrossRef] [PubMed]

32. Berhane, Y.; Hisanaga, T.; Kehler, H.; Neufeld, J.; Manning, L.; Argue, C.; Handel, K.; Hooper-McGrevy, K.; Jonas, M.; Robinson, J.; et al. Highly pathogenic avian influenza virus A (H7N3) in domestic poultry, Saskatchewan, Canada, 2007. Emerg. Infect. Dis. 2009, 15, 1492. [CrossRef] [PubMed]

33. Jonges, M.; Bataille, A.; Enserink, R.; Meijer, A.; Fouchier, R.A.; Stegeman, A.; Koch, G.; Koopmans, M. Comparative analysis of avian influenza virus diversity in poultry and humans during a highly pathogenic avian influenza A (H7N7) virus outbreak. J. Virol. 2011, 85, 10598-10604. [CrossRef]

34. Selleck, P.W.; Arzey, G.; Kirkland, P.D.; Reece, R.L.; Gould, A.R.; Daniels, P.W.; Westbury, H.A. An outbreak of highly pathogenic avian influenza in Australia in 1997 caused by an H7N4 virus. Avian Dis. 2003, 47, 806-811. [CrossRef] [PubMed]

35. Lee, M.S.; Chen, L.H.; Chen, Y.P.; Liu, Y.P.; Li, W.C.; Lin, Y.L.; Lee, F. Highly pathogenic avian influenza viruses H5N2, H5N3, and H5N8 in Taiwan in 2015. Vet. Microbiol. 2016, 187, 50-57. [CrossRef]

36. Heider, A.; Mochalova, L.; Harder, T.; Tuzikov, A.; Bovin, N.; Wolff, T.; Matrosovich, M.; Schweiger, B. Alterations in hemagglutinin receptor-binding specificity accompany the emergence of highly pathogenic avian influenza viruses. J. Virol. 2015, 89, 5395-5405. [CrossRef]

37. Ping, J.; Selman, M.; Tyler, S.; Forbes, N.; Keleta, L.; Brown, E.G. Low-pathogenic avian influenza virus A/turkey/Ontario/6213/1966 (H5N1) is the progenitor of highly pathogenic A/turkey/Ontario/7732/1966 (H5N9). J. Gen. Virol. 2012, 93, 1649-1657. [CrossRef]

38. CDC. Highly Pathogenic Avian Influenza A(H5N1) in Birds and other Animals. Available online: https: //www.cdc.gov/flu/avianflu/h5n1-animals.htm (accessed on 1 September 2020).

39. Sriwilaijaroen, N.; Kondo, S.; Yagi, H.; Takemae, N.; Saito, T.; Hiramatsu, H.; Kato, K.; Suzuki, Y. N-glycans from porcine trachea and lung: Predominant NeuAc $\alpha 2-6 \mathrm{Gal}$ could be a selective pressure for influenza variants in favor of human-type receptor. PLoS ONE 2011, 6, e16302. [CrossRef]

40. Suzuki, T.; Horiike, G.; Yamazaki, Y.; Kawabe, K.; Masuda, H.; Miyamoto, D.; Matsuda, M.; Nishimura, S.I.; Yamagata, T.; Ito, T.; et al. Swine influenza virus strains recognize sialylsugar chains containing the molecular species of sialic acid predominantly present in the swine tracheal epithelium. FEBS Lett. 1997, 404, 192-196. [CrossRef]

41. Ito, T.; Couceiro, J.N.; Kelm, S.; Baum, L.G.; Krauss, S.; Castrucci, M.R.; Donatelli, I.; Kida, H.; Paulson, J.C.; Webster, R.G.; et al. Molecular basis for the generation in pigs of influenza A viruses with pandemic potential. J. Virol. 1998, 72, 7367-7373. [CrossRef]

42. Suzuki, Y.; Ito, T.; Suzuki, T.; Holland, R.E., Jr.; Chambers, T.M.; Kiso, M.; Ishida, H.; Kawaoka, Y. Sialic acid species as a determinant of the host range of influenza A viruses. J. Virol. 2000, 74, 11825-11831. [CrossRef]

43. Feng, K.H.; Gonzalez, G.; Deng, L.; Yu, H.; Tse, V.L.; Huang, L.; Huang, K.; Wasik, B.R.; Zhou, B.; Wentworth, D.E.; et al. Equine and canine influenza H3N8 viruses show minimal biological differences despite phylogenetic divergence. J. Virol. 2015, 89, 6860-6873. [CrossRef]

44. Lin, D.; Sun, S.; Du, L.; Ma, J.; Fan, L.; Pu, J.; Sun, Y.; Zhao, J.; Sun, H.; Liu, J. Natural and experimental infection of dogs with pandemic H1N1/2009 influenza virus. J. Gen. Virol. 2012, 93, 119-123. [CrossRef] 
45. Pulit-Penaloza, J.A.; Simpson, N.; Yang, H.; Creager, H.M.; Jones, J.; Carney, P.; Belser, J.A.; Yang, G.; Chang, J.; Zeng, H.; et al. Assessment of molecular, antigenic, and pathological features of canine influenza A(H3N2) viruses that emerged in the United States. J. Infect. 2017, 216, S499-S507. [CrossRef]

46. Song, Q.Q.; Zhang, F.X.; Liu, J.J.; Ling, Z.S.; Zhu, Y.L.; Jiang, S.J.; Xie, Z.J. Dog to dog transmission of a novel influenza virus (H5N2) isolated from a canine. Vet. Microbiol. 2013, 161, 331-333. [CrossRef]

47. Song, D.S.; An, D.J.; Moon, H.J.; Yeom, M.J.; Jeong, H.Y.; Jeong, W.S.; Park, S.J.; Kim, H.K.; Han, S.Y.; Oh, J.S.; et al. Interspecies transmission of the canine influenza H3N2 virus to domestic cats in South Korea, 2010. J. Gen. Virol. 2011, 92, 2350-2355. [CrossRef]

48. Hatta, M.; Zhong, G.; Gao, Y.; Nakajima, N.; Fan, S.; Chiba, S.; Deering, K.; Ito, M.; Imai, M.; Kiso, M.; et al. Characterization of a feline Influenza A(H7N2) virus. Emerg. Infect. Dis. 2018, 24, 75. [CrossRef]

49. Patterson, A.R.; Cooper, V.L.; Yoon, K.J.; Janke, B.H.; Gauger, P.C. Naturally occurring influenza infection in a ferret (Mustela putorius furo) colony. J. Vet. Diagn. Investig. 2009, 21, 527-530. [CrossRef]

50. Lin, H.T.; Wang, C.H.; Wu, W.L.; Chi, C.H.; Wang, L.C. Natural A (H1N1) pdm09 influenza virus infection case in a pet ferret in Taiwan. Jpn. J. Vet. Res. 2014, 62, 181-185.

51. Hinshaw, V.S.; Bean, W.J.; Geraci, J.; Fiorelli, P.; Early, G.; Webster, R.G. Characterization of two influenza A viruses from a pilot whale. J. Virol. 1986, 58, 655-656. [CrossRef]

52. Hussein, I.T.M.; Krammer, F.; Ma, E.; Estrin, M.; Viswanathan, K.; Stebbins, N.W.; Quinlan, D.S.; Sasisekharan, R.; Runstadler, J. New England harbor seal H3N8 influenza virus retains avian-like receptor specificity. Sci. Rep. 2016, 6, 21428. [CrossRef]

53. Ito, T.; Kawaoka, Y.; Nomura, A.; Otsuki, K. Receptor specificity of influenza A viruses from sea mammals correlates with lung sialyloligosaccharides in these animals. J. Vet. Med. Sci. 1999, 61, 955-958. [CrossRef]

54. Naguib, M.M.; Kinne, J.; Chen, H.; Chan, K.-H.; Joseph, S.; Wong, P.-C.; Woo, P.C.Y.; Wernery, R.; Beer, M.; Wernery, U.; et al. Outbreaks of highly pathogenic avian influenza H5N1 clade 2.3.2.1c in hunting falcons and kept wild birds in Dubai implicate intercontinental virus spread. J. Gen. Virol. 2015, 96, 3212-3222. [CrossRef]

55. Yong-Feng, Z.; Fei-Fei, D.; Jia-Yu, Y.; Feng-Xia, Z.; Chang-Qing, J.; Jian-Li, W.; Shou-Yu, G.; Kai, C.; Chuan-Yi, L.; Xue-Hua, W.; et al. Intraspecies and interspecies transmission of mink H9N2 influenza virus. Sci. Rep. 2017, 7, 7429. [CrossRef]

56. Yamaguchi, E.; Fujii, K.; Ogawa, H.; Imai, K. First detection of influenza A virus genes from wild raccoons in Japan. Virus Genes 2018, 54, 591-595. [CrossRef]

57. WHO. Influenza (Avian and other Zoonotic). Available online: https:/www.who.int/news-room/fact-sheets/ detail/influenza-(avian-and-other-zoonotic) (accessed on 1 September 2020).

58. Zhang, T.; Bi, Y.; Tian, H.; Li, X.; Liu, D.; Wu, Y.; Jin, T.; Wang, Y.; Chen, Q.; Chen, Z.; et al. Human infection with influenza virus $\mathrm{A}(\mathrm{H} 10 \mathrm{~N} 8)$ from live poultry markets, China, 2014. Emerg. Infect. Dis. 2014, 20, 2076-2079. [CrossRef]

59. Yuan, J.; Zhang, L.; Kan, X.; Jiang, L.; Yang, J.; Guo, Z.; Ren, Q. Origin and molecular characteristics of a novel 2013 avian influenza A(H6N1) virus causing human infection in Taiwan. Clin. Infect. Dis. 2013, 57, 1367-1368. [CrossRef]

60. Gulati, S.; Smith, D.F.; Cummings, R.D.; Couch, R.B.; Griesemer, S.B.; St George, K.; Webster, R.G.; Air, G.M. Human H3N2 influenza viruses isolated from 1968 to 2012 show varying preference for receptor substructures with no apparent consequences for disease or spread. PLoS ONE 2013, 8, e66325. [CrossRef]

61. Childs, R.A.; Palma, A.S.; Wharton, S.; Matrosovich, T.; Liu, Y.; Chai, W.; Campanero-Rhodes, M.A.; Zhang, Y.; Eickmann, M.; Kiso, M.; et al. Receptor-binding specificity of pandemic influenza A (H1N1) 2009 virus determined by carbohydrate microarray. Nat. Biotechnol. 2009, 27, 797-799. [CrossRef] [PubMed]

62. Karakus, U.; Thamamongood, T.; Ciminski, K.; Ran, W.; Gunther, S.C.; Pohl, M.O.; Eletto, D.; Jeney, C.; Hoffmann, D.; Reiche, S.; et al. MHC class II proteins mediate cross-species entry of bat influenza viruses. Nature 2019, 567, 109-112. [CrossRef] [PubMed]

63. Giotis, E.S.; Carnell, G.; Young, E.F.; Ghanny, S.; Soteropoulos, P.; Wang, L.F.; Barclay, W.S.; Skinner, M.A.; Temperton, N. Entry of the bat influenza H17N10 virus into mammalian cells is enabled by the MHC class II HLA-DR receptor. Nat. Microbiol. 2019, 4, 2035-2038. [CrossRef] [PubMed]

64. Kandeil, A.; Gomaa, M.R.; Shehata, M.M.; El Taweel, A.N.; Mahmoud, S.H.; Bagato, O.; Moatasim, Y.; Kutkat, O.; Kayed, A.S.; Dawson, P.; et al. Isolation and characterization of a distinct influenza A virus from Egyptian bats. J. Virol. 2019, 93. [CrossRef] [PubMed] 
65. Tsai, C.P.; Tsai, H.J. Influenza B viruses in pigs, Taiwan. Influenza Other Respir. Viruses 2019, 13, 91-105. [CrossRef] [PubMed]

66. Wang, Y.F.; Chang, C.F.; Chi, C.Y.; Wang, H.C.; Wang, J.R.; Su, I.J. Characterization of glycan binding specificities of influenza B viruses with correlation with hemagglutinin genotypes and clinical features. J. Med. Virol. 2012, 84, 679-685. [CrossRef]

67. Lugovtsev, V.Y.; Smith, D.F.; Weir, J.P. Changes of the receptor-binding properties of influenza B virus B/Victoria/504/2000 during adaptation in chicken eggs. Virology 2009, 394, 218-226. [CrossRef]

68. Ni, F.; Nnadi Mbawuike, I.; Kondrashkina, E.; Wang, Q. The roles of hemagglutinin Phe-95 in receptor binding and pathogenicity of influenza B virus. Virology 2014, 450-451, 71-83. [CrossRef]

69. Guo, Y.J.; Jin, F.G.; Wang, P.; Wang, M.; Zhu, J.M. Isolation of influenza C virus from pigs and experimental infection of pigs with influenza C virus. J. Gen. Virol. 1983, 64 Pt 1, 177-182. [PubMed]

70. Zhang, H.; Porter, E.; Lohman, M.; Lu, N.; Peddireddi, L.; Hanzlicek, G.; Marthaler, D.; Liu, X.; Bai, J. Influenza $C$ virus in cattle with respiratory disease, United States, 2016-2018. Emerg. Infect. Dis. 2018, 24, 1926. [CrossRef]

71. Matsuzaki, Y.; Sugawara, K.; Furuse, Y.; Shimotai, Y.; Hongo, S.; Oshitani, H.; Mizuta, K.; Nishimura, H. Genetic lineage and reassortment of influenza C viruses circulating between 1947 and 2014. J. Virol. 2016, 90, 8251-8265. [CrossRef] [PubMed]

72. Liu, R.; Sreenivasan, C.; Yu, H.; Sheng, Z.; Newkirk, S.J.; An, W.; Smith, D.F.; Chen, X.; Wang, D.; Li, F. Influenza $\mathrm{D}$ virus diverges from its related influenza $\mathrm{C}$ virus in the recognition of 9-O-acetylated $\mathrm{N}$-acetyl- or $\mathrm{N}$-glycolyl-neuraminic acid-containing glycan receptors. Virology 2020, 545, 16-23. [CrossRef] [PubMed]

73. Murakami, S.; Sato, R.; Ishida, H.; Katayama, M.; Takenaka-Uema, A.; Horimoto, T. Influenza D virus of new phylogenetic lineage, Japan. Emerg. Infect. Dis. 2020, 26, 168. [CrossRef] [PubMed]

74. Woo, P.C.; Lau, S.K.; Wernery, U.; Wong, E.Y.; Tsang, A.K.; Johnson, B.; Yip, C.C.; Lau, C.C.; Sivakumar, S.; Cai, J.P.; et al. Novel betacoronavirus in dromedaries of the Middle East, 2013. Emerg. Infect. Dis. 2014, 20, 560-572. [CrossRef]

75. Jaimes, J.A.; Whittaker, G.R. Feline coronavirus: Insights into viral pathogenesis based on the spike protein structure and function. Virology 2018, 517, 108-121. [CrossRef]

76. Schultze, B.; Krempl, C.; Ballesteros, M.L.; Shaw, L.; Schauer, R.; Enjuanes, L.; Herrler, G. Transmissible gastroenteritis coronavirus, but not the related porcine respiratory coronavirus, has a sialic acid ( $N$-glycolylneuraminic acid) binding activity. J. Virol. 1996, 70, 5634-5637. [CrossRef]

77. Stoian, A.; Rowland, R.R.R.; Petrovan, V.; Sheahan, M.; Samuel, M.S.; Whitworth, K.M.; Wells, K.D.; Zhang, J.; Beaton, B.; Cigan, M.; et al. The use of cells from ANPEP knockout pigs to evaluate the role of aminopeptidase $\mathrm{N}(\mathrm{APN})$ as a receptor for porcine deltacoronavirus (PDCoV). Virology 2020, 541, 136-140. [CrossRef]

78. Li, W.; van Kuppeveld, F.J.M.; He, Q.; Rottier, P.J.M.; Bosch, B.J. Cellular entry of the porcine epidemic diarrhea virus. Virus Res. 2016, 226, 117-127. [CrossRef]

79. Shirato, K.; Maejima, M.; Islam, M.T.; Miyazaki, A.; Kawase, M.; Matsuyama, S.; Taguchi, F. Porcine aminopeptidase $\mathrm{N}$ is not a cellular receptor of porcine epidemic diarrhea virus, but promotes its infectivity via aminopeptidase activity. J. Gen. Virol. 2016, 97, 2528-2539. [CrossRef]

80. Hansen, G.H.; Delmas, B.; Besnardeau, L.; Vogel, L.K.; Laude, H.; Sjostrom, H.; Noren, O. The coronavirus transmissible gastroenteritis virus causes infection after receptor-mediated endocytosis and acid-dependent fusion with an intracellular compartment. J. Virol. 1998, 72, 527-534. [CrossRef]

81. Hohdatsu, T.; Izumiya, Y.; Yokoyama, Y.; Kida, K.; Koyama, H. Differences in virus receptor for type I and type II feline infectious peritonitis virus. Arch. Virol. 1998, 143, 839-850. [CrossRef]

82. Regan, A.D.; Ousterout, D.G.; Whittaker, G.R. Feline lectin activity is critical for the cellular entry of feline infectious peritonitis virus. J. Virol. 2010, 84, 7917-7921. [CrossRef]

83. Wong, A.H.M.; Tomlinson, A.C.A.; Zhou, D.; Satkunarajah, M.; Chen, K.; Sharon, C.; Desforges, M.; Talbot, P.J.; Rini, J.M. Receptor-binding loops in alphacoronavirus adaptation and evolution. Nat. Commun. 2017, 8, 1735. [CrossRef]

84. Hofmann, H.; Pyrc, K.; van der Hoek, L.; Geier, M.; Berkhout, B.; Pohlmann, S. Human coronavirus NL63 employs the severe acute respiratory syndrome coronavirus receptor for cellular entry. Proc. Natl. Acad. Sci. USA 2005, 102, 7988-7993. [CrossRef] 
85. Lau, S.K.; Woo, P.C.; Li, K.S.; Tsang, A.K.; Fan, R.Y.; Luk, H.K.; Cai, J.P.; Chan, K.H.; Zheng, B.J.; Wang, M.; et al. Discovery of a novel coronavirus, China Rattus coronavirus HKU24, from Norway rats supports the murine origin of Betacoronavirus 1 and has implications for the ancestor of Betacoronavirus lineage A. J. Virol. 2015, 89, 3076-3092. [CrossRef]

86. Sriwilaijaroen, N.; Suzuki, Y. Sialoglycovirology of lectins: Sialyl glycan binding of enveloped and non-enveloped Viruses. Methods Mol. Biol. 2020, 2132, 483-545. [PubMed]

87. Bakkers, M.J.; Zeng, Q.; Feitsma, L.J.; Hulswit, R.J.; Li, Z.; Westerbeke, A.; van Kuppeveld, F.J.; Boons, G.J.; Langereis, M.A.; Huizinga, E.G.; et al. Coronavirus receptor switch explained from the stereochemistry of protein-carbohydrate interactions and a single mutation. Proc. Natl. Acad. Sci. USA 2016, 113, E3111-E3119. [CrossRef]

88. Peng, G.; Sun, D.; Rajashankar, K.R.; Qian, Z.; Holmes, K.V.; Li, F. Crystal structure of mouse coronavirus receptor-binding domain complexed with its murine receptor. Proc. Natl. Acad. Sci. USA 2011, 108, 10696-10701. [CrossRef]

89. Langereis, M.A.; Zeng, Q.; Heesters, B.A.; Huizinga, E.G.; de Groot, R.J. The murine coronavirus hemagglutinin-esterase receptor-binding site: A major shift in ligand specificity through modest changes in architecture. PLoS Pathog. 2012, 8, e1002492. [CrossRef]

90. Langereis, M.A.; Bakkers, M.J.; Deng, L.; Padler-Karavani, V.; Vervoort, S.J.; Hulswit, R.J.; van Vliet, A.L.; Gerwig, G.J.; de Poot, S.A.; Boot, W.; et al. Complexity and diversity of the mammalian sialome revealed by nidovirus virolectins. Cell Rep. 2015, 11, 1966-1978. [CrossRef]

91. Dong, B.; Gao, W.; Lu, H.; Zhao, K.; Ding, N.; Liu, W.; Zhao, J.; Lan, Y.; Tang, B.; Jin, Z.; et al. A small region of porcine hemagglutinating encephalomyelitis virus spike protein interacts with the neural cell adhesion molecule. Intervirology 2015, 58, 130-137. [CrossRef] [PubMed]

92. Hulswit, R.J.G.; Lang, Y.; Bakkers, M.J.G.; Li, W.; Li, Z.; Schouten, A.; Ophorst, B.; van Kuppeveld, F.J.M.; Boons, G.J.; Bosch, B.J.; et al. Human coronaviruses OC43 and HKU1 bind to 9-O-acetylated sialic acids via a conserved receptor-binding site in spike protein domain A. Proc. Natl. Acad. Sci. USA 2019, 116, 2681-2690. [CrossRef] [PubMed]

93. Krempl, C.; Schultze, B.; Herrler, G. Analysis of cellular receptors for human coronavirus OC43. Adv. Exp. Med. Biol. 1995, 380, 371-374. [PubMed]

94. Bakkers, M.J.; Lang, Y.; Feitsma, L.J.; Hulswit, R.J.; de Poot, S.A.; van Vliet, A.L.; Margine, I.; de Groot-Mijnes, J.D.; van Kuppeveld, F.J.; Langereis, M.A.; et al. Betacoronavirus adaptation to humans involved progressive loss of hemagglutinin-esterase lectin activity. Cell Host Microbe 2017, 21, 356-366. [CrossRef] [PubMed]

95. Lau, S.K.; Woo, P.C.; Li, K.S.; Huang, Y.; Tsoi, H.W.; Wong, B.H.; Wong, S.S.; Leung, S.Y.; Chan, K.H.; Yuen, K.Y. Severe acute respiratory syndrome coronavirus-like virus in Chinese horseshoe bats. Proc. Natl. Acad. Sci. USA 2005, 102, 14040-14045. [CrossRef]

96. Bolles, M.; Donaldson, E.; Baric, R. SARS-CoV and emergent coronaviruses: Viral determinants of interspecies transmission. Curr. Opin. Virol. 2011, 1, 624-634. [CrossRef]

97. Jaimes, J.A.; André, N.M.; Chappie, J.S.; Millet, J.K.; Whittaker, G.R. Phylogenetic analysis and structural modeling of SARS-CoV-2 spike protein reveals an evolutionary distinct and proteolytically sensitive activation loop. J. Mol. Biol. 2020, 432, 3309-3325. [CrossRef]

98. Li, F. Structure, function, and evolution of coronavirus spike proteins. Annu. Rev. Virol. 2016, 3, $237-261$. [CrossRef]

99. Shi, Z.; Hu, Z. A review of studies on animal reservoirs of the SARS coronavirus. Virus Res. 2008, 133, 74-87. [CrossRef]

100. Kan, B.; Wang, M.; Jing, H.; Xu, H.; Jiang, X.; Yan, M.; Liang, W.; Zheng, H.; Wan, K.; Liu, Q.; et al. Molecular evolution analysis and geographic investigation of severe acute respiratory syndrome coronavirus-like virus in palm civets at an animal market and on farms. J. Virol. 2005, 79, 11892-11900. [CrossRef]

101. Tiwari, R.; Dhama, K.; Sharun, K.; Iqbal Yatoo, M.; Malik, Y.S.; Singh, R.; Michalak, I.; Sah, R.; Bonilla-Aldana, D.K.; Rodriguez-Morales, A.J. COVID-19: Animals, veterinary and zoonotic links. Vet. Q. 2020, 40, 169-182. [CrossRef] [PubMed]

102. Halfmann, P.J.; Hatta, M.; Chiba, S.; Maemura, T.; Fan, S.; Takeda, M.; Kinoshita, N.; Hattori, S.I.; Sakai-Tagawa, Y.; Iwatsuki-Horimoto, K.; et al. Transmission of SARS-CoV-2 in domestic cats. N. Engl. J. Med. 2020, 383, 592-594. [CrossRef] [PubMed] 
103. Xiao, K.; Zhai, J.; Feng, Y.; Zhou, N.; Zhang, X.; Zou, J.J.; Li, N.; Guo, Y.; Li, X.; Shen, X.; et al. Isolation of SARS-CoV-2-related coronavirus from Malayan pangolins. Nature 2020, 583, 286-289. [CrossRef] [PubMed]

104. Graham, R.L.; Donaldson, E.F.; Baric, R.S. A decade after SARS: Strategies for controlling emerging coronaviruses. Nat. Rev. Microbiol. 2013, 11, 836-848. [CrossRef] [PubMed]

105. Glowacka, I.; Bertram, S.; Pöhlmann, S. Cellular entry of the SARS coronavirus: Implications for transmission, pathogenicity and antiviral strategies. In Molecular Biology of the SARS-Coronavirus; Lal, S.K., Ed.; Springer: Berlin/Heidelberg, Germany, 2010; pp. 3-22. [CrossRef]

106. Chan, J.F.; Lau, S.K.; To, K.K.; Cheng, V.C.; Woo, P.C.; Yuen, K.Y. Middle East respiratory syndrome coronavirus: Another zoonotic betacoronavirus causing SARS-like disease. Clin. Microbiol. Rev. 2015, 28, 465-522. [CrossRef]

107. Lau, S.K.P.; Zhang, L.; Luk, H.K.H.; Xiong, L.; Peng, X.; Li, K.S.M.; He, X.; Zhao, P.S.; Fan, R.Y.Y.; Wong, A.C.P.; et al. Receptor usage of a novel bat lineage $\mathrm{C}$ betacoronavirus reveals evolution of Middle East respiratory syndrome-related coronavirus spike proteins for human dipeptidyl peptidase 4 binding. J. Infect. Dis. 2018, 218, 197-207. [CrossRef]

108. Widagdo, W.; Okba, N.M.A.; Li, W.; de Jong, A.; de Swart, R.L.; Begeman, L.; van den Brand, J.M.A.; Bosch, B.-J.; Haagmans, B.L. Species-specific colocalization of Middle East respiratory syndrome coronavirus attachment and entry receptors. J. Virol. 2019, 93, e00107-e00119. [CrossRef]

109. Adney, D.; Bielefeldt-Ohmann, H.; Hartwig, A.; Bowen, R. Infection, replication, and transmission of Middle East respiratory syndrome coronavirus in Alpacas. Emerg. Infect. Dis. 2016, 22, 1031. [CrossRef]

110. Khalafalla, A.; Lu, X.; Al-Mubarak, A.I.A.; Dalab, A.H.; Al-Busadah, K.A.S.; Erdman, D. MERS-CoV in upper respiratory tract and lungs of dromedary camels, Saudi Arabia, 2013-2014. Emerg. Infect. Dis. 2015, 21, 1153. [CrossRef]

111. Alnaeem, A.; Kasem, S.; Qasim, I.; Al-Doweriej, A.; Refaat, M.; Al-Shabebi, A.; Hemida, M.G. The dipeptidyl peptidase-4 expression in some MERS-CoV naturally infected dromedary camels in Saudi Arabia 2018-2019. VirusDis. 2020, 31, 200-203. [CrossRef]

112. Li, W.; Hulswit, R.J.G.; Widjaja, I.; Raj, V.S.; McBride, R.; Peng, W.; Widagdo, W.; Tortorici, M.A.; van Dieren, B.; Lang, Y.; et al. Identification of sialic acid-binding function for the Middle East respiratory syndrome coronavirus spike glycoprotein. Proc. Natl. Acad. Sci. USA 2017, 114, E8508-E8517. [CrossRef] [PubMed]

113. Qing, E.; Hantak, M.; Perlman, S.; Gallagher, T. Distinct roles for sialoside and protein receptors in coronavirus infection. MBio 2020, 11. [CrossRef] [PubMed]

114. Ambepitiya Wickramasinghe, I.N.; de Vries, R.P.; Weerts, E.A.; van Beurden, S.J.; Peng, W.; McBride, R.; Ducatez, M.; Guy, J.; Brown, P.; Eterradossi, N.; et al. Novel receptor specificity of avian gammacoronaviruses that cause enteritis. J. Virol. 2015, 89, 8783-8792. [CrossRef] [PubMed]

115. Madu, I.G.; Chu, V.C.; Lee, H.; Regan, A.D.; Bauman, B.E.; Whittaker, G.R. Heparan sulfate is a selective attachment factor for the avian coronavirus infectious bronchitis virus beaudette. Avian Dis. 2007, 51, 45-51, 47. [CrossRef]

116. Lau, S.K.P.; Wong, E.Y.M.; Tsang, C.C.; Ahmed, S.S.; Au-Yeung, R.K.H.; Yuen, K.Y.; Wernery, U.; Woo, P.C.Y. Discovery and sequence analysis of four deltacoronaviruses from birds in the Middle East reveal interspecies jumping with recombination as a potential mechanism for avian-to-avian and avian-to-mammalian transmission. J. Virol. 2018, 92, e00265-18. [CrossRef]

117. International Committee on Taxonomy of Viruses (ICTV). Available online: https:/talk.ictvonline.org/ (accessed on 27 September 2020).

118. Coronaviridae. Fenner's Veterinary Virology (Fifth Edition); MacLachlan, N.J., Dubovi, E.J., Eds.; Academic Press: Boston, MA, USA, 2017; pp. 435-461.

119. Tong, S.; Li, Y.; Rivailler, P.; Conrardy, C.; Castillo, D.A.; Chen, L.M.; Recuenco, S.; Ellison, J.A.; Davis, C.T.; York, I.A.; et al. A distinct lineage of influenza A virus from bats. Proc. Natl. Acad. Sci. USA 2012, 109, 4269-4274. [CrossRef]

120. Tong, S.; Zhu, X.; Li, Y.; Shi, M.; Zhang, J.; Bourgeois, M.; Yang, H.; Chen, X.; Recuenco, S.; Gomez, J.; et al. New world bats harbor diverse influenza A viruses. PLoS Pathog. 2013, 9, e1003657. [CrossRef]

121. Ito, T.; Suzuki, Y.; Suzuki, T.; Takada, A.; Horimoto, T.; Wells, K.; Kida, H.; Otsuki, K.; Kiso, M.; Ishida, H.; et al. Recognition of $N$-glycolylneuraminic acid linked to galactose by the $\alpha 2,3$ linkage is associated with intestinal replication of influenza A virus in ducks. J. Virol. 2000, 74, 9300-9305. [CrossRef] 
122. Hiono, T.; Okamatsu, M.; Nishihara, S.; Takase-Yoden, S.; Sakoda, Y.; Kida, H. A chicken influenza virus recognizes fucosylated a2,3 sialoglycan receptors on the epithelial cells lining upper respiratory tracts of chickens. Virology 2014, 456-457, 131-138. [CrossRef]

123. Venkatesh, D.; Poen, M.J.; Bestebroer, T.M.; Scheuer, R.D.; Vuong, O.; Chkhaidze, M.; Machablishvili, A.; Mamuchadze, J.; Ninua, L.; Fedorova, N.B.; et al. Avian influenza viruses in wild birds: Virus evolution in a multihost ecosystem. J. Virol. 2018, 92, e00433-18. [CrossRef]

124. Smits, S.L.; Gerwig, G.J.; van Vliet, A.L.; Lissenberg, A.; Briza, P.; Kamerling, J.P.; Vlasak, R.; de Groot, R.J. Nidovirus sialate-O-acetylesterases: Evolution and substrate specificity of coronaviral and toroviral receptor-destroying enzymes. J. Biol. Chem. 2005, 280, 6933-6941. [CrossRef] [PubMed]

125. Pfefferle, S.; Oppong, S.; Drexler, J.F.; Gloza-Rausch, F.; Ipsen, A.; Seebens, A.; Muller, M.A.; Annan, A.; Vallo, P.; Adu-Sarkodie, Y.; et al. Distant relatives of severe acute respiratory syndrome coronavirus and close relatives of human coronavirus 229E in bats, Ghana. Emerg. Infect. Dis. 2009, 15, 1377-1384. [CrossRef] [PubMed]

126. Corman, V.M.; Baldwin, H.J.; Tateno, A.F.; Zerbinati, R.M.; Annan, A.; Owusu, M.; Nkrumah, E.E.; Maganga, G.D.; Oppong, S.; Adu-Sarkodie, Y.; et al. Evidence for an ancestral association of human coronavirus 229E with bats. J. Virol. 2015, 89, 11858-11870. [CrossRef] [PubMed]

127. Tao, Y.; Shi, M.; Chommanard, C.; Queen, K.; Zhang, J.; Markotter, W.; Kuzmin, I.V.; Holmes, E.C.; Tong, S. Surveillance of bat coronaviruses in Kenya identifies relatives of human coronaviruses NL63 and 229E and their recombination history. J. Virol. 2017, 91, e01953-16. [CrossRef] [PubMed]

128. Hu, B.; Zeng, L.P.; Yang, X.L.; Ge, X.Y.; Zhang, W.; Li, B.; Xie, J.Z.; Shen, X.R.; Zhang, Y.Z.; Wang, N.; et al. Discovery of a rich gene pool of bat SARS-related coronaviruses provides new insights into the origin of SARS coronavirus. PLoS Pathog. 2017, 13, e1006698. [CrossRef] [PubMed]

129. Lau, S.K.P.; Feng, Y.; Chen, H.; Luk, H.K.H.; Yang, W.H.; Li, K.S.M.; Zhang, Y.Z.; Huang, Y.; Song, Z.Z.; Chow, W.-N.; et al. Severe acute respiratory syndrome (SARS) coronavirus ORF8 protein Is acquired from SARS-related coronavirus from greater horseshoe bats through recombination. J. Virol. 2015, 89, 10532-10547. [CrossRef]

130. Hon, C.C.; Lam, T.Y.; Shi, Z.L.; Drummond, A.J.; Yip, C.W.; Zeng, F.; Lam, P.Y.; Leung, F.C. Evidence of the recombinant origin of a bat severe acute respiratory syndrome (SARS)-like coronavirus and its implications on the direct ancestor of SARS coronavirus. J. Virol. 2008, 82, 1819-1826. [CrossRef]

131. Lau, S.K.P.; Li, K.S.M.; Tsang, A.K.L.; Lam, C.S.F.; Ahmed, S.; Chen, H.; Chan, K.-H.; Woo, P.C.Y.; Yuen, K.-Y. Genetic characterization of betacoronavirus lineage $C$ viruses in bats reveals marked sequence divergence in the spike protein of Pipistrellus bat coronavirus HKU5 in Japanese pipistrelle: Implications for the origin of the novel Middle East respiratory syndrome coronavirus. J. Virol. 2013, 87, 8638-8650. [PubMed]

132. Zhou, P.; Yang, X.L.; Wang, X.-G.; Hu, B.; Zhang, L.; Zhang, W.; Si, H.R.; Zhu, Y.; Li, B.; Huang, C.L.; et al. A pneumonia outbreak associated with a new coronavirus of probable bat origin. Nature 2020, 579, 270-273. [CrossRef]

133. Zhou, H.; Chen, X.; Hu, T.; Li, J.; Song, H.; Liu, Y.; Wang, P.; Liu, D.; Yang, J.; Holmes, E.C.; et al. A novel bat coronavirus closely related to SARS-CoV-2 contains natural insertions at the S1/S2 cleavage site of the spike protein. Curr. Biol. 2020, 30, 2196-2203. [CrossRef]

134. Braakman, I.; Hoover-Litty, H.; Wagner, K.R.; Helenius, A. Folding of influenza hemagglutinin in the endoplasmic reticulum. J. Cell. Biol. 1991, 114, 401-411. [CrossRef] [PubMed]

135. Steinhauer, D.A. Role of hemagglutinin cleavage for the pathogenicity of influenza virus. Virology 1999, 258, 1-20. [CrossRef] [PubMed]

136. Kido, H.; Okumura, Y.; Takahashi, E.; Pan, H.Y.; Wang, S.; Chida, J.; Le, T.Q.; Yano, M. Host envelope glycoprotein processing proteases are indispensable for entry into human cells by seasonal and highly pathogenic avian influenza viruses. J. Mol. Genet. Med. 2008, 3, 167-175. [CrossRef] [PubMed]

137. Armstrong, R.T.; Kushnir, A.S.; White, J.M. The transmembrane domain of influenza hemagglutinin exhibits a stringent length requirement to support the hemifusion to fusion transition. J. Cell Biol. 2000, 151, 425-437. [CrossRef]

138. Ohuchi, M.; Fischer, C.; Ohuchi, R.; Herwig, A.; Klenk, H.D. Elongation of the cytoplasmic tail interferes with the fusion activity of influenza virus hemagglutinin. J. Virol. 1998, 72, 3554-3559. [CrossRef]

139. Xu, R.; McBride, R.; Nycholat, C.M.; Paulson, J.C.; Wilson, I.A. Structural characterization of the hemagglutinin receptor specificity from the $2009 \mathrm{H} 1 \mathrm{~N} 1$ influenza pandemic. J. Virol. 2012, 86, 982-990. [CrossRef] 
140. Neuman, B.W.; Kiss, G.; Kunding, A.H.; Bhella, D.; Baksh, M.F.; Connelly, S.; Droese, B.; Klaus, J.P.; Makino, S.; Sawicki, S.G.; et al. A structural analysis of M protein in coronavirus assembly and morphology. J. Struct. Biol. 2011, 174, 11-22. [CrossRef]

141. Schoeman, D.; Fielding, B.C. Coronavirus envelope protein: Current knowledge. Virol. J. 2019, 16, 69. [CrossRef]

142. Gallagher, T.M.; Buchmeier, M.J. Coronavirus spike proteins in viral entry and pathogenesis. Virology 2001, 279, 371-374. [CrossRef]

143. Ou, X.; Liu, Y.; Lei, X.; Li, P.; Mi, D.; Ren, L.; Guo, L.; Guo, R.; Chen, T.; Hu, J.; et al. Characterization of spike glycoprotein of SARS-CoV-2 on virus entry and its immune cross-reactivity with SARS-CoV. Nat. Commun. 2020, 11, 1620. [CrossRef]

144. Zeng, Q.; Langereis, M.A.; van Vliet, A.L.; Huizinga, E.G.; de Groot, R.J. Structure of coronavirus hemagglutinin-esterase offers insight into corona and influenza virus evolution. Proc. Natl. Acad. Sci. USA 2008, 105, 9065-9069. [CrossRef] [PubMed]

145. Rota, P.A.; Oberste, M.S.; Monroe, S.S.; Nix, W.A.; Campagnoli, R.; Icenogle, J.P.; Peñaranda, S.; Bankamp, B.; Maher, K.; Chen, M.-H.; et al. Characterization of a novel coronavirus associated with severe acute respiratory syndrome. Science 2003, 300, 1394-1399. [CrossRef] [PubMed]

146. Coutard, B.; Valle, C.; de Lamballerie, X.; Canard, B.; Seidah, N.G.; Decroly, E. The spike glycoprotein of the new coronavirus 2019-nCoV contains a furin-like cleavage site absent in $\mathrm{CoV}$ of the same clade. Antivir. Res. 2020, 176, 104742. [CrossRef]

147. Bosch, B.J.; van der Zee, R.; de Haan, C.A.; Rottier, P.J. The coronavirus spike protein is a class I virus fusion protein: Structural and functional characterization of the fusion core complex. J. Virol. 2003, 77, 8801-8811. [CrossRef]

148. Park, Y.J.; Walls, A.C.; Wang, Z.; Sauer, M.M.; Li, W.; Tortorici, M.A.; Bosch, B.J.; DiMaio, F.; Veesler, D. Structures of MERS-CoV spike glycoprotein in complex with sialoside attachment receptors. Nat. Struct. Mol. Biol. 2019, 26, 1151-1157. [CrossRef] [PubMed]

149. Ha, Y.; Stevens, D.J.; Skehel, J.J.; Wiley, D.C. X-ray structure of the hemagglutinin of a potential H3 avian progenitor of the 1968 Hong Kong pandemic influenza virus. Virology 2003, 309, 209-218. [CrossRef]

150. Wu, N.C.; Otwinowski, J.; Thompson, A.J.; Nycholat, C.M.; Nourmohammad, A.; Wilson, I.A. Major antigenic site B of human influenza H3N2 viruses has an evolving local fitness landscape. Nat. Commun. 2020, 11, 1233. [CrossRef]

151. Wu, N.C.; Zost, S.J.; Thompson, A.J.; Oyen, D.; Nycholat, C.M.; McBride, R.; Paulson, J.C.; Hensley, S.E.; Wilson, I.A. A structural explanation for the low effectiveness of the seasonal influenza H3N2 vaccine. PLoS Pathog. 2017, 13, e1006682. [CrossRef]

152. Wu, N.C.; Thompson, A.J.; Xie, J.; Lin, C.W.; Nycholat, C.M.; Zhu, X.; Lerner, R.A.; Paulson, J.C.; Wilson, I.A. A complex epistatic network limits the mutational reversibility in the influenza hemagglutinin receptor-binding site. Nat. Commun. 2018, 9, 1264. [CrossRef]

153. Clustal Omega. Available online: https://www.ebi.ac.uk/Tools/msa/clustalo/ (accessed on 27 September 2020).

154. WHO. WHO Pandemic Phase Descriptions and Main Actions by Phase. Available online: https://www.who.int/ influenza/resources/documents/pandemic_phase_descriptions_and_actions.pdf (accessed on 1 September 2020).

155. Reid, A.H.; Janczewski, T.A.; Lourens, R.M.; Elliot, A.J.; Daniels, R.S.; Berry, C.L.; Oxford, J.S.; Taubenberger, J.K. 1918 influenza pandemic caused by highly conserved viruses with two receptor-binding variants. Emerg. Infect. Dis. 2003, 9, 1249-1253. [CrossRef]

156. Xu, R.; McBride, R.; Paulson, J.C.; Basler, C.F.; Wilson, I.A. Structure, receptor binding, and antigenicity of influenza virus hemagglutinins from the $1957 \mathrm{H} 2 \mathrm{~N} 2$ pandemic. J. Virol. 2010, 84, 1715-1721. [CrossRef] [PubMed]

157. Van Poucke, S.; Doedt, J.; Baumann, J.; Qiu, Y.; Matrosovich, T.; Klenk, H.D.; Van Reeth, K.; Matrosovich, M. Role of substitutions in the hemagglutinin in the emergence of the 1968 pandemic influenza virus. J. Virol. 2015, 89, 12211-12216. [CrossRef] [PubMed]

158. de Vries, R.P.; de Vries, E.; Moore, K.S.; Rigter, A.; Rottier, P.J.; de Haan, C.A. Only two residues are responsible for the dramatic difference in receptor binding between swine and new pandemic H1 hemagglutinin. J. Biol. Chem. 2011, 286, 5868-5875. [CrossRef] [PubMed]

159. Taubenberger, J.K. The origin and virulence of the 1918 "Spanish" influenza virus. Proc. Am. Philos. Soc. 2006, 150, 86-112. [PubMed] 
160. Lin, Y.P.; Xiong, X.; Wharton, S.A.; Martin, S.R.; Coombs, P.J.; Vachieri, S.G.; Christodoulou, E.; Walker, P.A.; Liu, J.; Skehel, J.J.; et al. Evolution of the receptor binding properties of the influenza A(H3N2) hemagglutinin. Proc. Natl. Acad. Sci. USA 2012, 109, 21474-21479. [CrossRef] [PubMed]

161. Chandrasekaran, A.; Srinivasan, A.; Raman, R.; Viswanathan, K.; Raguram, S.; Tumpey, T.M.; Sasisekharan, V.; Sasisekharan, R. Glycan topology determines human adaptation of avian H5N1 virus hemagglutinin. Nat. Biotechnol. 2008, 26, 107-113. [CrossRef] [PubMed]

162. Peng, W.; de Vries, R.P.; Grant, O.C.; Thompson, A.J.; McBride, R.; Tsogtbaatar, B.; Lee, P.S.; Razi, N.; Wilson, I.A.; Woods, R.J.; et al. Recent H3N2 viruses have evolved specificity for extended, branched human-type receptors, conferring potential for increased avidity. Cell Host Microbe 2017, 21, 23-34. [CrossRef] [PubMed]

163. Tharakaraman, K.; Jayaraman, A.; Raman, R.; Viswanathan, K.; Stebbins, N.W.; Johnson, D.; Shriver, Z.; Sasisekharan, V.; Sasisekharan, R. Glycan receptor binding of the influenza A virus H7N9 hemagglutinin. Cell 2013, 153, 1486-1493. [CrossRef]

164. Uiprasertkul, M.; Puthavathana, P.; Sangsiriwut, K.; Pooruk, P.; Srisook, K.; Peiris, M.; Nicholls, J.M.; Chokephaibulkit, K.; Vanprapar, N.; Auewarakul, P. Influenza A H5N1 replication sites in humans. Emerg. Infect. Dis. 2005, 11, 1036-1041. [CrossRef]

165. Shieh, W.J.; Blau, D.M.; Denison, A.M.; Deleon-Carnes, M.; Adem, P.; Bhatnagar, J.; Sumner, J.; Liu, L.; Patel, M.; Batten, B.; et al. 2009 pandemic influenza A (H1N1): Pathology and pathogenesis of 100 fatal cases in the United States. Am. J. Pathol. 2010, 177, 166-175. [CrossRef]

166. Jia, N.; Byrd-Leotis, L.; Matsumoto, Y.; Gao, C.; Wein, A.N.; Lobby, J.L.; Kohlmeier, J.E.; Steinhauer, D.A.; Cummings, R.D. The human lung glycome reveals novel glycan ligands for influenza A virus. Sci. Rep. 2020, 10, 5320. [CrossRef] [PubMed]

167. Walther, T.; Karamanska, R.; Chan, R.W.; Chan, M.C.; Jia, N.; Air, G.; Hopton, C.; Wong, M.P.; Dell, A.; Malik Peiris, J.S.; et al. Glycomic analysis of human respiratory tract tissues and correlation with influenza virus infection. PLoS Pathog. 2013, 9, e1003223. [CrossRef] [PubMed]

168. WHO. Clinical Management of Human Infection with Pandemic (H1N1) 2009: Revised Guidance. Available online: https://www.who.int/csr/resources/publications/swineflu/clinical_management_h1n1.pdf (accessed on 1 September 2020).

169. Kuiken, T.; Taubenberger, J.K. Pathology of human influenza revisited. Vaccine 2008, 26 (Suppl. S4), 59-66. [CrossRef]

170. Rota, P.A.; Wallis, T.R.; Harmon, M.W.; Rota, J.S.; Kendal, A.P.; Nerome, K. Cocirculation of two distinct evolutionary lineages of influenza type B virus since 1983. Virology 1990, 175, 59-68. [CrossRef]

171. WHO. Summary of Neuraminidase Amino acid Substitutions Associated with Reduced Inhibition by Neuraminidase Inhibitors. Available online: https://www.who.int/influenza/gisrs_laboratory/antiviral_ susceptibility/NAI_Reduced_Susceptibility_Marker_Table_WHO.pdf?ua=1 (accessed on 1 September 2020).

172. Magesh, S.; Sriwilaijaroen, N.; Moriya, S.; Ando, H.; Miyagi, T.; Suzuki, Y.; Ishida, H.; Kiso, M. Evaluation of a set of C9 $\mathrm{N}$-acyl Neu5Ac2en mimetics as viral sialidase selective inhibitors. Int. J. Med. Chem. 2011, 2011, 539245.

173. Sriwilaijaroen, N.; Magesh, S.; Imamura, A.; Ando, H.; Ishida, H.; Sakai, M.; Ishitsubo, E.; Hori, T.; Moriya, S.; Ishikawa, T.; et al. A novel potent and highly specific inhibitor against influenza viral N1-N9 neuraminidases: Insight into neuraminidase-inhibitor interactions. J. Med. Chem. 2016, 59, 4563-4577. [CrossRef]

174. Vavricka, C.J.; Liu, Y.; Kiyota, H.; Sriwilaijaroen, N.; Qi, J.; Tanaka, K.; Wu, Y.; Li, Q.; Li, Y.; Yan, J.; et al. Influenza neuraminidase operates via a nucleophilic mechanism and can be targeted by covalent inhibitors. Nat. Commun. 2013, 4, 1491. [CrossRef]

175. Sriwilaijaroen, N.; Fukumoto, S.; Kumagai, K.; Hiramatsu, H.; Odagiri, T.; Tashiro, M.; Suzuki, Y. Antiviral effects of Psidium guajava Linn. (guava) tea on the growth of clinical isolated H1N1 viruses: Its role in viral hemagglutination and neuraminidase inhibition. Antivir. Res. 2012, 94, 139-146. [CrossRef]

176. Sriwilaijaroen, N.; Wilairat, P.; Hiramatsu, H.; Takahashi, T.; Suzuki, T.; Ito, M.; Ito, Y.; Tashiro, M.; Suzuki, Y. Mechanisms of the action of povidone-iodine against human and avian influenza A viruses: Its effects on hemagglutination and sialidase activities. Virol. J. 2009, 6, 124. [CrossRef]

177. Taylor, R.M. Studies on survival of influenza virus between epidemics and antigenic variants of the virus. Am. J. Public Health Nations Health 1949, 39, 171-178. [CrossRef] 
178. Matsuzaki, Y.; Abiko, C.; Mizuta, K.; Sugawara, K.; Takashita, E.; Muraki, Y.; Suzuki, H.; Mikawa, M.; Shimada, S.; Sato, K.; et al. A nationwide epidemic of influenza C virus infection in Japan in 2004. J. Clin. Microbiol. 2007, 45, 783-788. [CrossRef] [PubMed]

179. Homma, M.; Ohyama, S.; Katagiri, S. Age distribution of the antibody to type C influenza virus. Microbiol. Immunol. 1982, 26, 639-642. [CrossRef] [PubMed]

180. Herrler, G.; Durkop, I.; Becht, H.; Klenk, H.D. The glycoprotein of influenza C virus is the haemagglutinin, esterase and fusion factor. J. Gen. Virol. 1988, 69 Pt 4, 839-846. [CrossRef]

181. Wang, M.; Veit, M. Hemagglutinin-esterase-fusion (HEF) protein of influenza C virus. Protein Cell 2016, 7, 28-45. [CrossRef] [PubMed]

182. Herrler, G.; Rott, R.; Klenk, H.D.; Muller, H.P.; Shukla, A.K.; Schauer, R. The receptor-destroying enzyme of influenza $C$ virus is neuraminate-O-acetylesterase. EMBO J. 1985, 4, 1503-1506. [CrossRef]

183. Hause, B.M.; Ducatez, M.; Collin, E.A.; Ran, Z.; Liu, R.; Sheng, Z.; Armien, A.; Kaplan, B.; Chakravarty, S.; Hoppe, A.D.; et al. Isolation of a novel swine influenza virus from Oklahoma in 2011 which is distantly related to human influenza C viruses. PLoS Pathog. 2013, 9, e1003176. [CrossRef]

184. Song, H.; Qi, J.; Khedri, Z.; Diaz, S.; Yu, H.; Chen, X.; Varki, A.; Shi, Y.; Gao, G.F. Correction: An open receptor-binding cavity of hemagglutinin-esterase-fusion glycoprotein from newly-identified influenza D virus: Basis for its broad cell tropism. PLoS Pathog. 2016, 12, e1005505. [CrossRef]

185. Bardor, M.; Nguyen, D.H.; Diaz, S.; Varki, A. Mechanism of uptake and incorporation of the non-human sialic acid N-glycolylneuraminic acid into human cells. J. Biol. Chem. 2005, 280, 4228-4237. [CrossRef]

186. McIntosh, K.; Becker, W.B.; Chanock, R.M. Growth in suckling-mouse brain of "IBV-like" viruses from patients with upper respiratory tract disease. Proc. Natl. Acad. Sci. USA 1967, 58, 2268-2273. [CrossRef]

187. St-Jean, J.R.; Jacomy, H.; Desforges, M.; Vabret, A.; Freymuth, F.; Talbot, P.J. Human respiratory coronavirus OC43: Genetic stability and neuroinvasion. J. Virol. 2004, 78, 8824-8834. [CrossRef]

188. Woo, P.C.; Lau, S.K.; Chu, C.M.; Chan, K.H.; Tsoi, H.W.; Huang, Y.; Wong, B.H.; Poon, R.W.; Cai, J.J.; Luk, W.K.; et al. Characterization and complete genome sequence of a novel coronavirus, coronavirus HKU1, from patients with pneumonia. J. Virol. 2005, 79, 884-895. [CrossRef]

189. Decaro, N.; Lorusso, A. Novel human coronavirus (SARS-CoV-2): A lesson from animal coronaviruses. Vet. Microbiol. 2020, 244, 108693. [CrossRef] [PubMed]

190. Vlasak, R.; Luytjes, W.; Spaan, W.; Palese, P. Human and bovine coronaviruses recognize sialic acid-containing receptors similar to those of influenza C viruses. Proc. Natl. Acad. Sci. USA 1988, 85, 4526-4529. [CrossRef] [PubMed]

191. Huang, X.; Dong, W.; Milewska, A.; Golda, A.; Qi, Y.; Zhu, Q.K.; Marasco, W.A.; Baric, R.S.; Sims, A.C.; Pyrc, K.; et al. Human coronavirus HKU1 spike protein uses $O$-acetylated sialic acid as an attachment receptor determinant and employs hemagglutinin-esterase protein as a receptor-destroying enzyme. J. Virol. 2015, 89, 7202-7213. [CrossRef] [PubMed]

192. Suzuki, Y.; Nagao, Y.; Kato, H.; Matsumoto, M.; Nerome, K.; Nakajima, K.; Nobusawa, E. Human influenza A virus hemagglutinin distinguishes sialyloligosaccharides in membrane-associated gangliosides as its receptor which mediates the adsorption and fusion processes of virus infection. Specificity for oligosaccharides and sialic acids and the sequence to which sialic acid is attached. J. Biol. Chem. 1986, 261, 17057-17061. [PubMed]

193. Tortorici, M.A.; Walls, A.C.; Lang, Y.; Wang, C.; Li, Z.; Koerhuis, D.; Boons, G.J.; Bosch, B.J.; Rey, F.A.; de Groot, R.J.; et al. Structural basis for human coronavirus attachment to sialic acid receptors. Nat. Struct. Mol. Biol. 2019, 26, 481-489. [CrossRef]

194. Li, Z.; Tomlinson, A.C.; Wong, A.H.; Zhou, D.; Desforges, M.; Talbot, P.J.; Benlekbir, S.; Rubinstein, J.L.; Rini, J.M. The human coronavirus HCoV-229E S-protein structure and receptor binding. Elife 2019, 8, e51230. [CrossRef]

195. Yan, R.; Zhang, Y.; Li, Y.; Xia, L.; Guo, Y.; Zhou, Q. Structural basis for the recognition of SARS-CoV-2 by full-length human ACE2. Science 2020, 367, 1444-1448. [CrossRef]

196. Oefner, C.; D’Arcy, A.; Mac Sweeney, A.; Pierau, S.; Gardiner, R.; Dale, G.E. High-resolution structure of human apo dipeptidyl peptidase IV/CD26 and its complex with 1-[(\{2-[(5-iodopyridin-2-yl)amino]-ethyl\}amino)-acetyl]-2-cyano-(S)-pyrrolidine. Acta Cryst. 2003, D59, 1206-1212. [CrossRef] 
197. Kirchdoerfer, R.N.; Cottrell, C.A.; Wang, N.; Pallesen, J.; Yassine, H.M.; Turner, H.L.; Corbett, K.S.; Graham, B.S.; McLellan, J.S.; Ward, A.B. Pre-fusion structure of a human coronavirus spike protein. Nature 2016, 531, 118-121. [CrossRef]

198. Wu, Y.; Wu, Y.; Tefsen, B.; Shi, Y.; Gao, G.F. Bat-derived influenza-like viruses H17N10 and H18N11. Trends Microbiol. 2014, 22, 183-191. [CrossRef] [PubMed]

199. Ciminski, K.; Ran, W.; Gorka, M.; Lee, J.; Malmlov, A.; Schinkothe, J.; Eckley, M.; Murrieta, R.A.; Aboellail, T.A.; Campbell, C.L.; et al. Bat influenza viruses transmit among bats but are poorly adapted to non-bat species. Nat. Microbiol. 2019, 4, 2298-2309. [CrossRef] [PubMed]

200. Tyrrell, D.A.; Bynoe, M.L. Cultivation of a novel type of common-cold virus in organ cultures. Br. Med. J. 1965, 1, 1467-1470. [CrossRef] [PubMed]

201. Hamre, D.; Procknow, J.J. A new virus isolated from the human respiratory tract. Proc. Soc. Exp. Biol. Med. 1966, 121, 190-193. [CrossRef] [PubMed]

202. Corman, V.M.; Eckerle, I.; Memish, Z.A.; Liljander, A.M.; Dijkman, R.; Jonsdottir, H.; Juma Ngeiywa, K.J.; Kamau, E.; Younan, M.; Al Masri, M.; et al. Link of a ubiquitous human coronavirus to dromedary camels. Proc. Natl. Acad. Sci. USA 2016, 113, 9864-9869. [CrossRef] [PubMed]

203. Wentworth, D.E.; Holmes, K.V. Molecular determinants of species specificity in the coronavirus receptor aminopeptidase N (CD13): Influence of N-linked glycosylation. J. Virol. 2001, 75, 9741-9752. [CrossRef] [PubMed]

204. Walls, A.C.; Tortorici, M.A.; Frenz, B.; Snijder, J.; Li, W.; Rey, F.A.; DiMaio, F.; Bosch, B.J.; Veesler, D. Glycan shield and epitope masking of a coronavirus spike protein observed by cryo-electron microscopy. Nat. Struct. Mol. Biol. 2016, 23, 899-905. [CrossRef]

205. Yuan, Y.; Cao, D.; Zhang, Y.; Ma, J.; Qi, J.; Wang, Q.; Lu, G.; Wu, Y.; Yan, J.; Shi, Y.; et al. Cryo-EM structures of MERS-CoV and SARS-CoV spike glycoproteins reveal the dynamic receptor binding domains. Nat. Commun. 2017, 8, 15092. [CrossRef]

206. Corti, D.; Lanzavecchia, A. Broadly neutralizing antiviral antibodies. Annu. Rev. Immunol. 2013, 31, 705-742. [CrossRef]

207. van der Hoek, L.; Pyrc, K.; Jebbink, M.F.; Vermeulen-Oost, W.; Berkhout, R.J.; Wolthers, K.C.; Wertheim-van Dillen, P.M.; Kaandorp, J.; Spaargaren, J.; Berkhout, B. Identification of a new human coronavirus. Nat. Med. 2004, 10, 368-373. [CrossRef]

208. Esper, F.; Weibel, C.; Ferguson, D.; Landry, M.L.; Kahn, J.S. Evidence of a novel human coronavirus that is associated with respiratory tract disease in infants and young children. J. Infect. Dis. 2005, 191, 492-498. [CrossRef] [PubMed]

209. Donaldson, E.F.; Haskew, A.N.; Gates, J.E.; Huynh, J.; Moore, C.J.; Frieman, M.B. Metagenomic analysis of the viromes of three North American bat species: Viral diversity among different bat species that share a common habitat. J. Virol. 2010, 84, 13004-13018. [CrossRef] [PubMed]

210. Huynh, J.; Li, S.; Yount, B.; Smith, A.; Sturges, L.; Olsen, J.C.; Nagel, J.; Johnson, J.B.; Agnihothram, S.; Gates, J.E.; et al. Evidence supporting a zoonotic origin of human coronavirus strain NL63. J. Virol. 2012, 86, 12816-12825. [CrossRef]

211. Corman, V.M.; Muth, D.; Niemeyer, D.; Drosten, C. Hosts and sources of endemic human coronaviruses. Adv. Virus Res. 2018, 100, 163-188. [PubMed]

212. Xu, R.-H.; He, J.-F.; Evans, M.R.; Peng, G.-W.; Field, H.E.; Yu, D.-W.; Lee, C.-K.; Luo, H.-M.; Lin, W.-S.; Lin, P.; et al. Epidemiologic clues to SARS origin in China. Emerg. Infect. Dis. 2004, 10, 1031. [CrossRef] [PubMed]

213. Lam, W.K.; Zhong, N.S.; Tan, W.C. Overview on SARS in Asia and the world. Respirology 2003, 8, S2-S5. [CrossRef]

214. Song, H.D.; Tu, C.C.; Zhang, G.W.; Wang, S.Y.; Zheng, K.; Lei, L.C.; Chen, Q.X.; Gao, Y.W.; Zhou, H.Q.; Xiang, H.; et al. Cross-host evolution of severe acute respiratory syndrome coronavirus in palm civet and human. Proc. Natl. Acad. Sci. USA 2005, 102, 2430-2435. [CrossRef]

215. Liang, G.; Chen, Q.; Xu, J.; Liu, Y.; Lim, W.; Peiris, J.S.M.; Anderson, L.J.; Ruan, L.; Li, H.; Kan, B.; et al. Laboratory diagnosis of four recent sporadic cases of community-acquired SARS, Guangdong province, China. Emerg. Infect. Dis. 2004, 10, 1774. [CrossRef]

216. WHO. Severe Acute Respiratory Syndrome (SARS). Available online: https://www.who.int/csr/don/archive/ disease/severe_acute_respiratory_syndrome/en/ (accessed on 1 September 2020). 
217. Guan, Y.; Zheng, B.J.; He, Y.Q.; Liu, X.L.; Zhuang, Z.X.; Cheung, C.L.; Luo, S.W.; Li, P.H.; Zhang, L.J.; Guan, Y.J.; et al. Isolation and characterization of viruses related to the SARS coronavirus from animals in southern China. Science 2003, 302, 276-278. [CrossRef]

218. Wang, L.F.; Shi, Z.; Zhang, S.; Field, H.; Daszak, P.; Eaton, B.T. Review of bats and SARS. Emerg. Infect. Dis. 2006, 12, 1834-1840. [CrossRef]

219. Poon, L.L.; Chu, D.K.; Chan, K.H.; Wong, O.K.; Ellis, T.M.; Leung, Y.H.; Lau, S.K.; Woo, P.C.; Suen, K.Y.; Yuen, K.Y.; et al. Identification of a novel coronavirus in bats. J. Virol. 2005, 79, 2001-2009. [CrossRef] [PubMed]

220. Li, W.; Shi, Z.; Yu, M.; Ren, W.; Smith, C.; Epstein, J.H.; Wang, H.; Crameri, G.; Hu, Z.; Zhang, H.; et al. Bats are natural reservoirs of SARS-like coronaviruses. Science 2005, 310, 676-679. [CrossRef] [PubMed]

221. Zhou, Y.; Hou, Y.; Shen, J.; Huang, Y.; Martin, W.; Cheng, F. Network-based drug repurposing for novel coronavirus 2019-nCoV/SARS-CoV-2. Cell Discov. 2020, 6, 14. [CrossRef]

222. Huang, C.; Wang, Y.; Li, X.; Ren, L.; Zhao, J.; Hu, Y.; Zhang, L.; Fan, G.; Xu, J.; Gu, X.; et al. Clinical features of patients infected with 2019 novel coronavirus in Wuhan, China. Lancet 2020, 395, 497-506. [CrossRef]

223. Xu, Z.; Shi, L.; Wang, Y.; Zhang, J.; Huang, L.; Zhang, C.; Liu, S.; Zhao, P.; Liu, H.; Zhu, L.; et al. Pathological findings of COVID-19 associated with acute respiratory distress syndrome. Lancet Respir. Med. 2020, 8, 420-422. [CrossRef]

224. Gandhi, R.T.; Lynch, J.B.; del Rio, C. Mild or moderate Covid-19. N. Engl. J. Med. 2020. [CrossRef]

225. WHO. Coronavirus Disease (COVID-19) Weekly Epidemiological Update and Weekly Operational Update. Available online: https://www.who.int/emergencies/diseases/novel-coronavirus-2019/situation-reports/?gclid= EAIaIQobChMIsdzRkq3o6QIV1zMrCh2kNA1REAAYASACEgJFnPD_BwE (accessed on 1 September 2020).

226. Lau, S.K.P.; Luk, H.K.H.; Wong, A.C.P.; Li, K.S.M.; Zhu, L.; He, Z.; Fung, J.; Chan, T.T.Y.; Fung, K.S.C.; Woo, P.C.Y. Possible bat origin of severe acute respiratory syndrome coronavirus 2. Emerg. Infect. Dis. 2020, 26, 1542. [CrossRef]

227. Ji, W.; Wang, W.; Zhao, X.; Zai, J.; Li, X. Cross-species transmission of the newly identified coronavirus 2019-nCoV. J. Med. Virol. 2020, 92, 433-440. [CrossRef]

228. Xia, X. Extreme genomic CpG deficiency in SARS-CoV-2 and evasion of host antiviral defense. Mol. Biol. Evol. 2020. [CrossRef]

229. Mallapaty, S. Coronavirus can infect cats-Dogs, not so much. Nature 2020. [CrossRef]

230. Shi, J.; Wen, Z.; Zhong, G.; Yang, H.; Wang, C.; Huang, B.; Liu, R.; He, X.; Shuai, L.; Sun, Z.; et al. Susceptibility of ferrets, cats, dogs, and other domesticated animals to SARS-coronavirus 2. Science 2020, 368, 1016-1020. [CrossRef] [PubMed]

231. Lam, T.T.; Jia, N.; Zhang, Y.W.; Shum, M.H.; Jiang, J.F.; Zhu, H.C.; Tong, Y.G.; Shi, Y.X.; Ni, X.B.; Liao, Y.S.; et al. Identifying SARS-CoV-2-related coronaviruses in Malayan pangolins. Nature 2020, 583, 282-285. [CrossRef] [PubMed]

232. Wu, K.; Li, W.; Peng, G.; Li, F. Crystal structure of NL63 respiratory coronavirus receptor-binding domain complexed with its human receptor. Proc. Natl. Acad. Sci. USA 2009, 106, 19970-19974. [CrossRef]

233. Li, W.; Moore, M.J.; Vasilieva, N.; Sui, J.; Wong, S.K.; Berne, M.A.; Somasundaran, M.; Sullivan, J.L.; Luzuriaga, K.; Greenough, T.C.; et al. Angiotensin-converting enzyme 2 is a functional receptor for the SARS coronavirus. Nature 2003, 426, 450-454. [CrossRef]

234. Li, F.; Li, W.; Farzan, M.; Harrison, S.C. Structure of SARS coronavirus spike receptor-binding domain complexed with receptor. Science 2005, 309, 1864-1868. [CrossRef]

235. Lan, J.; Ge, J.; Yu, J.; Shan, S.; Zhou, H.; Fan, S.; Zhang, Q.; Shi, X.; Wang, Q.; Zhang, L.; et al. Structure of the SARS-CoV-2 spike receptor-binding domain bound to the ACE2 receptor. Nature 2020, 581, 215-220. [CrossRef] [PubMed]

236. Li, W.; Sui, J.; Huang, I.C.; Kuhn, J.H.; Radoshitzky, S.R.; Marasco, W.A.; Choe, H.; Farzan, M. The S proteins of human coronavirus NL63 and severe acute respiratory syndrome coronavirus bind overlapping regions of ACE2. Virology 2007, 367, 367-374. [CrossRef]

237. Wu, K.; Chen, L.; Peng, G.; Zhou, W.; Pennell, C.A.; Mansky, L.M.; Geraghty, R.J.; Li, F. A virus-binding hot spot on human angiotensin-converting enzyme 2 is critical for binding of two different coronaviruses. J. Virol. 2011, 85, 5331-5337. [CrossRef] 
238. Li, W.; Zhang, C.; Sui, J.; Kuhn, J.H.; Moore, M.J.; Luo, S.; Wong, S.K.; Huang, I.C.; Xu, K.; Vasilieva, N.; et al. Receptor and viral determinants of SARS-coronavirus adaptation to human ACE2. EMBO J. 2005, 24, 1634-1643. [CrossRef]

239. Qiu, Y.; Zhao, Y.B.; Wang, Q.; Li, J.Y.; Zhou, Z.J.; Liao, C.H.; Ge, X.Y. Predicting the angiotensin converting enzyme 2 (ACE2) utilizing capability as the receptor of SARS-CoV-2. Microbes Infect. 2020, 22, 221-225. [CrossRef]

240. Luan, J.; Lu, Y.; Jin, X.; Zhang, L. Spike protein recognition of mammalian ACE2 predicts the host range and an optimized ACE2 for SARS-CoV-2 infection. Biochem. Biophys. Res. Commun. 2020, 526, 165-169. [CrossRef] [PubMed]

241. Li, W.; Greenough, T.C.; Moore, M.J.; Vasilieva, N.; Somasundaran, M.; Sullivan, J.L.; Farzan, M.; Choe, H. Efficient replication of severe acute respiratory syndrome coronavirus in mouse cells is limited by murine angiotensin-converting enzyme 2. J. Virol. 2004, 78, 11429-11433. [CrossRef] [PubMed]

242. Nagata, N.; Iwata, N.; Hasegawa, H.; Fukushi, S.; Yokoyama, M.; Harashima, A.; Sato, Y.; Saijo, M.; Morikawa, S.; Sata, T. Participation of both host and virus factors in induction of severe acute respiratory syndrome in F344 rats infected with SARS coronavirus. J. Virol. 2006. [CrossRef] [PubMed]

243. Xie, X.; Chen, J.; Wang, X.; Zhang, F.; Liu, Y. Age- and gender-related difference of ACE2 expression in rat lung. Life Sci. 2006, 78, 2166-2171. [CrossRef] [PubMed]

244. Wang, Y.; Li, X.; Liu, W.; Gan, M.; Zhang, L.; Wang, J.; Zhang, Z.; Zhu, A.; Li, F.; Sun, J.; et al. Discovery of a subgenotype of human coronavirus NL63 associated with severe lower respiratory tract infection in China, 2018. Emerg. Microbes Infect. 2020, 9, 246-255. [CrossRef] [PubMed]

245. Shang, J.; Wan, Y.; Luo, C.; Ye, G.; Geng, Q.; Auerbach, A.; Li, F. Cell entry mechanisms of SARS-CoV-2. Proc. Natl. Acad. Sci. USA 2020, 117, 11727-11734. [CrossRef]

246. Zaki, A.M.; van Boheemen, S.; Bestebroer, T.M.; Osterhaus, A.D.; Fouchier, R.A. Isolation of a novel coronavirus from a man with pneumonia in Saudi Arabia. N. Engl. J. Med. 2012, 367, 1814-1820. [CrossRef]

247. de Groot, R.J.; Baker, S.C.; Baric, R.S.; Brown, C.S.; Drosten, C.; Enjuanes, L.; Fouchier, R.A.; Galiano, M.; Gorbalenya, A.E.; Memish, Z.A.; et al. Middle East respiratory syndrome coronavirus (MERS-CoV): Announcement of the coronavirus study group. J. Virol. 2013, 87, 7790-7792. [CrossRef]

248. Smits, S.L.; Raj, V.S.; Pas, S.D.; Reusken, C.B.; Mohran, K.; Farag, E.A.; Al-Romaihi, H.E.; AlHajri, M.M.; Haagmans, B.L.; Koopmans, M.P. Reliable typing of MERS-CoV variants with a small genome fragment. J. Clin. Virol. 2015, 64, 83-87. [CrossRef]

249. Raj, V.S.; Mou, H.; Smits, S.L.; Dekkers, D.H.W.; Müller, M.A.; Dijkman, R.; Muth, D.; Demmers, J.A.A.; Zaki, A.; Fouchier, R.A.M.; et al. Dipeptidyl peptidase 4 is a functional receptor for the emerging human coronavirus-EMC. Nature 2013, 495, 251-254. [CrossRef]

250. Shang, J.; Wan, Y.; Liu, C.; Yount, B.; Gully, K.; Yang, Y.; Auerbach, A.; Peng, G.; Baric, R.; Li, F. Structure of mouse coronavirus spike protein complexed with receptor reveals mechanism for viral entry. PLoS Pathog. 2020, 16, e1008392. [CrossRef] [PubMed]

251. Wang, N.; Shi, X.; Jiang, L.; Zhang, S.; Wang, D.; Tong, P.; Guo, D.; Fu, L.; Cui, Y.; Liu, X.; et al. Structure of MERS-CoV spike receptor-binding domain complexed with human receptor DPP4. Cell Res. 2013, 23, 986-993. [CrossRef] [PubMed]

252. OIE. Avian Influenza Vaccination. Available online: https://www.oie.int/doc/ged/D4410.PDF (accessed on 1 September 2020).

253. Yang, L.; Zhao, X.; Li, X.; Bo, H.; Li, D.; Liu, J.; Wang, D. Case report for human infection with a highly pathogenic avian influenza A(H5N6) virus in Beijing, China 2019. Biosaf. Health 2020, 2, 49-52. [CrossRef]

254. Yu, D.; Xiang, G.; Zhu, W.; Lei, X.; Li, B.; Meng, Y.; Yang, L.; Jiao, H.; Li, X.; Huang, W.; et al. The re-emergence of highly pathogenic avian influenza H7N9 viruses in humans in mainland China, 2019. Eurosurveillance 2019, 24, 1900273. [CrossRef]

255. Cui, J.; Li, F.; Shi, Z.-L. Origin and evolution of pathogenic coronaviruses. Nat. Rev. Microbiol. 2019, 17, 181-192. [CrossRef]

256. Guan, L.; Shi, J.; Kong, X.; Ma, S.; Zhang, Y.; Yin, X.; He, X.; Liu, L.; Suzuki, Y.; Li, C.; et al. H3N2 avian influenza viruses detected in live poultry markets in China bind to human-type receptors and transmit in guinea pigs and ferrets. Emerg. Microbes Infect. 2019, 8, 1280-1290. [CrossRef]

257. Sriwilaijaroen, N.; Suzuki, Y. A simple viral neuraminidase-based detection for high-throughput screening of viral hemagglutinin-host receptor specificity. Methods Mol. Biol. 2014, 1200, 107-120. [PubMed] 
258. Stevens, J.; Blixt, O.; Paulson, J.C.; Wilson, I.A. Glycan microarray technologies: Tools to survey host specificity of influenza viruses. Nat. Rev. Microbiol. 2006, 4, 857-864. [CrossRef]

259. Nakakita, S.I.; Sriwilaijaroen, N.; Suzuki, Y.; Hirabayashi, J. Preparation and detection of glycan-binding activity of influenza virus. Methods Mol. Biol. 2020, 2132, 567-583.

260. Watanabe, Y.; Ito, T.; Ibrahim, M.S.; Arai, Y.; Hotta, K.; Phuong, H.V.M.; Hang, N.L.K.; Mai, L.Q.; Soda, K.; Yamaoka, M.; et al. A novel immunochromatographic system for easy-to-use detection of group 1 avian influenza viruses with acquired human-type receptor binding specificity. Biosens. Bioelectron. 2015, 65, 211-219. [CrossRef]

261. Sun, H.; Xiao, Y.; Liu, J.; Wang, D.; Li, F.; Wang, C.; Li, C.; Zhu, J.; Song, J.; Sun, H.; et al. Prevalent Eurasian avian-like H1N1 swine influenza virus with 2009 pandemic viral genes facilitating human infection. Proc. Natl. Acad. Sci. USA 2020, 117, 17204-17210. [CrossRef] [PubMed]

262. Rajao, D.S.; Gauger, P.C.; Anderson, T.K.; Lewis, N.S.; Abente, E.J.; Killian, M.L.; Perez, D.R.; Sutton, T.C.; Zhang, J.; Vincent, A.L. Novel reassortant human-like H3N2 and H3N1 influenza A viruses detected in pigs are virulent and antigenically distinct from swine viruses endemic to the United States. J. Virol. 2015, 89, 11213-11222. [CrossRef] [PubMed]

263. Watanabe, Y.; Ibrahim, M.S.; Ellakany, H.F.; Kawashita, N.; Mizuike, R.; Hiramatsu, H.; Sriwilaijaroen, N.; Takagi, T.; Suzuki, Y.; Ikuta, K. Acquisition of human-type receptor binding specificity by new H5N1 influenza virus sublineages during their emergence in birds in Egypt. PLoS Pathog. 2011, 7, e1002068. [CrossRef] [PubMed]

264. Shi, J.; Deng, G.; Kong, H.; Gu, C.; Ma, S.; Yin, X.; Zeng, X.; Cui, P.; Chen, Y.; Yang, H.; et al. H7N9 virulent mutants detected in chickens in China pose an increased threat to humans. Cell Res. 2017, 27, 1409-1421. [CrossRef] [PubMed]

265. Saito, T.; Lim, W.; Suzuki, T.; Suzuki, Y.; Kida, H.; Nishimura, S.I.; Tashiro, M. Characterization of a human H9N2 influenza virus isolated in Hong Kong. Vaccine 2001, 20, 125-133. [CrossRef]

266. Belser, J.A.; Blixt, O.; Chen, L.M.; Pappas, C.; Maines, T.R.; Van Hoeven, N.; Donis, R.; Busch, J.; McBride, R.; Paulson, J.C.; et al. Contemporary North American influenza H7 viruses possess human receptor specificity: Implications for virus transmissibility. Proc. Natl. Acad. Sci. USA 2008, 105, 7558-7563. [CrossRef]

267. Khan, S.; Siddique, R.; Shereen, M.A.; Ali, A.; Liu, J.; Bai, Q.; Bashir, N.; Xue, M. Emergence of a novel coronavirus, severe acute respiratory syndrome coronavirus 2: Biology and therapeutic options. J. Clin. Microbiol. 2020, 58. [CrossRef]

268. Azhar, E.I.; El-Kafrawy, S.A.; Farraj, S.A.; Hassan, A.M.; Al-Saeed, M.S.; Hashem, A.M.; Madani, T.A. Evidence for camel-to-human transmission of MERS coronavirus. N. Engl. J. Med. 2014, 370, 2499-2505. [CrossRef]

269. Li, X.; Giorgi, E.E.; Marichannegowda, M.H.; Foley, B.; Xiao, C.; Kong, X.-P.; Chen, Y.; Gnanakaran, S.; Korber, B.; Gao, F. Emergence of SARS-CoV-2 through recombination and strong purifying selection. Sci. Adv. 2020, 6, eabb9153. [CrossRef]

270. Sriwilaijaroen, N.; Suzuki, Y. Hemagglutinin inhibitors are potential future anti-influenza drugs for monoand combination therapies. Methods Mol. Biol. 2020, 2132, 547-565.

271. Sriwilaijaroen, N.; Suzuki, K.; Takashita, E.; Hiramatsu, H.; Kanie, O.; Suzuki, Y. 6SLN-lipo PGA specifically catches (coats) human influenza virus and synergizes neuraminidase-targeting drugs for human influenza therapeutic potential. J. Antimicrob. Chemother. 2015, 70, 2797-2809. [CrossRef] [PubMed]

(C) 2020 by the authors. Licensee MDPI, Basel, Switzerland. This article is an open access article distributed under the terms and conditions of the Creative Commons Attribution (CC BY) license (http://creativecommons.org/licenses/by/4.0/). 